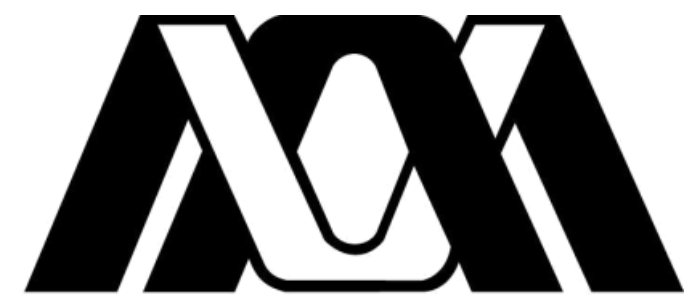

Universidad Autónoma Metropolitana Unidad Iztapalapa Ciencias Básicas e Ingeniería y Ciencias Biológicas y de la Salud Posgrado en Energía y Medio Ambiente

\title{
"Análisis de biomarcadores en la almeja Polymesoda caroliniana para la generación de un índice de salud y vulnerabilidad"
}

\author{
T E S I S \\ Que para obtener el grado de \\ DOCTOR EN CIENCIAS (ENERGÍA Y MEDIO AMBIENTE) \\ P R E S E N T A: \\ M. en B. José Roberto Jerónimo Juárez.
}

Directora:

Dra. Xochitl Guzmán García.

Coasesoras:

Dra. Marcela Arteaga Silva.

Dra. María del Rocío Zarate Hernández. 
El Doctorado en Energía y Medio Ambiente de la Universidad Autónoma Metropolitana Unidad Iztapalapa (UAM-I), pertenece al Padrón Nacional de Posgrados de Calidad del CONACyT (Consejo Nacional de Ciencia y Tecnología) y cuenta con apoyo del mismo Consejo con el convenio 005383, por lo que agradece el apoyo recibido a través de la beca CONACyT-SENER (Secretaría de Energía) Sustentabilidad Energética 2017, Tipo B, Primer periodo, número: 470845 para el desarrollo de esta tesis.

La obtención de los organismos se llevó a cabo en el municipio de Tecolutla, Veracruz de acuerdo con los permisos oficiales otorgados por la SEMARNAT (Secretaria de Medio Ambiente y Recursos Naturales) Número de permiso: SGPA/DGVS/004013/18. Para el manejo y experimentación con los organismos se siguieron los "Lineamientos para la conducción ética de la investigación, docencia y la difusión en la División de Ciencias Biológicas y de Salud" aprobados por el Consejo Divisional de CBS de la UAM-I en su sucesión 8.10 del 18 de mayo de 2010. 
El análisis para la obtención de resultados de esta tesis se llevó a cabo en el PIMVS (Predios o Instalaciones que Manejan Vida Silvestre) "CIDMIRA" (Centro de Investigación y Docencia para el Manejo Integral de los Recursos Acuáticos) con registro ante SEMARNAT DGVS-02594/1806, ubicado en el Laboratorio de Ecotoxicología del Departamento de Hidrobiología. Esta investigación contó con financiamiento de los proyectos: "Indicadores de Integridad Ecológica y Salud Ambiental" de la UAM-I (2014-2018) у “Diagnóstico ambiental del Municipio de Tecolutla, Veracruz" del Programa para el Desarrollo Profesional Docente de Tipo Superior PRODEP-SEP (20192020).

También se contó con el apoyo de dos becas para la asistencia a "Eventos de Difusión y de Investigación en Ciencia y Tecnología" por parte de la Universidad Autónoma Metropolitana en los trimestres 17-P y 19-O; con este apoyo, se presentaron avances parciales en el congreso internacional de la Sociedad Española de Histología e Ingeniería Tisular SEHIT, durante los meses de septiembre de los años 2017 y 2019. Finalmente fue otorgada la Beca para Apoyos Extraordinarios UAM-2019 por un periodo de tres meses (de febrero a abril de 2020), para la continuación de estudios. 


\section{Comité Asesor:}

Directora:

Dra. Xochitl Guzmán García. Laboratorio de Ecotoxicología. Departamento de Hidrobiología. División de Ciencias Biológicas y de la Salud. UAM-I.

Coasesoras:

Dra. Marcela Arteaga Silva. Laboratorio de Neuroendocrinología reproductiva. Departamento de Biología de la Reproducción. División de Ciencias Biológicas y de la Salud. UAM-I.

Dra. María del Rocío Zarate Hernández. Laboratorio de Peces. Departamento de Biología. División de Ciencias Biológicas y de la Salud. UAM-I. 
El jurado designado por la Comisión Académica del Posgrado en Energía y Medio Ambiente de la Unidad Iztapalapa aprobó la tesis que presentó:

\section{EN B. JOSÉ ROBERTO JERÓNIMO JUÁREZ.}

El 4 de diciembre del 2020.

\section{Miembros del Jurado:}

Dra. Maria Isabel del Carmen Guerrero Legarreta.

Departamento de Biotecnología.

Universidad Autónoma Metropolitana Unidad Iztapalapa.

Presidenta.

Dra. Marcela Arteaga Silva.

Departamento de Biología de la Reproducción.

Universidad Autónoma Metropolitana Unidad Iztapalapa.

Secretaria.

Dra. Marcela Galar Martínez.

Escuela Nacional de Ciencias Biológicas.

Instituto Politécnico Nacional.

Vocal.

Dr. Juan Carlos Segoviano Ramírez.

Centro de Investigación y Desarrollo en Ciencias de la

Salud. Unidad de Bioimagen.

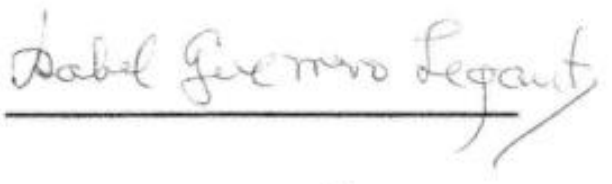

Universidad Autónoma de Nuevo León.

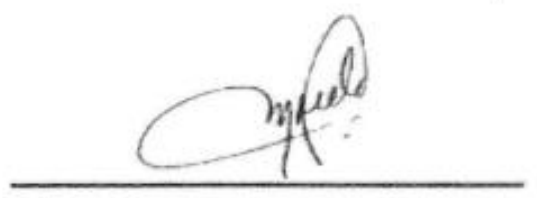

Vocal.

Dra. Guadalupe Barrera Escorcia.

Departamento de Hidrobiología.

Universidad Autónoma Metropolitana Unidad Iztapalapa.

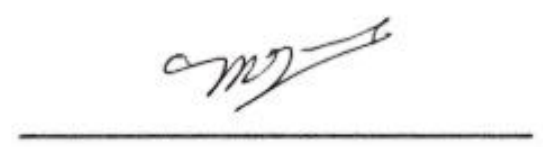

Vocal. 


\section{Dedicatoria}

Dedicada a ese niño que jugaba con caracoles, aves y lagartijas. Para ese niño que jugaba con la tierra y admiraba la naturaleza. Para ese niño que soñó, por él que nunca se rindió, por él que siempre perseveró y por él que ahora lo logró. Dedicada a él, igracias por resistir!

A todos mis maestros $\boldsymbol{y}$ maestras cuya pasión por educar me inspiró a seguir sus pasos. A todos mis alumnos y exalumnos, quienes creyeron en mí y me permitieron inspirarlos.

¡Gracias a todos!

Y en especial quiero dedicar todo mi trabajo a Gus, Cami, Dante y al pequeño Yeye. ¡Sueñen y nunca dejen de hacerlo! 


\section{Agradecimientos}

Este proyecto doctoral no hubiera sido igual sin la visión, guía, corrección y dirección de la Dra. Xochitl Guzmán García. A ella agradezco primeramente la aceptación para dirigir este proyecto, la disposición de colaborar siempre y la aportación económica de reactivos y consumibles para llevar a cabo este proyecto. Gracias por todo lo que me ha enseñado, tanto académica como personalmente. Gracias por todo lo que me ha permitido vivir al acompañarla en este camino de la ciencia. Gracias por todo lo que hace por sus alumnos, gracias por todo lo que ha contribuido a la ciencia de este país y gracias por permitirme contribuir en este trabajo con observaciones, aportaciones y nuevas visiones para fortalecer lo que hoy presentamos. Desde el fondo de mi corazón, siempre y por siempre estaré agradecido con usted.

A las asesoras de este proyecto. La Dra. Rocío Zarate Hernández por aceptar asesorar este proyecto. Gracias por la revisión crítica del trabajo, por sus aportaciones y comentarios para el mejoramiento de este. Muchas gracias por los abrazos de aliento, la escucha atenta y las palabras de empuje para no derrotarme. A la Dra. Marcela Arteaga Silva, porque su historia y sus ganas de vivir me salvaron y me ayudaron para no rendirme. Jamás olvidaré su consejo porque eso es lo que me tiene hoy aquí. Gracias por el esfuerzo que implicó revisar y corregir este trabajo, invaluables son sus observaciones.

A los sinodales de este proyecto, cuyo esfuerzo maratónico permitió que el examen se llevará a cabo, nunca olvidaré lo que hicieron hoy por mí. A la Dra. Isabel Guerrero Legarreta (UAM-I), no tengo palabras para expresar el orgullo y el honor que siento de que una investigadora de su nivel haya leído, corregido y evaluado este trabajo, infinitas gracias. A la Dra. Marcela Galar Martínez (IPN), por aceptarme en su laboratorio durante la estancia de investigación, no se imagina todo lo que aprendí esos días. Gracias por formar parte del examen predoctoral, porque sus sugerencias ayudaron a orientar el proyecto. Pero sobre todo gracias por formar parte de esta etapa en mi vida, usted es un claro ejemplo de que la grandeza y la sencillez no están peleadas en ciencia, gracias. A la Dra. Guadalupe Barrera Escorcia (UAM-I) que me conoce desde hace más de 10 años. Gracias por aceptar de nueva cuenta evaluar un proyecto de investigación donde participo. Invaluables son sus observaciones y comentarios para la mejora del trabajo, mil gracias por su cariño y muestras de apoyo. Finalmente, pero no menos importante, al Dr. Juan Carlos Segoviano (UANL) por la oportunidad de aprender bajo su dirección, por la confianza brindada, por reconocer mis capacidades y habilidades como investigador, pero sobre todo por enseñarme la calidad de ser humano que debe tener un verdadero Doctor. Me llevo en el corazón las pláticas de vida en su laboratorio, gracias. 
A la Universidad Autónoma Metropolitana Unidad Iztapalapa, mi alma máter, que desde la licenciatura, maestría y doctorado me ha arropado y me ha brindado el apoyo académico, intelectual y económico para vivir los 13 años más turbulentos, excitantes e irrepetibles de mi vida.

A la Universidad Autónoma Metropolitana por el otorgamiento de una beca de manutención de posgrado durante mi primer año de doctorado.

Al CONACyT por el apoyo económico a través de la beca de manutención que permitió que culminará mis estudios de doctorado.

A la Dra. Patricia Ramírez Romero y a el Dr. Juan José Ambriz García, que como coordinadores del Posgrado en Energía y Medio Ambiente (PEMA), me motivaron a ingresar, participar y continuar con mis estudios. Gracias por todo el apoyo y gestiones que hicieron para que este proyecto se llevará a cabo. Con especial agradecimiento a la Mtra. Iseo González, asistente del Posgrado, por su apoyo infinito en el proceso administrativo para la asignación de la beca y por todas las veces que respondió amablemente mis dudas sobre el posgrado. Espero con esto hacer un reconocimiento a todo su trabajo que hace en apoyo de los alumnos y profesores del Posgrado. A la Lic. Rocío Hernández Solís Jefa del Departamento de Becas UAM por todo el apoyo que recibí de su parte para que su gestión sobre el apoyo económico permitiera la obtención de beca de manutención UAM.

A mis compañeros del laboratorio de Ecotoxicología-Histología, tantos momentos juntos, tantos lugares visitados y muchas horas de trabajo, nos hacen ya una familia: Pamela, Mariela, Alberto, Ivonne, Iñaqui, Fernando Mares, Fernando Matadamas, Vanessa, Suleyma, Kartagena, Gabriela, Verónica, Patsy, Anahí, Diana, Luz, Felipe y Meztli, he aprendido mucho de ustedes, continúen esforzándose para que pronto todo el mundo de la ciencia conozca quiénes somos. En especial a Dalia y Jimena que se dejaron contagiar por el entusiasmo de los bivalvos y me permitieron asesorarlas y guiarlas, son brillantes. Muy en especial a la Biol. Irma Hernández Calderas ¿qué te puedo decir? Mira hasta donde vamos y mira hasta donde nos han llevado los tejidos. Mil gracias por permitirme conocerte, por enseñarme y asesorarme, pero, sobre todo gracias por impulsarme a culminar este compromiso. Irma, atesoro todo lo que me enseñaste, lo guardo y lo comparto con las nuevas generaciones, eres un ejemplo.

A todos mis compañeros y compañeras del Laboratorio de Ecotoxicología y a las Dras. Paty y Lupita que siempre estuvieron al pendiente de mi crecimiento académico.

A la Dra. Meztli Lucia Matadamas Guzmán por su valiosa contribución en la corrección del artículo doctoral, así como su apoyo en el mejoramiento de este. Un honor y orgullo aprender de una mujer tan talentosa como tú. 
A la Dra. Kathy Frank, Eli y Pepe del CEMAI-CONACyT por todo lo que aprendí a su lado, durante el curso de escritura de artículos en inglés. Gracias por abrirme las puertas de sus oficinas y por sus comentarios a mi manuscrito. Mil gracias los llevo en mi corazón y memoria.

A mis amigos: Ángel, Misael, Alejandra y Brian sin ustedes esto no hubiera sido posible. No hay palabras que existan o que completen todo el agradecimiento que siento por cada uno de ustedes. Gracias por confiar en mí, gracias por las tardes de comida y sobremesa en la UAM-I, gracias por sus abrazos de aliento y palabras que sanaban mi alma, gracias por cada kilómetro recorrido a su lado, pero sobre todo gracias por todas aquellas noches de distracción que parecían interminables y que nos hacían resistir el tedio de la vida. Los quiero y los admiro mucho. Esto va por ustedes.

Gracias Mali, por estar siempre desde que nos conocimos. Gracias por los comentarios que hiciste a este escrito y por apoyarme siempre. Te quiero mucho.

A mis compañeros y amigos del PEMA: Martha Ramírez, Fernando Mares y Eric Espinosa gracias por su apoyo. Pero en especial a Carlos Fernández Rendón ¿qué hubiera sido de mi sin no nos hubiéramos acompañado en este largo camino?, muchas gracias. Y por último, pero no menos importante un agradecimiento especial a Carolina Gutiérrez Henao, gracias por brindarme tu cariño y amistad, sirva este agradecimiento como promesa de que algún día estaré en Colombia.

Con especial agradecimiento a los profesores del Colegio de Bachilleres: Ana María Pedroza $\uparrow$ y Paulo Ruiz del Plantel 8 así como a Iván Blas, Omar Rosas y Guadalupe Pereyra del Plantel 3, gracias por todo el apoyo que recibí de su parte como jefes de materia para que yo pudiera desarrollar mi proyecto doctoral y al mismo tiempo desempeñarme como docente. Gracias infinitas desde el fondo de mi corazón.

A Cesar Rodríguez y Daniel López de la Unidad de Bioimagen del CIDCS de la UANL por todo su apoyo en el captura de fotomicrografías y asesoría en microscopía, fueron semanas de agradable convivencia y mucho aprendizaje.

Al Dr. Miguel Ángel León Tapia del Instituto de Biología UNAM por la elaboración del mapa de Tecolutla. Al M. en D. Jonathan Hernández Torres, gracias por tu apoyo, entusiasmo y palabras de aliento que me ayudaron a continuar. Gracias a M. en B. Azucena Ramírez, gracias por creer en mí y alentarme a continuar aprendiendo.

Con un cariño muy especial a Valentina Alvares Fabbiani por permitirme gracias al arte, un canal de ayuda, perseverancia y salvación. Gracias por motivarme a seguir adelante y por todas las palabras de aliento. A Katy Aragón, muchas gracias por ayudarme a canalizar mi 
energía en trabajo productivo, gracias por creer en mi aún sin conocerme y por hacerme ver que debo valorar todo mi esfuerzo y trabajo. Muchas gracias a los dos.

A los pescadores de Tecolutla, Veracruz. En especial al Sr. Abel, la Sra. Margarita y a Juan, por su guía, compañía y asesoramiento en la recolecta de las almejas. Gracias por todas las facilidades otorgadas y por contribuir en el desarrollo de la ciencia en su Municipio.

Quiero agradecer desde el fondo de mi corazón a mis padres y a Dios porque siempre me han inspirado, acompañado y porque nunca me han dejado solo. Gracias papá (Sr. Ernesto Jerónimo), gracias mamá (Sra. Margarita Juárez), sepan que los admiro mucho y todos los días agradezco a la vida por tenerlos a mi lado y las enseñanzas que me han dado. Felicidades a ustedes por este logro, es de ustedes y para ustedes. Dios los bendiga por todo lo que me han dado.

A mis hermanos Tito y Claudia por apoyarme siempre, por soportarme, por creer en mí y por alentarme a no rendirme. Y sobre todo por cuidar a mi Rocko, Ringo, Mini y Hachi cuando la tesis no me lo permitía.

A mi familia quienes me alentaron a seguir adelante, mis compadres Martha y Daniel por todo su apoyo y cariño y a Fabiola mi cuñada por esta al pendiente siempre de mí.

Desde el fondo de mi corazón, a todos...Gracias. 


\section{Índice}

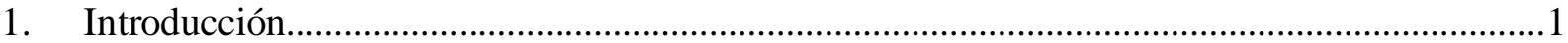

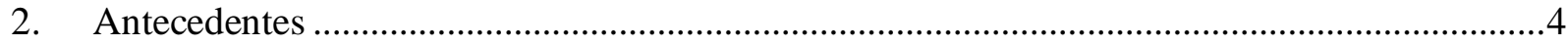

2.1. Vulnerabilidad de los sistemas acuáticos por la presencia de contaminantes ......................4

2.2. Elementos para evaluar la vulnerabilidad .........................................................................

2.3. Biomarcador histopatológico en bivalvos .........................................................................

2.3.1. Índice histopatológico como indicador de la de salud de los bivalvos .........................

2.3.2. Análisis inmunohistoquímico …………………….................................................11

2.4. Evaluación de la vulnerabilidad: exposición, sensibilidad y capacidad de recuperación .15

2.5. Perspectiva de estudio para evaluar la vulnerabilidad en Tecolutla, Veracruz ..................17

2.6. Polymesoda caroliniana como modelo para evaluar la vulnerabilidad.............................21

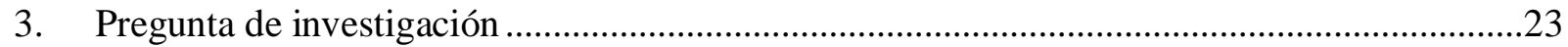

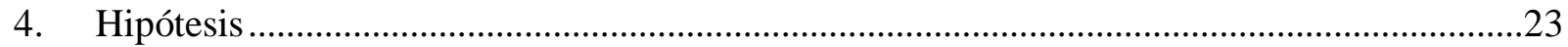

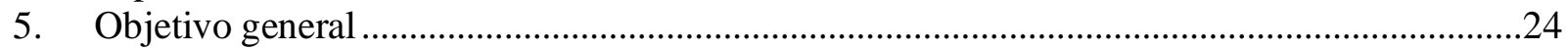

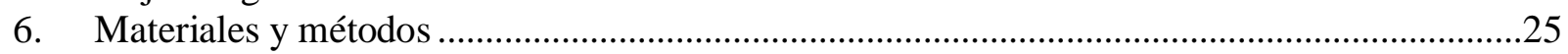

6.1. Obtención de la muestra y análisis macroscópico ………………………………….........2

6.2. Análisis histopatológico........................................................................................26

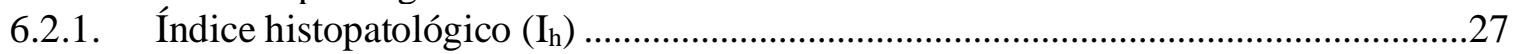

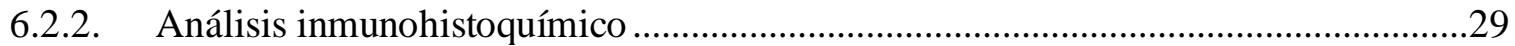

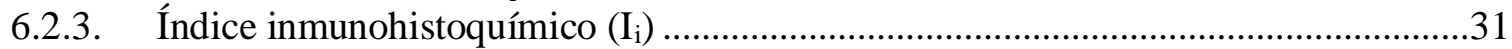

6.3. Evaluación de la vulnerabilidad: exposición, sensibilidad y capacidad de recuperación .31

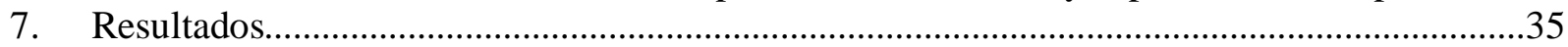

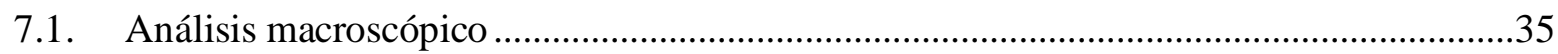

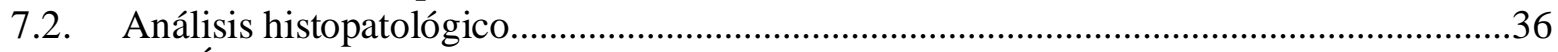

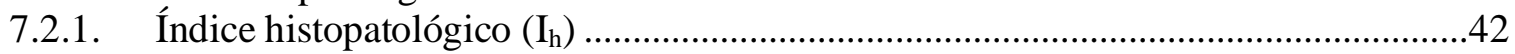

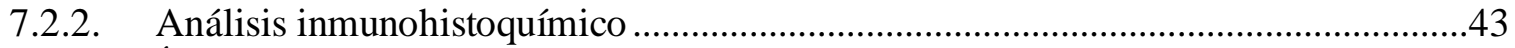

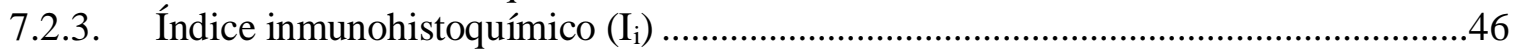

7.3. Evaluación de la vulnerabilidad: exposición, sensibilidad y capacidad de recuperación .46

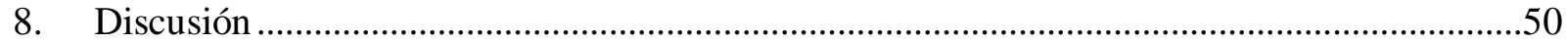

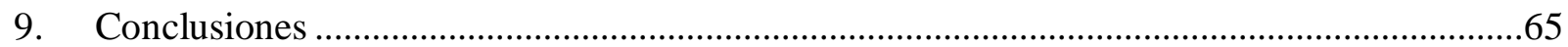

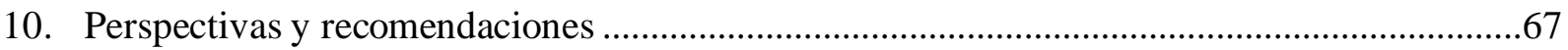

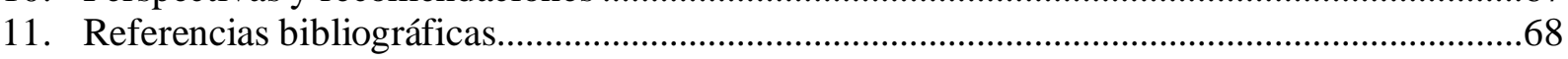

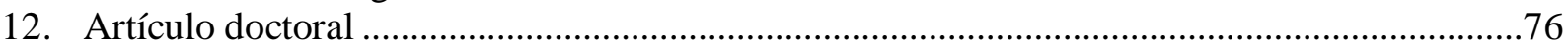




\section{Índice de Figuras}

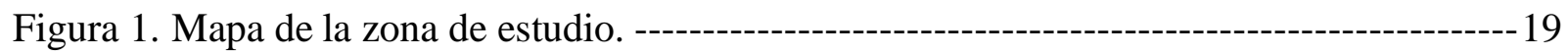

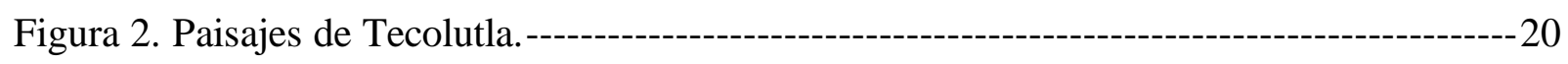

Figura 3. Aspecto externo de la almeja de Tecolutla Veracruz. -------------------------------------22

Figura 4. Método empleado para evaluar la vulnerabilidad y el estado de salud de la almeja

Polymesoda caroliniana de Tecolutla, Veracruz. ------------------------------------------------------34

Figura 5. Aspecto externo de la almeja en cuarentena, no se observan organismos asociados ni

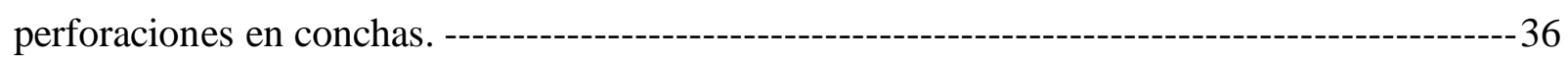

Figura 6. Descripción tisular de los túbulos de la glándula digestiva de la almeja $P$. caroliniana (organismos control). ---------------------------------------------------------------------37

Figura 7. Descripción histopatológica de la glándula digestiva de la almeja $P$. caroliniana

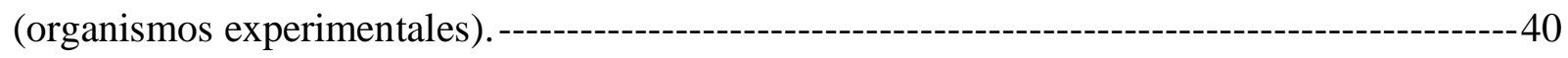

Figura 8. Descripción histopatológica de la glándula digestiva de la almeja $P$. caroliniana

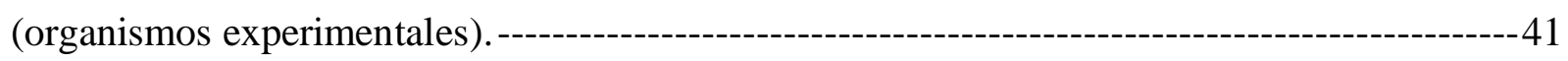

Figura 9. Inmunorreacción positiva de los marcadores CYP, proteínas HSP70 y Metalotioneínas (MTs) en diferentes tejidos de la almeja de Tecolutla. ----------------------------45 


\section{Índice de Tablas}

Tabla 1. Criterio propuesto para asignar el valor de $(a)$ de diseminación de una alteración histopatológica. .28

Tabla 2. Matriz de prevalencia de alteraciones patológicas observadas en la almeja $P$. caroliniana, se muestra la prevalencia $(\mathrm{P} \%)$. .38

Tabla 3. Valores de importancia patológica $(w)$ y grado de diseminación $(a)$ en las almejas del grupo experimental. .42

Tabla 4. Matriz de inmunorreacción positiva (+) y negativa (-) por órganos, tejidos observados y marcador aplicado.

Tabla 5. Número de marcadores inmunohistoquímicos observados en órganos blanco de las almejas....... .46

Tabla 6. Relación entre la prevalencia de alteraciones histopatológicas y el nivel de exposición.

Tabla 7. Propuesta semicuantitativa para la estimación de indicadores de vulnerabilidad 49 


\section{Resumen}

El estudio de la vulnerabilidad depende del análisis de los elementos que la componen: exposición, sensibilidad y capacidad de recuperación. En este trabajo, se propone el uso de respuestas tisulares que se han recomendado como biomarcadores para medir los elementos de la vulnerabilidad en la almeja Polymesoda caroliniana, además de obtener un índice histopatológico para evaluar su estado de salud. El análisis histopatológico revela alteraciones que pueden ser producto del estrés ambiental, reflejando así, el nivel de sensibilidad. Mientras que el análisis inmunohistoquímico utiliza marcadores para determinar la presencia de compuestos tóxicos, lo que refleja el nivel de exposición de un organismo. En este trabajo se realizó un análisis de prevalencia de alteraciones tisulares en la glándula digestiva y el cálculo de un índice histopatológico para estimar el estado de salud. Se analizaron, además respuestas inmunohistoquímicas de tres marcadores de estrés ambiental (HSP70, MTs y CYP). Por otro lado, para la evaluación de la vulnerabilidad, se diseñó una estrategia semicuantitativa para determinar el nivel de exposición mediante el promedio de marcadores inmunohistoquímicos positivos en diferentes órganos. El nivel de sensibilidad fue determinado mediante la relación entre la prevalencia de alteraciones histopatológicas y el nivel de exposición. Finalmente, para estimar la capacidad de recuperación, se colocó al grupo control en un ambiente limpio durante 40 días. El promedio de marcadores inmunohistoquímicos positivos observados en la almeja la coloca en una categoría de exposición moderada. La relación entre la baja prevalencia de alteraciones y el nivel moderado de exposición de la almeja la coloca en una categoría de sensibilidad baja. Las almejas del grupo control permitieron observar la capacidad de revertir los efectos del estrés ambiental. Con las respuestas obtenidas mediante la evaluación de los elementos de la vulnerabilidad, la almeja $P$. caroliniana se ubica en una categoría de vulnerabilidad baja. La propuesta de evaluación presentada en esta tesis es una alternativa para la evaluación integral de los recursos acuáticos, busca además que en los estudios de vulnerabilidad se consideren las respuestas fisiológicas de los organismos. El análisis de respuestas fisiológicas de organismos se puede integrar en la evaluación de la vulnerabilidad de los sistemas acuáticos.

Palabras clave: Polymesoda caroliniana, índice histopatológico, inmunohistoquímica, vulnerabilidad, estrés ambiental. 


\section{Abstract}

The vulnerability depends on the analysis of the elements that compose it: exposure, sensitivity, and recovery capacity. In this work, the use of tissue responses that have been recommended as biomarkers to measure the elements of vulnerability in the Polymesoda caroliniana clam is proposed, in addition to obtaining a histopathological index to assess its health status. Histopathological analysis reveals alterations that may be the product of environmental stress, thus reflecting the level of sensitivity. While immunohistochemical analysis uses markers to determine the presence of toxic compounds, which reflects the level of exposure of an organism. In this work, an analysis of the prevalence of tissue alterations in the digestive gland and the calculation of a histopathological index to estimate health status was performed. Immunohistochemical responses of three environmental stress markers (HSP70, MTs and CYP) were also analyzed. On the other hand, for the vulnerability assessment, a semi-quantitative strategy was designed to determine the level of exposure through the average of positive immunohistochemical markers in different organs. The level of sensitivity was determined by the relationship between the prevalence of histopathological alterations and the level of exposure. Finally, to estimate the recovery capacity, the control group was placed in a clean environment for 40 days. The average number of positive immunohistochemical markers observed in the clam places it in a moderate exposure category. The relationship between the low prevalence of disorders and the moderate level of exposure of the clam places it in a category of low sensitivity. The clams of the control group allowed to observe the ability to reverse the effects of environmental stress. With the responses obtained by evaluating the elements of vulnerability, the $P$. caroliniana clam is located in a low vulnerability category. The evaluation proposal presented in this thesis is an alternative for the comprehensive evaluation of aquatic resources, it also seeks that in vulnerability studies the physiological responses of organisms are considered. Analysis of physiological responses of organisms can be integrated into the vulnerability assessment of aquatic systems.

Key words: Polymesoda caroliniana, histopathological index, immunohistochemistry, vulnerability, environmental stress. 


\section{Introducción}

Las zonas costeras se consideran uno de los ambientes más vulnerables ante el efecto de los contaminantes (Botello, 2010). Los estudios que evalúan la vulnerabilidad de las zonas costeras han propuesto algunos parámetros para estimarla (Ramírez y Torres, 2010). Sin embargo, ninguno de ellos, incluye parámetros fisiológicos que describan el estado de salud de los organismos que se desarrollan en un ambiente potencialmente vulnerable ante los efectos del estrés ambiental.

El estrés ambiental puede causar efectos medibles sobre el estado fisiológico de los organismos comprometiendo su salud (Baum et al., 1984; Bayne et al., 1976; Häder et al., 2020). Existen enfoques metodológicos que miden estos efectos a diferentes niveles de organización biológica. Los análisis histopatológicos e inmunohistoquímicos evalúan los efectos del estrés ambiental a nivel tisular (Costa et al., 2013; Cuevas et al., 2015a). Por un lado, el análisis histopatológico determina las consecuencias fisiológicas de la sensibilidad de los organismos a los contaminantes, mediante la caracterización de alteraciones tisulares (Boscolo Papo et al., 2014b; Usheva et al., 2006). Estas respuestas tisulares se pueden cuantificar mediante un índice histopatológico $\left(\mathrm{I}_{\mathrm{h}}\right)$, reflejando el estado de salud de un organismo (Costa et al., 2013; Cuevas et al., 2015a). Por otro lado, el análisis inmunohistoquímico determina respuestas citológicas relacionadas con la presencia de algunos contaminantes. Se utilizan diversos marcadores inmunohistoquímicos para este fin, sin embargo, en moluscos bivalvos se ha propuesto la evaluación del estrés ambiental mediante la evaluación de la sobreexpresión de proteínas HSP70, metalotioneínas (MTs) y el citocromo P450 (CYP) (Boscolo Papo et al., 2014b, 2014a). Estos marcadores, al sobreexpresarse en las células, reflejan la exposición a diferentes componentes tóxicos y sus efectos en los 
organismos vivos (Boscolo Papo et al., 2014a; Moraga et al., 2005; Wang et al., 2010; Zhang et al., 2012). En consecuencia, la integración de enfoques histopatológicos e inmunohistoquímicos constituye una estrategia valiosa para evaluar la vulnerabilidad de un organismo a un entorno específico (Boscolo Papo et al., 2014a). Esto se logra gracias a que el análisis histopatológico hace evidentes alteraciones que son consecuencia de los mecanismos de defensa de los organismos ante un agente estresor, revelando así el nivel de sensibilidad. Por otro lado, el análisis inmunohistoquímico constituye un biomarcador bioquímico que se induce a ese nivel cuando se generan respuestas endógenas preventivas constituyendo un mecanismo para evaluar la exposición de un organismo.

Para evaluar la vulnerabilidad es necesario analizar los elementos que la componen: la exposición ante algún estresor ambiental, la sensibilidad o grado de afectación ante un estresor y la forma en la que se recupera ante una presión especifica (Carantoña y Hernández, 2017; Dagnino et al., 2008; Ocaña y Pech, 2018; Villa y McLeod, 2002). Existen diversas metodologías para evaluar la vulnerabilidad, sin embargo, la generación de indicadores cualitativos o cuantitativos sigue siendo la que predomina, sin dejar de lado la relación que tienen estos indicadores con los elementos que componen a la vulnerabilidad (Magaña, 2012). A pesar de las diferentes metodologías para el estudio de la vulnerabilidad, en México son escasas las investigaciones que empleen este enfoque, lo que provoca un área de oportunidad para llevar a cabo este tipo de estudio en zonas costeras en donde no se conocen los efectos que puede provocar el estrés ambiental en los organismos.

Una zona costera característica del Golfo de México es Tecolutla en el estado de Veracruz, en ella existe una importante riqueza de recursos acuáticos, pero no se tiene suficiente información sobre el estatus de salud y vulnerabilidad de sus recursos biológicos. Pese a que se han realizado algunos estudios para determinar la calidad del agua del río Tecolutla, así 
como las fuentes y tipos de contaminantes (Arriaga-Gaona et al., 2013; Limón-Hernández, 2019; López-Portillo et al., 2009), ninguno de ellos incluye la evaluación de los efectos de los contaminantes en organismos silvestres. Uno de los organismos más comunes en esta zona, es la almeja negra Polymesoda caroliniana, la cual representa un recurso económico, nutricional y de importancia biológica para la región. Las almejas están consideradas dentro de los estudios de monitoreo ambiental como organismos bioindicadores del estado de salud de un ambiente (Boscolo Papo et al., 2014a, 2014b; Carneiro et al., 2015; Cuevas et al., 2015a; Delgado-Alvarez et al., 2019; Santovito et al., 2015; Vodopivez et al., 2015; Zhang et al., 2012). Por lo tanto, en este trabajo se describe el uso de respuestas tisulares como indicadores para evaluar la vulnerabilidad mediante una propuesta semicuantitativa que relacione estas respuestas y los elementos que la componen: exposición, sensibilidad y capacidad de recuperación. Conocer el estatus de salud de los organismos en vida silvestre, los posibles factores de estrés ambiental y la vulnerabilidad que tienen en las zonas costeras donde habitan, permitirá obtener información que facilite la toma de decisiones en materia de legislación, evaluación y remediación ambiental. 


\section{Antecedentes}

\subsection{Vulnerabilidad de los sistemas acuáticos por la presencia de contaminantes}

La contaminación es la introducción de sustancias y energía en un ambiente hecha por el hombre que resulta perjudicial para los organismos vivos lo que se traduce también en daños a la salud humana. Según Espina y Vanegas, (2005) el Golfo de México, como otros mares, se encuentra contaminado por las actividades humanas, tales como: asentamientos urbanos, actividades en playas, desechos industriales o descargas de aguas residuales lo que lo hace un sistema vulnerable.

México cuenta con 11,000 kilómetros de litorales y una red de 663,000 kilómetros de ríos y arroyos a lo largo y ancho del país en donde se producen 14 millones de metros cúbicos de aguas residuales al año, de las cuales cerca del $57 \%$ se vierten sin ningún tratamiento en los cuerpos de agua. En este sentido y hasta el año 2015 la CONAGUA reportaba que solo el 56 $\%$ de los cuerpos acuáticos en el país se colocaban en la categoría de "Excelente calidad" (CONAGUA, 2016).

Además de las aguas residuales, existen otros contaminantes que afectan a las zonas costeras como son: los restos de productos agroquímicos, los hidrocarburos, detergentes y metales pesados como arsénico, cadmio y mercurio (Singh y Gupta, 2017). Desafortunadamente, no en todos los cuerpos acuáticos del país se conoce el tipo de contaminantes específicos, ya que los esfuerzos de monitoreo se han enfocado en la evaluación la calidad del agua para satisfacer necesidades humanas $\mathrm{y}$ en el análisis de las respuestas fisiológicas que provocan los contaminantes.

En el estado de Veracruz, particularmente en el municipio de Tecolutla, se han realizado estudios para evaluar la calidad del agua en sus cuerpos acuáticos. En el río Tecolutla, por 
ejemplo, se ha reportado que excede los límites de bacterias coliformes totales y fecales de acuerdo con las normas mexicanas derivado de la contaminación antropogénica, lo que lo coloca con un índice de calidad que va de "regular" a "malo" (Arriaga-Gaona et al., 2013). También se ha reportado que en esta zona existen alrededor de 30 puntos de descarga de aguas residuales procedentes del municipio, hogares y negocios locales, situación que le lleva a tener un índice de calidad de agua de "contaminado" a "muy contaminado" (Limón-Hernández, 2019). Finalmente, la CONABIO ha reportado que existen impactos indirectos que afectan al manglar de Tecolutla dentro de los que se encuentran: la contaminación por agroquímicos, contaminación por el rompimiento de ductos de petróleo y daño por el tránsito de lanchas turísticas; sin que se reporte específicamente la presencia de metales pesados, detergentes, contaminantes emergentes o hidrocarburos como contaminantes (López-Portillo et al., 2009).

En términos generales, los sistemas acuáticos se pueden ver afectados por diferentes tipos de contaminantes los cuales, representan una fuente de estrés en los organismos (Botello, 2010). El estrés ambiental, causado por las actividades humanas puede originar una alteración medible del estado fisiológico (bioquímico, celular o conductual), que hace al individuo más vulnerable, por lo que eventualmente su existencia y bienestar pueden estar en peligro (Baum et al., 1984; Bayne et al., 1976). Dentro de los diferentes campos de la ciencia ambiental se busca contar con métodos que permitan evaluar los riesgos o efectos que tiene la contaminación en los organismos (Estudios de Riesgo Ecológico, ERE) a través del estudio de la vulnerabilidad. 


\subsection{Elementos para evaluar la vulnerabilidad}

La vulnerabilidad es el grado en el cual un sistema es susceptible a los efectos adversos causados por el estrés ambiental (Ocaña y Pech, 2018; Villa y McLeod, 2002). La vulnerabilidad puede ser estimada de acuerdo con el sistema mediante distintos enfoques los cuales incluyen aspectos genéticos, ecológicos, reproductivos, de desarrollo, evolutivos, geográficos y que pueden ser convertidos en indicadores de vulnerabilidad (Carantoña y Hernández, 2017; Magaña, 2012). Otro enfoque para la evaluación de la vulnerabilidad incluye la generación de índices de vulnerabilidad que recopila las respuestas obtenidas a través de biomarcadores a nivel molecular (Dagnino et al., 2008). Son diversas las metodologías para evaluar la vulnerabilidad, sin embargo, en ninguna se emplean como indicadores las respuestas obtenidas de biomarcadores como la histopatología. Biomarcadores que se encuentran a nivel intermedio de la organización biológica.

Los biomarcadores como elementos de la vulnerabilidad son importantes ya que estos son variaciones bioquímicas, fisiológicas o de comportamiento que pueden ser medidas en células, tejidos, fluidos biológicos u organismos y que ofrecen información importante sobre el medio en el que se desarrollan (Boscolo Papo et al., 2014b; Newton y Cope, 2007; Ryan y Hightwer, 1996). Los efectos generados por los contaminantes en los organismos dependerán del grado de toxicidad, el tiempo de exposición, la concentración del contaminante, de factores fisiológicos, entre otros, mismos que pueden ser evaluados a través de los biomarcadores (Newton y Cope, 2007; Toro-Restrepo, 2011). En moluscos bivalvos se han empleado técnicas histopatológicas como biomarcadores ya que estas representan la integración de diversos procesos celulares y bioquímicos que son alterados en respuesta a los cambios ambientales (Guzmán-García, 2007). Otras respuestas evaluadas en moluscos bivalvos y que se han vinculado a los efectos que provoca el estrés ambiental incluyen el marcaje y detección de 
proteínas específicas como las HSP70 (proteínas que se sobreexpresan ante el estrés térmico), las metalotioneínas (asociadas a la exposición con metales) y el citocromo P450 (asociado a la presencia de hidrocarburos) (Boscolo Papo et al., 2014b; Colombres et al., 1999; Coronato et al., 1999). Estas respuestas especificas pueden servir como indicadores de vulnerabilidad, ya que al igual que los biomarcadores permiten la detección desde la primera fase de daño biológico antes de que se presenten en un nivel de organización superior como la población o la comunidad (Toro-Restrepo, 2011).

\subsection{Biomarcador histopatológico en bivalvos}

La histopatología es un biomarcador útil en el monitoreo de los efectos que pueden provocar los contaminantes en los organismos. Esta ciencia permite la evaluación de respuestas biológicas en células, tejidos y órganos para determinar la presencia de lesiones que pueden ser vinculadas a la exposición de contaminantes (Toro-Restrepo, 2011). En el campo internacional la NOAA (National Oceanic and Atmospheric Administration por sus siglas en inglés) recomienda estudios tisulares con moluscos bivalvos para el análisis de daños ambientales (Villamar, 2011). En este sentido, estudios realizados con almejas en diferentes cuerpos acuáticos han demostrado las alteraciones provocadas por contaminantes como metales pesados, hidrocarburos o bien parásitos. Se puede observar en estos análisis daños morfológicos en células y tejidos del sistema digestivo, respiratorio y tegumentario de los moluscos bivalvos que pueden ser reversibles o irreversibles (efectos deletéreos). En estos trabajos, los autores asocian las respuestas tisulares a los daños provocados por dichos estresores (Bonnail et al., 2018; Boscolo Papo et al., 2014a, 2014b; Santovito et al., 2015).

Existen trabajos de evaluación de respuestas tisulares en moluscos bivalvos de vida silvestre en México, entre los que destacan los realizados con el ostión Crassostrea virginica de 
diferentes lagunas del estado de Veracruz. En estos trabajos se han encontrado lesiones patológicas dentro de las que destacan las respuestas inflamatorias, degeneración de epitelios en intestino, presencia y aumento de la concentración y tamaño de células cafés (gránulos de lipofuscina), pérdida de cilios en branquias y necrosis en filamentos branquiales (CamarenaNovelo, 2012; Flores-López, 2014; Guzmán-García, 2007; Hernández-Calderas, 2013).

Mientras que con la almeja $P$. caroliniana solo se tienen reportes de los estudios realizados en Tecolutla, Veracruz, donde se presenta la caracterización de los tejidos de tres órganos: pie, branquia y manto, así como las alteraciones tisulares que presenta en vida silvestre, las cuales según los autores no comprometen la salud del organismo (Jerónimo-Juárez, 2013). Por otro lado, se ha reportado la relación que existe cuando se expone a esta almeja a un metal pesado como el cadmio, observando el aumento de alteraciones patológicas en concentraciones subletales de este metal (Vázquez-Castro, 2019).

Cabe destacar que, tanto en estudios nacionales como internacionales, cuando se aplica el biomarcador histopatológico generalmente se suelen obtener resultados cualitativos, generando un área de oportunidad en el análisis de los efectos de los contaminantes ya que en materia de remediación y legislación ambiental se requieren de métodos numéricos que permitan la toma de decisiones a partir de las inferencias realizadas con la histopatología.

\subsection{1. Índice histopatológico como indicador de la de salud de los bivalvos}

Estadísticamente, un índice es una medida que permite estudiar los cambios que se producen en una magnitud con respecto al tiempo o al espacio. Los índices se emplean en distintos contextos: económico, social, o en el campo de la salud y estos sirven para aportar información que coadyuve en la toma de decisiones o marcar el rumbo de alguna estrategia. 
En materia ambiental, hace poco más de 20 años surgió una propuesta en la cual se podían relacionar los estudios histopatológicos en peces y el diseño de un índice que permitiera evaluar la contaminación acuática (Bernet et al., 1999). En este trabajo se reconoce la ventaja de la histopatología como biomarcador, al ubicarla en un nivel intermedio de la organización biológica y propone la construcción de una herramienta de evaluación estandarizada que pueda ser empleada en diferentes estudios de contaminación acuática. La propuesta de estos autores es un índice que analiza las respuestas histopatológicas, asignándoles un factor de importancia patológica y el grado de diseminación de una alteración; con cuyos valores, se obtiene un coeficiente matemático que puede compararse entre órganos del mismo animal o entre diferentes organismos, sugiriendo el nivel de daño de la lesión patológica. Este índice compromete, además, el estudio de reacciones patrón (conjunto de alteraciones que están directamente relacionadas con una unidad funcional u órgano); de órganos blanco, seleccionados a partir del tipo de contacto que tengan con los contaminantes y de las unidades funcionales de un órgano (estructuras tisulares características de un órgano blanco). Con los datos obtenidos se genera un índice que nos permite interpretar el grado de contaminación que se presenta en un determinado cuerpo de agua.

Diferentes son los trabajos en organismos acuáticos (particularmente en peces y bivalvos) que retoman este índice como herramienta de evaluación de la contaminación de sistemas acuáticos; por ejemplo, en un estudio de los efectos histopatológicos en el pez "pejerrey" expuestos a diferentes concentraciones de fracciones de petróleo solubles en agua, se aplicó dicho índice y los autores pudieron categorizar las lesiones en las branquias de estos peces, generando una evaluación propia de éste órgano, de acuerdo con las alteraciones observadas (Gusmão et al., 2012). Otro estudio reporta que este índice se ha empleado en la comparación de las respuestas patológicas de dos especies de peces: Notothenia coriiceps y Notothenia 
rossi, al obtener los valores del índice, los autores reportan diferencias entre los coeficientes obtenidos, sugiriendo que el índice más alto corresponde a la especie con más alteraciones histopatológicas (Donatti et al., 2012). En México, el primer reporte de este índice en peces se realizó con en el pez Scomberomorus cavalla de Tecolutla, Veracruz. En este estudio se analizó el hígado y las branquias del pez y se hizo una comparación bibliográfica con otros estudios que usan este enfoque y concluyeron que el uso de métodos semicuantitativos ayudan a la determinación del estado de salud y a mantener un registro de los cambios ambientales a través del tiempo (Matadamas-Guzman et al., 2019).

El enfoque del índice histológico fue retomado posteriormente y se modificó para su aplicación en moluscos bivalvos, organismos centinelas por excelencia (Costa et al., 2013). En estudios realizados en bivalvos como los mejillones se ha evaluado la glándula digestiva y la gónada de estos organismos procedentes de dos zonas diferentes, encontrando alteraciones histopatológicas y diferencias entre los índices, asociando el índice más alto a la zona más contaminada (Cuevas et al., 2015a). En México, se realizó un acercamiento a este enfoque metodológico a través del estudio de la relación que existe entre las alteraciones histopatológicas y la exposición ante el cadmio en la almeja $P$. caroliniana de Tecolutla, Veracruz, los autores encontraron una relación que correspondía al aumento del índice en muestras de almejas que presentaban mayor tiempo de exposición al metal (Vázquez-Castro, et al., 2017).

Cabe destacar que la mayoría de los estudios histopatológicos se concentran en la caracterización de las alteraciones tisulares, sin embargo, en materia ambiental es necesario un modelo semicuantitativo como es el índice histopatológico para facilitar la toma de decisiones en materia de evaluación y remediación ambiental. Este índice histopatológico ofrece la ventaja de que, al ser un coeficiente numérico, permite la comparación de forma sencilla de 
los resultados obtenidos en un estudio de monitoreo ambiental. Esta característica le confiere además un valor agregado como indicador de vulnerabilidad al reflejar la sensibilidad de los organismos a los estresores con los que se relaciona en su medio.

\subsubsection{Análisis inmunohistoquímico}

En el campo de la histopatología, para ofrecer un diagnóstico complementario y específico se ha recomendado la aplicación de técnicas inmunohistoquímicas, las cuales, se han empleado en estudios analíticos de tipo clínico, inspección alimentaria y análisis ambientales (OteroGonzález, 2010). Estas técnicas permiten la identificación de una proteína específica en un tejido mediante anticuerpos; debido a que en situaciones de alteraciones tisulares, los tejidos pueden contener proteínas que no estaban en el tejido sano (Martín-Lacave y GarcíaCaballero, 2012). La técnica inmunohistoquímica se basa en la relación antígeno-anticuerpo. Un antígeno es la sustancia que se desea detectar en una sección de tejido, se denomina antígeno ya que se considera que actúa como una sustancia ajena cuando es inyectado a un animal de experimentación, desencadenando una reacción inmune y produciendo anticuerpos. Los anticuerpos o inmunoglobulinas (Ig) son glicoproteínas en forma de "Y" que son sintetizadas por las células plasmáticas (Martín-Lacave y García-Caballero, 2012). Estas proteínas están formadas por cuatro cadenas: dos ligeras "L" o ligth de $25 \mathrm{kDa}$ de peso molecular y dos pesadas o heavy "H" de $50 \mathrm{kDa}$, estas cadenas se encuentran unidas entre sí por puentes disulfuro, fuerzas de Van Der Waals o enlaces de hidrógeno. Los anticuerpos tienen diferentes funciones entre las que destacan: la unión con antígenos, neutralización de toxinas, bloqueo en la invasión de virus y reconocimiento de algún agente estresor o antígeno (Vargas Burgoa y Villalba Herrera, 2014). Existen dos tipos de anticuerpos: monoclonales y policlonales. Los anticuerpos policlonales son una mezcla heterogénea de anticuerpos 
producidos por diferentes células, se obtienen por la extracción del suero de un animal previamente inmunizado con el antígeno que se pretende estudiar. Estos anticuerpos tienen múltiples sitios de unión debido a su amplio rango de especificidad. Por otro lado, los anticuerpos monoclonales son generados por células idénticas procedentes de una misma célula madre, estas moléculas presentan alta especificidad y reproductividad (Martín-Lacave y García-Caballero, 2012).

En este trabajo se han seleccionado tres anticuerpos considerados en el plano internacional como marcadores que evalúan el estrés ambiental en moluscos bivalvos: proteínas HSP70, metalotioneínas (MTs) y el citocromo P450 (CYP). Las proteínas HSP70 son un tipo de proteínas que pertenecen a la familia de las Hsp (Heat shock protein, por sus siglas en inglés) con peso molecular de $70 \mathrm{kDa}$. Se pueden encontrar desde organismos procariotas hasta eucariotas. Participan en la adquisición de la estructura terciaria de las proteínas, degradación o reparación de proteínas anormales, actuando como chaperonas moleculares. Estas proteínas, se sobreexpresan cuando las células son sometidas a estímulos como el estrés del choque calórico, radiaciones o exposición a diversas sustancias e infecciones virales. Al sobreexpresarse confieren protección a las células afectadas volviéndolas resistentes a la apoptosis (Coronato et al., 1999). Los estudios sobre HSP70 en moluscos bivalvos se han centrado en la caracterización e identificación de nuevos genes de esta proteína, así como en el marcaje inmunohistoquímico en órganos blanco. Existen trabajos en donde se caracterizó un gen de la proteína HSP70 cuya función se sugiere muy importante en la defensa ante infecciones bacterianas en la almeja Meretrix meretrix (Yue et al., 2011). Otros estudios que utilizan el marcaje inmunohistoquímico se han realizado en la almeja Venerupis philippinarum, encontrando reacción positiva de HSP70 en hemocitos de almejas que habitan lagunas contaminadas, o bien, positividad en células cafés del intestino de esta almeja, 
respuesta que los autores asocian a la presencia de un hidrocarburo policíclico aromático (Boscolo Papo et al., 2014b).

Las metalotioneínas (MTs) se reconocen como proteínas de unión a metales ricos en cisteína, con baja masa molecular $(6-10 \mathrm{kDa})$ que participan en el mecanismo de desintoxicación al secuestrar metales divalentes a través de ligados específicos (Colombres et al., 1999). Se sabe que estas proteínas se encuentran en diversos tejidos de un organismo, sin embargo, su mayor expresión se da en el hígado y riñón de vertebrados, o bien, en la glándula digestiva e intestino de invertebrados (Roesijadi, 1992). Las metalotioneínas tienen dos funciones de protección, la primera representa la intercepción y unión con iones metálicos libres que absorbe la célula y la segunda en la extracción de metales (Newton y Cope, 2007). Las metalotioneínas han sido reportadas en diversos estudios de evaluación de estrés ambiental, provocado por metales. En un estudio con larvas de la almeja Meretrix meretrix, se logró identificar en la fase larvaria, el sitio en el cual se sintetizan las metalotioneínas, afirmando el rol importante que juegan estas en el estrés provocado por cadmio (Wang et al., 2010). Este resultado es apoyado por otros trabajos en los que se evalúa el estrés en bivalvos provocado por cadmio (Fang et al., 2010), cobre y zinc (Santovito et al., 2015); ambos estudios concluyen que las metalotioneínas son excelentes biomarcadores ligados al proceso de desintoxicación por metales. Se tienen reportes de un ensayo con metalotioneínas, en donde se concluye que estas proteínas, se pueden emplear como biomarcadores por exposición a metales en moluscos bivalvos (Figueira et al., 2012). Finalmente, un estudio reciente que empleó biomarcadores de exposición y efecto en ostiones de la especie Crassostrea virginica de Tecolutla Veracruz observó que la transferencia trófica de metales en estos organismos provoca desestabilización de las membranas lisosomales y estrés oxidativo, además de considerar importante la evaluación de 
biomarcadores en organismos de importancia comercial esta zona de estudio (Mares-Guzmán et al., 2020).

Por otro lado, el citocromo P450 o CYP pertenece a una de las familias más grandes de hemoproteínas que se han evaluado en organismos desde bacterias, hasta mamíferos. Estas proteínas, participan en la fase I del metabolismo de desintoxicación, el cual implica procesos de oxidación, reducción e hidrólisis. Las proteínas como CYP con un peso de 50 a 60 kDa, se han reportado en la membrana del retículo endoplásmico del hígado en peces y en el hepatopáncreas en moluscos bivalvos (Zhang et al., 2012). Dentro de los trabajos que utilizan el citocromo P450 como biomarcador encontramos uno que considera el uso de CYP en almejas como una herramienta en la evaluación del ambiente ante la presencia de Hidrocarburos Policíclicos Aromáticos (HPA) (Pan et al., 2011). Por otro lado, existen trabajos de identificación de una nueva forma de citocromo P450 en la almeja Venerupis philippinarum donde concluyen que esta nueva forma de citocromo responde a diversos tipos de xenobióticos además de ser un candidato importante en la evaluación ante metales pesados (Zhang et al., 2012). Finalmente, otros estudios con CYP utilizan herramientas histoquímicas para la evaluación de esta enzima en tejidos de bivalvos, tal es el caso de Boscolo Papo et al., (2014a); quienes encontraron respuesta inmune positiva del citocromo P4501A en hemocitos de la almeja Venerupis philippinarum de zonas altamente contaminadas, lo que sugiere que CYP se sobreexpresa ante contaminantes orgánicos como los hidrocarburos.

La sobreexpresión de este tipo de proteínas en células y tejidos de moluscos bivalvos son indicativos de la presencia de diversos estresores ambientales a los que están expuestos estos organismos. Al evidenciar la exposición a diferentes contaminantes, las técnicas inmunohistoquímicas pueden funcionar como un indicador para evaluar el elemento “exposición” en un estudio de vulnerabilidad. 


\subsection{Evaluación de la vulnerabilidad: exposición, sensibilidad y capacidad de recuperación}

Etimológicamente la palabra vulnerabilidad proviene del latín que significa "posibilidad de ser herido o ser dañado". En la literatura es posible encontrar diferentes conceptos sobre la vulnerabilidad. El que tiene que ver con el cambio climático la define como "el grado de un sistema de ser susceptible e incapaz de enfrentar los efectos adversos del cambio climático" (Magaña, 2012). Desde el punto de vista de las Naciones Unidas para la Reducción del Riesgo de Desastres, la vulnerabilidad es "la incapacidad de resistencia cuando se presenta un fenómeno amenazante o la incapacidad de reponerse después de que ha ocurrido un desastre" (UNDRR, 2004). Por otro lado, la vulnerabilidad ambiental está relacionada con el tipo de exposición (mayor o menor) que tenga un territorio para ser afectado por un evento (impactos ambientales) (Pérez Figueredo, 2012). Finalmente, en el campo de la salud, la vulnerabilidad se puede entender como la exposición continuada ante un riesgo (Araujo González, 2015). Tomando en consideración esto, un organismo será vulnerable cuando se vea disminuida su eficacia reproductiva y sus probabilidades de supervivencia o eficacia biológica (Cadena Monroy, 2009). Para fines prácticos de este trabajo un organismo será vulnerable cuando sea susceptible a los efectos de una amenaza o se encuentre expuesto ante algún riesgo en menor o mayor grado y sea incapaz de prevenirlo.

Para evaluar el grado de vulnerabilidad se han propuesto diferentes metodologías según el campo de estudio (Carantoña y Hernández, 2017; Dagnino et al., 2008; Gauthier et al., 2014; Ocaña y Pech, 2018; Villa y McLeod, 2002). En ecología por ejemplo, la vulnerabilidad se estudia con el objeto de implementar programas de gestión y cultura ambiental y así reducir la contaminación en un sistema, lo cual se logra a través de indicadores (Araya-Ulloa y CalvoBrenes, 2017). Aunque no existe un método universal para evaluar la vulnerabilidad, el 
establecimiento de indicadores son el enfoque más usado. Los indicadores son datos cualitativos o cuantitativos que sirven para ordenar y sistematizar información con el fin de que coadyuven en la planificación, evaluación y toma de decisiones (Magaña, 2012).

En términos generales la vulnerabilidad se compone de tres elementos: la exposición, la sensibilidad y la capacidad de recuperación (Carantoña y Hernández, 2017; Villa y McLeod, 2002). La exposición es la fase en la cual un sistema u organismo se encuentra en relación o contacto con fuentes de estrés o presiones diferentes. La sensibilidad es el grado de afectación que un sistema o un organismo puede tener al estar expuesto a una fuente de presión. Finalmente, la capacidad de recuperación es la habilidad en que un sistema u organismo puede hacer frente a las fuentes de presión (Dagnino et al., 2008; Ocaña y Pech, 2018). La vulnerabilidad se ha evaluado mediante la determinación de indicadores e índices matemáticos con el fin de determinar el grado de susceptibilidad de los organismos a los cambios ambientales (Magaña, 2012; Ocaña y Pech, 2018). Un protocolo para la evaluación de la vulnerabilidad biológica propone que además de la estimación de índices, se analicen las respuestas obtenidas a partir del estudio de biomarcadores de exposición y efecto a nivel molecular (Dagnino et al., 2008). También, se ha propuesto evaluarla a través de la caracterización de respuestas ante diferentes amenazas, mediante aspectos de sobrevivencia y reproducción que sirvan para determinar la sensibilidad ante presiones conocidas (Dagnino et al., 2008; Gauthier et al., 2014; Karmaoui et al., 2015; Ramírez y Torres, 2010). Finalmente, en estudios en donde se evalúa el nivel de vulnerabilidad en especies en contacto con estresores ambientales, se sugiere considerar estos componentes: la exposición, la sensibilidad y la capacidad de recuperación. Pese a los esfuerzos en investigación para estimar la vulnerabilidad, en ninguno de ellos se hace referencia al estudio de respuestas obtenidas de análisis histopatológicos o inmunohistoquímicos para estimarla, aunque estos tengan un gran 
potencial para ofrecer información que se puede relacionar con la exposición, sensibilidad y capacidad de recuperación.

En la almeja $P$. caroliniana los elementos que componen la vulnerabilidad se pueden relacionar con biomarcadores fisiológicos como los histopatológicos. Si se piensa que las respuestas histopatológicas se pueden relacionar con la sensibilidad que tiene el organismo al medio y que la evaluación de respuestas inmunohistoquímicas se relaciona con algún posible agente estresor con el cual están en contacto, entonces estos análisis nos pueden brindar información valiosa para emplearse como indicadores de vulnerabilidad. Finalmente, para evaluar el tercer elemento de la vulnerabilidad, la capacidad de recuperación, en esta almeja se puede emplear un grupo control que permita contrastar las respuestas entre organismos expuestos y no expuestos, con el fin de determinar la capacidad de recuperación.

\subsection{Perspectiva de estudio para evaluar la vulnerabilidad en Tecolutla, Veracruz}

El municipio de Tecolutla se encuentra en el estado de Veracruz, México, el cual colinda al norte con Papantla, al sur con los municipios de Martínez de la Torre y San Rafael, al oeste con Gutiérrez Zamora y al este con el Golfo de México. El sitio seleccionado como perspectiva de estudio se ubica en el río Tecolutla entre los paralelos $96^{\circ} 59^{\prime} 849^{\prime \prime}$ W y $20^{\circ}$ 27 "628” N (figura 1). El río es un humedal arbóreo categorizado como marino-costero y cuenta con las siguientes categorías de priorización según la CONABIO: "Región marina prioritaria", "Región hidrológica prioritaria” y “Área de importancia para la conservación de aves”. En el río Tecolutla existen escasos estudios que evalúen la riqueza faunística de animales bentónicos (vertebrados o invertebrados) así como estudios que determinen la calidad y salud del sistema. Pese a que los reportes de diversidad en la zona se han enfocado en la presencia de aves, mamíferos y reptiles, es posible encontrar especies de peces y 
moluscos bivalvos con importancia en el comercio y dieta de los pobladores del lugar que no figuran en los registros oficiales faunísticos del río, un ejemplo de ello es la almeja Polymesoda caroliniana conocida comúnmente como almeja negra.

Las principales actividades económicas de la población ribereña asociada al manglar son: la agricultura, ganadería, pesca y el turismo. Tecolutla es una importante zona turística ya que cuenta con diferentes playas las cuales son las más cercanas a la Ciudad de México (figura 2). Sus principales atractivos turísticos son los recorridos por el manglar, la liberación de tortugas en temporada de desove y el festival del coco que se realiza entre febrero y marzo.

La falta de estudios sobre su riqueza biológica, así como el estatus desconocido de salud y vulnerabilidad de los organismos propios del sistema, hacen de Tecolutla una zona de gran relevancia para estudios de vulnerabilidad. El río Tecolutla, pese a su importancia biológica y climatológica, es una zona descuidada y desprotegida en materia de legislación ambiental y estudios de protección a los recursos acuáticos. Por ello, realizar evaluaciones que permitan entender el estado actual de los recursos naturales, permitirá en el futuro evaluar la vulnerabilidad del sistema completo y así generar políticas de conservación y gestión ambiental en beneficio del ambiente, los organismos silvestres y la población ribereña. 


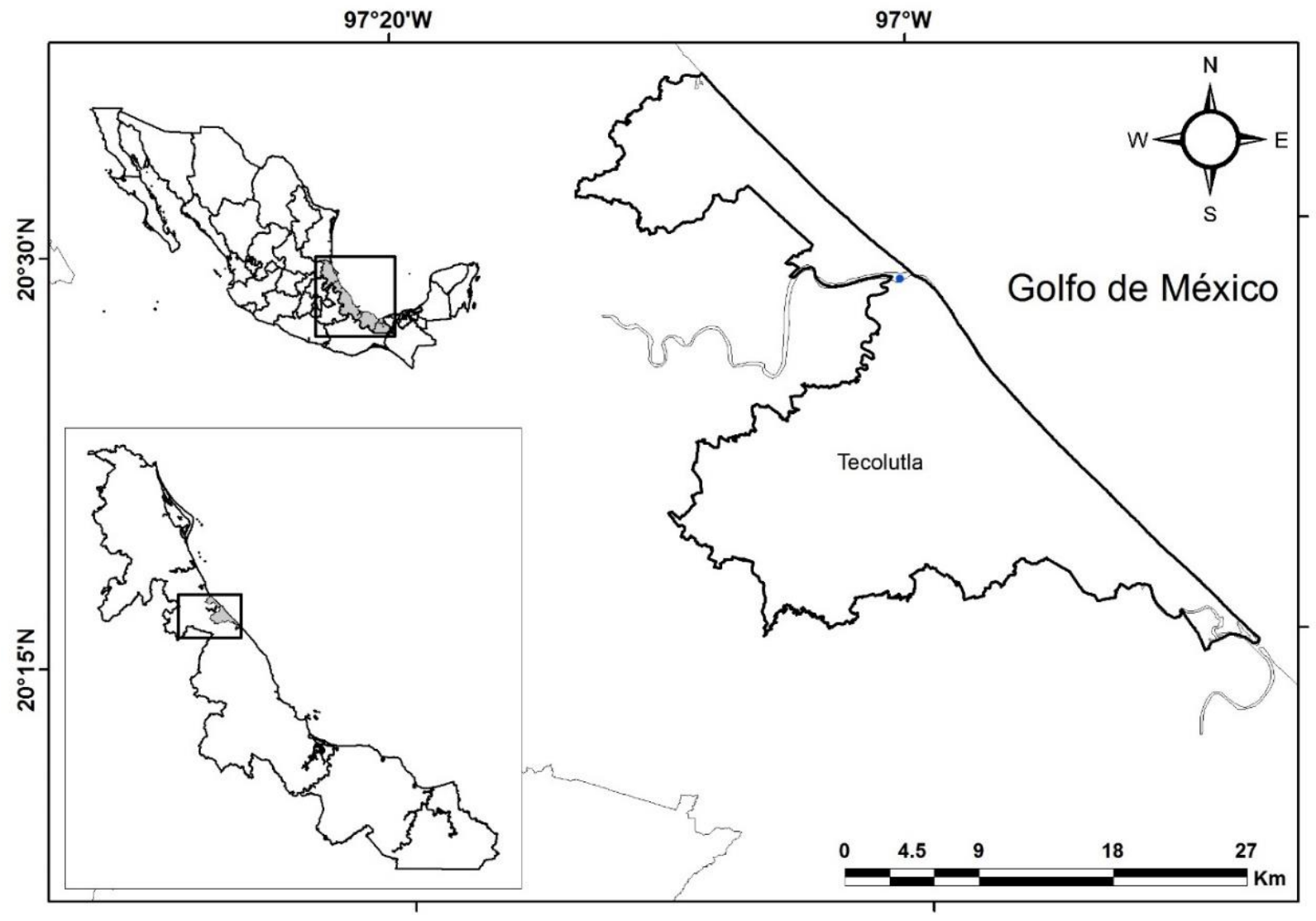

Figura 1. Mapa de la zona de estudio. Se muestra la ubicación geográfica del Municipio de Tecolutla, lugar donde se encuentra el río Tecolutla y su desembocadura con el Golfo de México. 

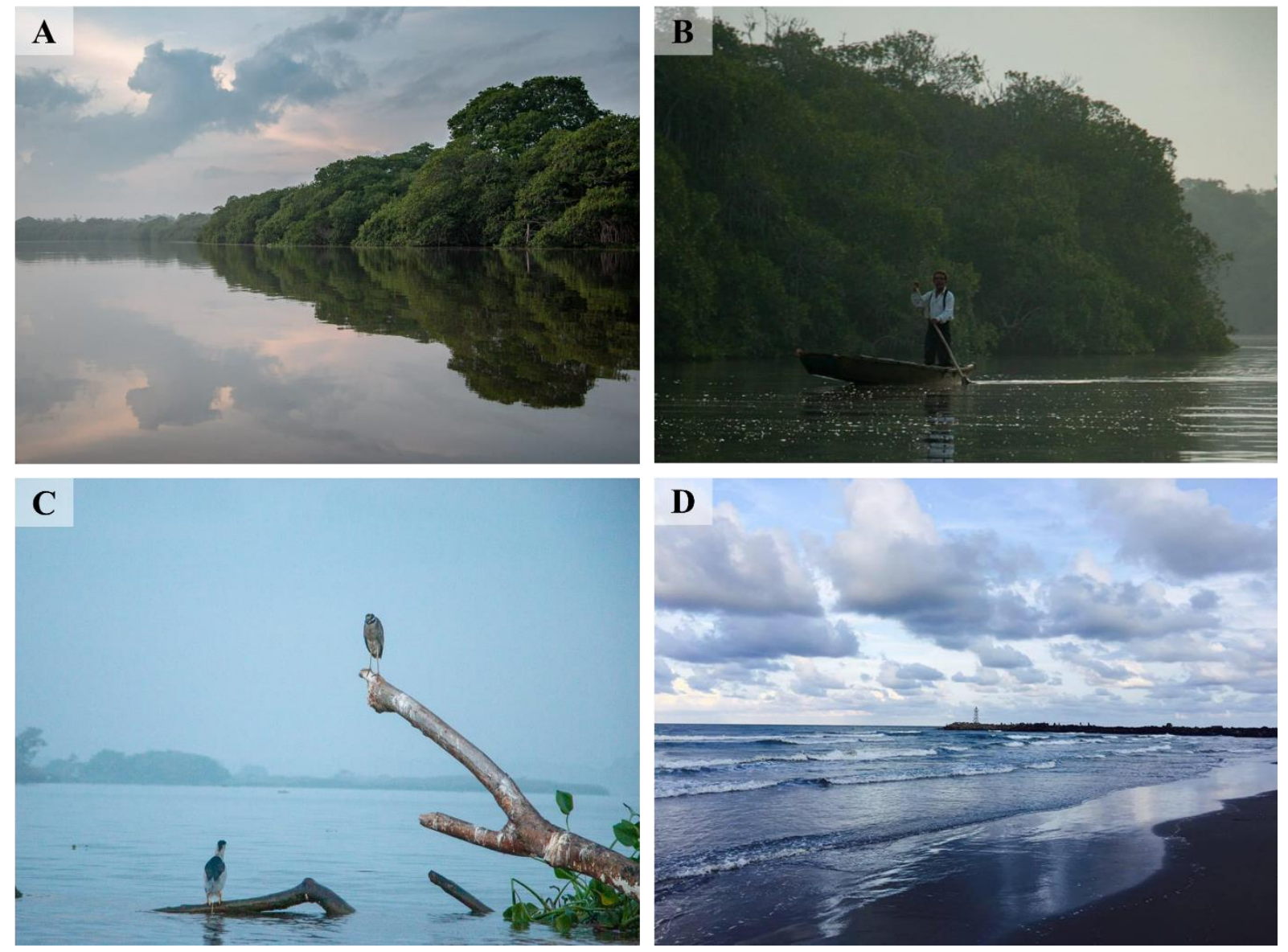

Figura 2. Paisajes de Tecolutla. A. Río Tecolutla con bosque de mangle, son características las especies vegetales Rhizophora mangle, Avicennia germinans y Laguncularia racemosa, especies en categoría de amenaza. B. Pescador en el río, la pesca es una de las actividades económicas del municipio, pero no la principal. C. Aves en el manglar, este tipo de fauna es la que se encuentra mayormente estudiada en el municipio. D. Playa de Tecolutla, al fondo de aprecia la escollera una zona rica en presencia de animales invertebrados como pepinos de mar, caracoles y anémonas. Fotografías capturas por Jerónimo Juárez J.R. y Márquez Ramos J.A (2016 y 2018). Acervo Fotográfico del Laboratorio de Ecotoxicología-Histología. UAM-I. 


\subsection{Polymesoda caroliniana como modelo para evaluar la vulnerabilidad}

La almeja $P$. caroliniana, es un organismo que presenta conchas no muy largas y ovaladas con líneas concéntricas sin umbo terminal, periostraco de color negro-pardo y con umbos erosionados (García-Cubas y Reguero, 2007; Mille-Pagaza et al., 1993) (figura 3). Esta almeja se distribuye desde las costas de Carolina en los Estados Unidos y hasta el Golfo de México, en México (García-Cubas y Reguero, 2007). En el Golfo de México, es la segunda especie de almeja más capturada con fines de consumo humano (SAGARPA-CONAPESCA, 2013). Sin embargo, se encuentra en categoría de protección especial (NOM-059 SEMARNAT, 2010). Recientemente se realizó un estudio para la caracterización parcial de enzimas proteolíticas de esta almeja colectada en Tecolutla, Veracruz; el análisis reveló que este organismo presenta una actividad enzimática en un rango amplio de temperatura $\left(50\right.$ a $\left.70^{\circ} \mathrm{C}\right)$ y $\mathrm{pH}(\mathrm{de} 8$ a 10$)$, lo cual hace relevante a dichas enzimas en estudios biotecnológicos (Jerónimo-Juárez, 2013). La almeja Polymesoda caroliniana se ha descrito tisularmente y se ha visto que responde a condiciones de estrés ambiental (Jerónimo-Juárez, 2013). Además, se ha reportado que estos organismos pueden inducir las respuestas ante metales, choque térmico e hidrocarburos (Boscolo Papo et al., 2014a; Vázquez-Castro, et al., 2017). Ecológicamente, estos organismos son animales sésiles y la mayor parte de su vida la desarrollan enterradas en el limo de la zona intermareal (García-Cubas y Reguero, 2007; Levine et al., 2006). Al estar desprovistas de mecanismos de protección; el enterrarse en el sedimento les confiere protección ante sus predadores naturales, como peces o cangrejos. Son organismos filtradores, que se alimentan de partículas que entran en al agua por medio de sus sifones y bañan las branquias (Hickman, 2009). Un órgano blanco que se ha considerado objeto de estudio en análisis histopatológicos de moluscos bivalvos es la glándula digestiva (Cuevas et al., 2015a; Usheva et al., 2006). La glándula digestiva se encuentra rodeando el estómago y está formada por una serie de túbulos 
diferenciados morfológicamente por el estado en el que participan durante la digestión. La función principal de la glándula digestiva es la digestión intracelular o la acumulación y desintoxicación de compuestos tóxicos (Mikkelsen y Bieler, 2008).

Estas características permiten realizar una evaluación semicuantitativa de las respuestas tisulares y establecer índices histopatológicos o de salud, sin embargo, en estudios de vulnerabilidad, el análisis de estas respuestas tisulares no ha sido consdierada como un indicador para estimarla.
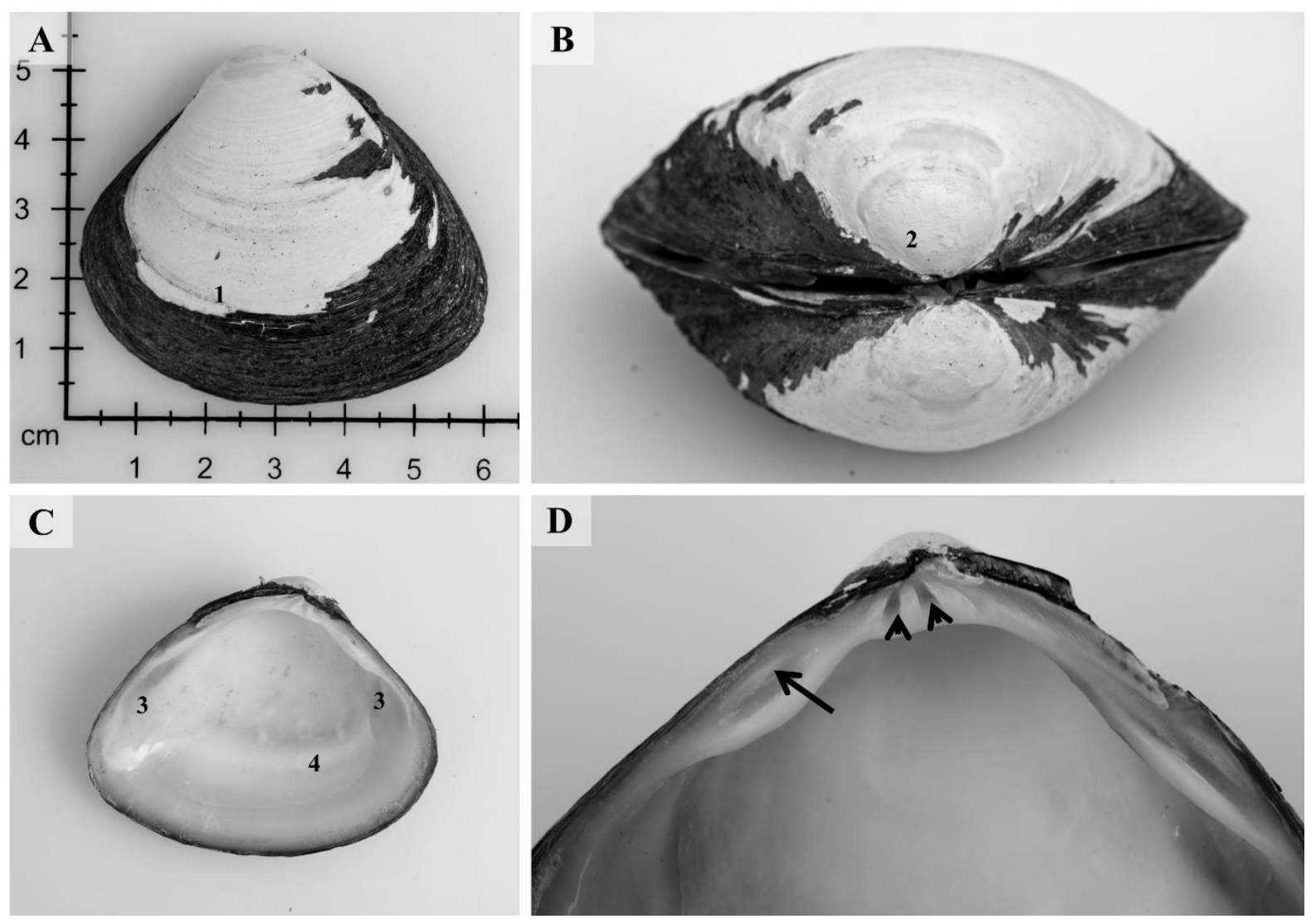

Figura 3. Aspecto externo de la almeja de Tecolutla Veracruz. A. Se observa la capa externa de las valvas denominada periostraco (1) de color negro pardo. B. Detalle del umbo (2), región más vieja de la concha, en esta especie se muestra el umbo erosionado. C. Apariencia interna de las valvas con dos impresiones musculares (3) e impresión paleal tenue (4). D. Charnela tipo no taxodonta con dientes cardinales (cabezas de flecha) y dientes laterales (flechas). Estos caracteres taxonómicos corresponden a la almeja $P$. caroliniana. Fotografías capturas por Luis Hernández D.I. (2012). Acervo Fotográfico del Laboratorio de Ecotoxicología-Histología. UAM-I. 


\section{Pregunta de investigación}

¿El análisis de biomarcadores tisulares permitirá generar información relevante para la evaluación del estado de salud y vulnerabilidad de la almeja Polymesoda caroliniana de Tecolutla, Veracruz?

\section{Hipótesis}

Si los biomarcadores tisulares permiten evaluar la exposición, sensibilidad y capacidad de recuperación en la almeja Polymesoda caroliniana, entonces se podrán establecer los mecanismos de respuesta ante el estrés ambiental, el estado de salud y la vulnerabilidad de este organismo en el sistema Tecolutla, Veracruz. 


\section{Objetivo general}

Analizar respuestas tisulares en la almeja Polymesoda caroliniana, con el fin de estimar el estado de salud y vulnerabilidad en el sistema Tecolutla, Veracruz.

\section{Objetivos particulares}

- Analizar respuestas histopatológicas con técnicas de rutina (H-E) en la glándula digestiva de la almeja para estimar la prevalencia de alteraciones en estos organismos.

- Asignar valores de importancia patológica (w) y el grado de diseminación (a) a cada alteración observada con el fin de obtener un índice histopatológico.

- Estimar el estado de salud de las almejas obtenidas en Tecolutla, Veracruz mediante el análisis del índice histopatológico $\left(\mathrm{I}_{\mathrm{h}}\right)$.

- Realizar el montaje y análisis de tres marcadores de estrés (proteínas HSP70, MTs y CYP) mediante técnicas inmunohistoquímicas con el fin de advertir la presencia y grado de exposición ante estresores ambientales.

- Generar categorías mediante las respuestas histopatológicas e inmunohistoquímicas (indicadores) observadas en la almeja para estimar su vulnerabilidad.

- Evaluar la vulnerabilidad de la almeja mediante la generación de una propuesta semicuantitativa que incluya la evaluación de la exposición, la sensibilidad y la capacidad de recuperación. 


\section{Materiales y métodos}

En la figura 4 se presenta un diagrama de flujo que representa los métodos seguidos para evaluar el estado de salud y vulnerabilidad en la almeja Polymesoda caroliniana. A continuación, se detalla cada análisis.

\subsection{Obtención de la muestra y análisis macroscópico}

Previo a la obtención de muestras, en el lugar se tomaron parámetros físicoquímicos del agua tales como: temperatura, salinidad, oxígeno disuelto y $\mathrm{pH}$ mediante un espectrofotómetro marca Hach® modelo DR/2000. Los parámetros fisicoquímicos obtenidos en el lugar fueron empleados como referentes para el mantenimiento de los organismos en el grupo control.

La obtención de los organismos se realizó mediante pesca local en un banco de almejas conocido por los pescadores como el punto de mayor abundancia de esta especie en el río Tecolutla, Veracruz. Se obtuvieron 100 organismos adultos (de 4 a $5.5 \mathrm{~cm}$ de longitud) y se dividieron en dos lotes iguales: 50 organismos en el lote experimental (almejas recolectadas del medio) y 50 organismos destinados al lote control (almejas en cuarentena). El tamaño de muestra es mayor al reportado para estudios con moluscos bivalvos (Cuevas et al., 2015a). El transporte de las almejas hasta el Laboratorio de Ecotoxicología UAM-I se realizó mediante hieleras a una temperatura de $4{ }^{\circ} \mathrm{C}$. Una vez en el laboratorio, todos los organismos se limpiaron con alcohol al 70 \% y se realizó un análisis macroscópico evaluando los siguientes parámetros: perforaciones en las valvas, presencia de vermes o ectoparásitos, así como malos olores en la masa visceral. Posteriormente, las almejas del lote control se colocaron en los acuarios de cuarentena en el PIMVS CIDMIRA-UAM-I (SEMARNAT DGVS-02594/1806). Las almejas del lote control se colocaron en acuarios de $40 \mathrm{~L}$ con agua salobre (2 \% ) tomando en cuenta el espacio entre cada uno de ellos $(\approx 5 \mathrm{~cm}$ entre cada uno). Se mantuvieron durante 
40 días con aireación y alimento constante (cultivo de Chlorella sp., a una concentración de 909, $935 \mathrm{cel} / \mathrm{ml})$. Diariamente se hizo un registro y control de los parámetros físicoquímicos (temperatura, pH y salinidad), así como el registro de mortalidad de los organismos. Transcurrido el periodo de cuarentena, las almejas fueron procesadas para el análisis histopatológico e inmunohistoquímico como se detalla a continuación.

\subsection{Análisis histopatológico}

Se extrajo la masa visceral completa de los organismos del lote experimental y del lote control (una vez transcurrida la cuarentena) y se fijaron en formol amortiguado al $10 \%$ (PBS 1mM, $\mathrm{pH}$ 7.4) por 48 horas. Posteriormente, la masa visceral se seccionó en tres regiones y se colocaron en cassetes histológicos marca Simport ${ }^{\circledR}$ modelo Histossete I para su deshidratación, infiltración y aclarado en un procesador de tejidos marca Leica ${ }^{\circledR}$ modelo TP1020. Las muestras se incluyeron en un medio de parafina marca Paraplast@ de Leica Microsystems (No. de catálogo: EM-400) mediante un centro de inclusión de tejidos marca Leica ${ }^{\circledR}$ modelo EG1140-H. Se realizaron tres cortes seriados a un nivel de $5 \mu \mathrm{m}$ con orientación transversal y con énfasis en la glándula digestiva (región media de la almeja) mediante un microtomo marca Microm ${ }^{\circledR}$ modelo HM3156 y se tiñeron con HematoxilinaEosina (Cuevas et al., 2015a).

El análisis histopatológico fue realizado con énfasis en la glándula digestiva de los organismos de ambos lotes de estudio. El análisis de las preparaciones tisulares fue realizado en un microscopio óptico marca Carl Zeiss ${ }^{\circledR}$ modelo Apotome Observer.Z1 acoplado una cámara marca Zeiss ${ }^{\circledR}$ modelo AxioCam MRC5 y a un ordenador Toshiba® modelo Satellite, donde se tomaron fotomicrografías de las zonas de interés. Las fotomicrografías obtenidas se editaron mediante el software Carl Zeiss® AxioVision versión SE 64 REL.4.9.1. De cada almeja se 
observaron tres preparaciones tisulares en tres diferentes magnificaciones 10x, 40x y 100x para caracterizar la estructura de la glándula digestiva (forma de los túbulos, presencia de lumen, apariencia y tipo de tejido conectivo circundante) y la presencia o ausencia de alteraciones tisulares.

El análisis histopatológico incluyó: $\boldsymbol{i}$. la observación y descripción de las alteraciones patológicas (la presencia de infiltraciones hemocíticas, células cafés, agregados de lipofuscina, atrofias o parásitos fueron consideradas como alteraciones), ii. la construcción de una matriz de prevalencia de alteraciones y iii. la asignación de un factor de importancia patológica (w) así como el grado de diseminación (a) para la estimación de un índice histopatológico. Para la calibración de las observaciones, tres personas diferentes en momentos distintos realizaron el mismo análisis siguiendo los mismos criterios de evaluación.

\subsection{1. Índice histopatológico $(\mathrm{Ih})$}

El índice histopatológico $\left(\mathrm{I}_{\mathrm{h}}\right)$ empleado en este trabajo es parte de un protocolo para la evaluación de la contaminación acuática propuesto originalmente por Bernet et al. (1999) con modificaciones para moluscos bivalvos de Costa et al. (2013). Previo al cálculo del índice histopatológico, cada alteración se agrupó en reacciones patrón; donde una alteración es cualquier cambio en el estado normal de una célula o un tejido y una reacción patrón es el grupo de alteraciones que se relacionan directamente con la unidad funcional de un órgano en donde se presentan. En este sentido, se categorizaron dos reacciones patrón: alteraciones tubulares (cuando las alteraciones se presentaban dentro del túbulo digestivo) y alteraciones intertubulares, cuando se observaban entre los túbulos (particularmente en el tejido conectivo laxo). Posteriormente, a cada alteración tisular observada se le asignaron dos valores, uno para el grado de diseminación (a) y otro para el factor de importancia patológica $(w)$. 
El factor de importancia patológica $(w)$ se define como el grado de daño o compromiso de un órgano después de una alteración, este factor toma valores desde 0 a 3 donde 0 es la ausencia de la alteración, 1 es mínima importancia, 2 moderada y 3 es severa importancia patológica (Costa et al., 2013; Cuevas et al., 2015a). En este sentido, los parásitos tuvieron un peso de $w=$ 3, infiltraciones hemocíticas y atrofias $w=2$, mientras que las célula cafés y agregados de lipofuscina un peso de $w=1$.

Por otro lado, el grado de diseminación ( $a$ ) implica la intensidad en la que se observa una alteración tisular. Al grado de diseminación se le asignan valores desde 0 a $6(0=\sin$ alteración, 2 = mínima, 4 = moderada y 6 = severa diseminación) (Costa et al., 2013; Cuevas et al., 2015a). Para calcular el grado de diseminación de una alteración se empleó el criterio de correspondencia que se presenta en la Tabla 1, el cual relaciona el porcentaje de diseminación de una alteración con un valor de a correspondiente.

Tabla 1. Criterio propuesto para asignar el valor de (a) de diseminación de una alteración histopatológica.

\begin{tabular}{cc}
\hline \hline Grado de diseminación $(\%)$ & Valor de $\boldsymbol{a}$ \\
\hline 0 a 9 & 0 \\
10 a 50 & 2 \\
50 a 70 & 4 \\
70 a 100 & 6 \\
\hline
\end{tabular}


El índice histopatológico fue calculado mediante la fórmula propuesta por Costa et al. (2013) para moluscos bivalvos:

$$
I_{h}=\frac{\sum_{1}^{j} w_{j} * a_{j h}}{\sum_{1}^{j} M_{j}}
$$

Donde:

- $I_{h}$ es el índice histopatológico por cada organismo.

- $w_{j}$ es el factor de importancia patológica para cada alteración

- $a_{j h}$ es el grado de diseminación de las alteraciones y

- $M_{j}$ es el máximo valor atribuible para una alteración estimada mediante el producto del valor máximo del factor de importancia patológica $(w=3)$ por el valor máximo de la diseminación de una alteración $(a=6)$ esto para ajustar los valores entre 0 y 1 . El ajuste de $I_{h}$ permite comparar entre diferentes áreas de estudio o distintos órganos.

\subsubsection{Análisis inmunohistoquímico}

Para la técnica inmunohistoquímica las preparaciones histológicas se colocaron en una estufa de secado marca Blue $\mathrm{M} \circledast{ }^{\circledR}$ modelo SW-11TA por 1 hora a $60{ }^{\circ} \mathrm{C}$ para desparafinar, complementando el proceso con dos tratamientos de xilol de 5 minutos cada uno. Transcurrido ese tiempo, las preparaciones se hidrataron mediante alcoholes a diferentes concentraciones (de alcohol absoluto a $96 \%$ ), dejando tres minutos en cada uno y un paso final en agua destilada para evitar la desecación de las muestras. La recuperación de antígenos se realizó mediante una olla de presión marca Biocare Medical ${ }^{\circledR}$ modelo DC2002 (25 PSI, $125^{\circ} \mathrm{C}$ por 5 minutos) colocando las preparaciones en una jarra coplin con $250 \mathrm{ml}$ del recuperador Diva Decloaker 20x de Biocare Medical® (No. de catálogo: DV2005 L2J) en una proporción 1:20 con agua destilada. Las muestras se dejaron enfriar a baño María por 20 minutos a temperatura 
ambiente. El exceso de recuperador se lavó con buffer TBS Auto Wash Buffer 40X marca Biocare Medical® (No. de catálogo: TWB946L2J). Posteriormente, cada muestra se colocó en una cámara de incubación Biocare Medical® modelo RMIQ105 y se aplicaron $100 \mu$ l del bloqueador de peroxidasas endógenas Dual Endogenous Enzyme Block marca Biocare Medical® (No. de catálogo: K4065) durante 5 minutos a temperatura ambiente. Transcurrido ese tiempo, se eliminó el sobrante del bloqueador mediante lavados con buffer TBS. Preparadas las muestras se colocaron los anticuerpos primarios de los marcadores de estrés ambiental como se describe a continuación:

Proteína HSP70. Seguido de los lavados, se aplicaron $100 \mu$ l del anticuerpo para HSP70 en una dilución 1:50 (Hsp70 [3A3] antibody Rabbit polyclonal antibody anti-human. Genetex®, No. de catálogo: GTX25439).

Metalotioneínas. Se aplicaron $100 \mu \mathrm{l}$ del anticuerpo para metalotioneínas en una dilución 1:30 (Metallothionein antibody [UC1MT] antibody mouse monoclonal antibody antirabbit/Genetex $®$, Catalogo: GTX12228).

Citocromo P450. Se aplicaron $100 \mu \mathrm{l}$ del anticuerpo para Citocromo P450 en una dilución 1:50 (CYP1A2 antibody [15E2] antibody mouse monoclonal antibody anti-human/Genetex®, Catalogo: GTX84638).

En cada anticuerpo, se dejaron reposar por 45 minutos a temperatura ambiente. Se eliminaron los sobrantes de los anticuerpos y se hicieron lavados con el buffer TBS, aplicando posteriormente $100 \mu \mathrm{l}$ del anticuerpo secundario Polimero EnVision+ System- HRP Labelled Polymer marca Dako® (No. de catálogo: K4000) por 45 minutos a temperatura ambiente. Para el sistema de revelado se empleó una mezcla de $1 \mathrm{ml}$ de DAB+ Substrate Buffer y 50 $\mu 1$ de DAB+Chromogen, ambos reactivos de la marca Dako Envision® (No. de catálogo: K4065) colocando en cada preparación tisular una alícuota de $100 \mu \mathrm{l}$ de esta mezcla para la 
visualización de la inmunorreacción. Finalmente se realizó una contratinción con Hematoxilina de Tacha marca Tacha's Auto Hematoxylin de Biocare Medical® (No. de catálogo: NM-HEM) durante 10 minutos, para después deshidratar (alcoholes de $96 \%$ a absoluto, 3 min cada uno) y xilol en dos tratamientos de 30 minutos cada uno. Las muestras se cubrieron mediante una solución de resina sintética-xilol al $50 \%$.

\subsection{3. Índice inmunohistoquímico $\left(I_{i}\right)$}

Las preparaciones histológicas se analizaron mediante un microscopio marca Zeiss ${ }^{\circledR}$ modelo PrimoStar. El análisis inmunohistoquímico se realizó de acuerdo el criterio de ubicación de la inmunorreacción (núcleo o citoplasma), así como de la intensidad de la reacción, considerándose positiva cuando la reacción era evidente y negativa cuando no hubo reacción (Jorge-Buys et al., 2007). Se empleó además un testigo negativo en el cual se omite la aplicación de anticuerpos primarios y manteniendo hidratado con buffer TBS.

Con las observaciones de inmunorreacción de cada marcador se propuso un cociente entre el número de marcadores inmunohistoquímicos observados y el número de órganos analizados ya que en esta técnica además de la glándula digestiva, se consideraron otros órganos blanco donde se observó inmunorreacción positiva. A este cociente se le denominó índice inmunohistoquímico $\left(\mathrm{I}_{\mathrm{i}}\right)$.

\subsection{Evaluación de la vulnerabilidad: exposición, sensibilidad y capacidad de recuperación}

Debido a la falta de trabajos similares en donde se evalúe la vulnerabilidad de organismos acuáticos ante estresores ambientales, se realizó una investigación bibliográfica y con base en trabajos similares se hizo la propuesta de la evaluación de la vulnerabilidad a través de los marcadores tisulares e inmunohistoquímicos. 
Para la evaluación de la vulnerabilidad se tomaron en cuenta los elementos que conforman a esta: exposición, sensibilidad y capacidad de recuperación (Carantoña y Hernández, 2017; Dagnino et al., 2008; Ocaña y Pech, 2018; Villa y McLeod, 2002). La exposición fue medida a través del índice inmunohistoquímico $\left(\mathrm{I}_{\mathrm{i}}\right)$ ya que es el marcador que ofrece respuestas ante estresores a los que están expuestas las almejas. Para dar una significancia en los valores de este índice, se propusieron las siguientes categorías: sin exposición $\left(\mathrm{I}_{\mathrm{i}}=0\right)$, mínima exposición $\left(\mathrm{I}_{\mathrm{i}}=\right.$ de 0.1 a 1$)$, moderada exposición $\left(\mathrm{I}_{\mathrm{i}}=\right.$ de 1.1 a 2$)$ y alta exposición $\left(\mathrm{I}_{\mathrm{i}}=\right.$ de 2.1 a 3$)$. Por otro lado, la sensibilidad fue evaluada mediante la relación entre el nivel de exposición y la prevalencia de alteraciones. Para ello, se propusieron categorías y valores que permitieran la relación matemática. El nivel de exposición fue categorizado en tres grupos diferentes con valores de exposición desde mínimo (1), moderado (2) y alto (3). Para asignar cualquiera de estos valores, se tomó el resultado obtenido en el índice inmunohistoquímico, así si se obtenía un $\mathrm{I}_{\mathrm{i}}$ de 2.1, le correspondía un valor exposición de 2 y una categoría de moderada exposición. Por otro lado, para la prevalencia de alteraciones se propusieron las siguientes categorías: baja (1), moderada (2) y alta prevalencia (3). Para asignar cualquiera de estos valores y categorías se empleó la interpretación del índice histopatológico $\left(\mathrm{I}_{\mathrm{h}}\right)$, donde de 0 a 0.25 es baja, de 0.25 a 0.50 es moderada, 0.50 a 0.75 es alta y de 0.75 a 1 es muy alta (para este trabajo, consideramos la categoría alta y muy alta como una misma). Esta categorización proviene de rangos establecidos para la interpretación del índice histopatológico (Costa et al., 2013). Finalmente, el valor de sensibilidad se calculó mediante la resta del valor de prevalencia menos el valor del nivel de exposición, con lo que se obtuvieron cinco categorías de sensibilidad: muy baja (-2), baja (-1), normal (0), alta (1) y muy alta (2). 
El tercer elemento de la vulnerabilidad, la capacidad de recuperación fue estimada mediante la comparación entre los valores obtenidos para el $\mathrm{I}_{\mathrm{h}} \mathrm{y}$ el $\mathrm{I}_{\mathrm{i}}$ del grupo control contra el experimental. Una vez estimados los elementos de la vulnerabilidad (exposición, sensibilidad y capacidad de recuperación), los indicadores (índice inmunohistoquímico, relación entre el $\mathrm{I}_{\mathrm{h}}$ y $\mathrm{I}_{\mathrm{i}}$, evaluación del grupo control) y las escalas para cada elemento, se construyó una propuesta semicuantitativa para determinar la vulnerabilidad de las almejas. 


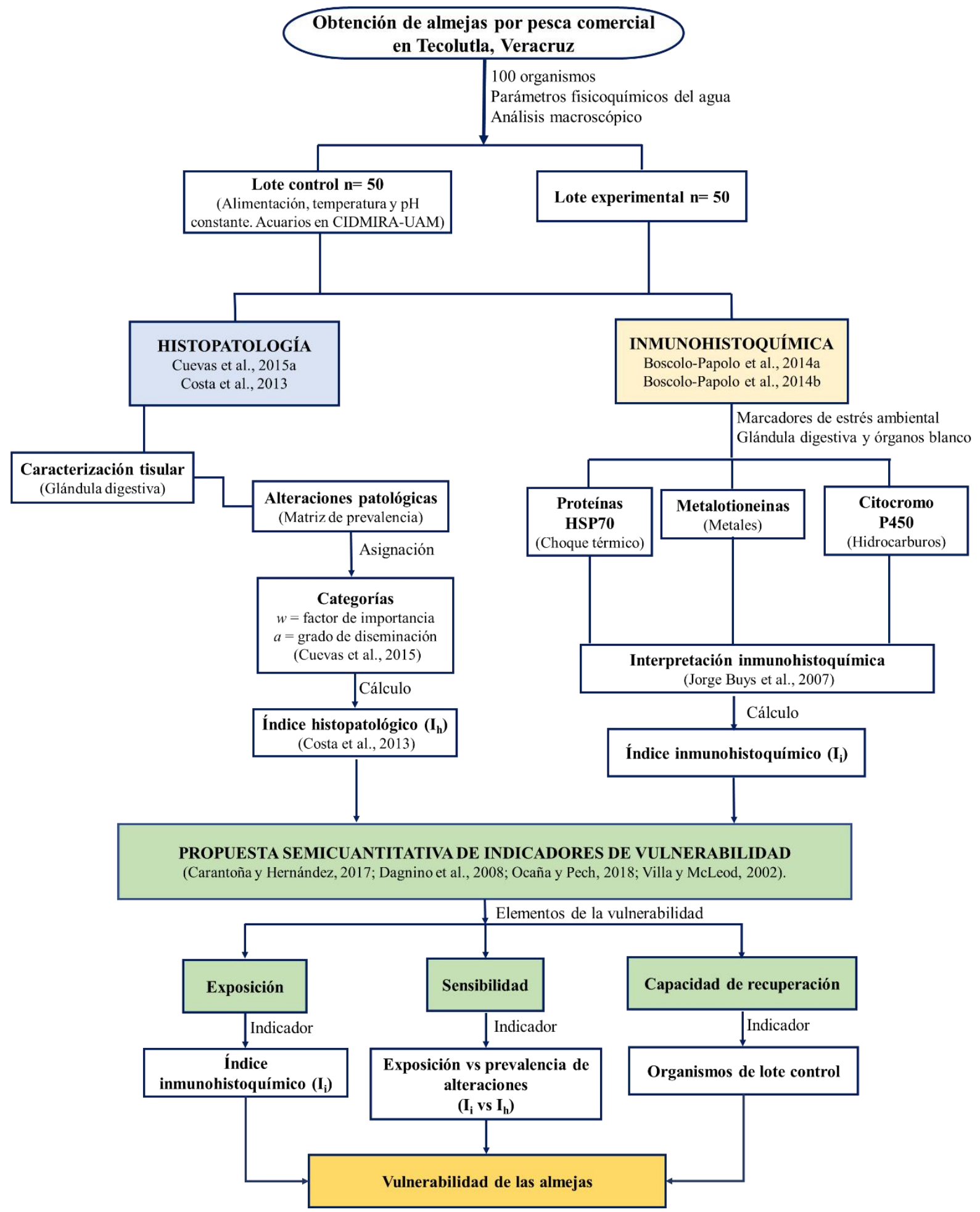

Figura 4. Método empleado para evaluar la vulnerabilidad y el estado de salud de la almeja Polymesoda caroliniana de Tecolutla, Veracruz. 


\section{Resultados}

\subsection{Análisis macroscópico}

Los parámetros fisicoquímicos del agua obtenidos fueron $22{ }^{\circ} \mathrm{C}$ de temperatura, $2 \%$ de salinidad, $5.4 \mathrm{mg} / \mathrm{L}$ de oxígeno disuelto y un $\mathrm{pH}$ de $7.7 \pm 0.5$; de acuerdo con estos parámetros, la temperatura se encuentra dentro del intervalo para la óptima reproducción. Por otro lado, la salinidad obtenida es típica de sistemas de agua salobre, mientras que el oxígeno disuelto y el $\mathrm{pH}$ coinciden con ambientes de tipo eurihalinos.

Los organismos recolectados pertenecen a la especie Polymesoda caroliniana (o almeja negra). El análisis de los parámetros biológicos demostró que las almejas recolectadas no presentaron perforaciones en conchas, ni malos olores, o daños en la masa visceral. Sin embargo, en un $25 \%$ de las almejas estudiadas se evidenció la presencia de organismos asociados a las conchas del tipo de los vermes. En las almejas del lote control no se evidenció la mortalidad de ningún organismo bajo las condiciones de control y mantenimiento establecidas. En la figura 5 se muestra la apariencia externa de las almejas al salir del periodo de cuarentena, en donde no se observaron alteraciones macroscópicas ni presencia de vermes aparentes. 

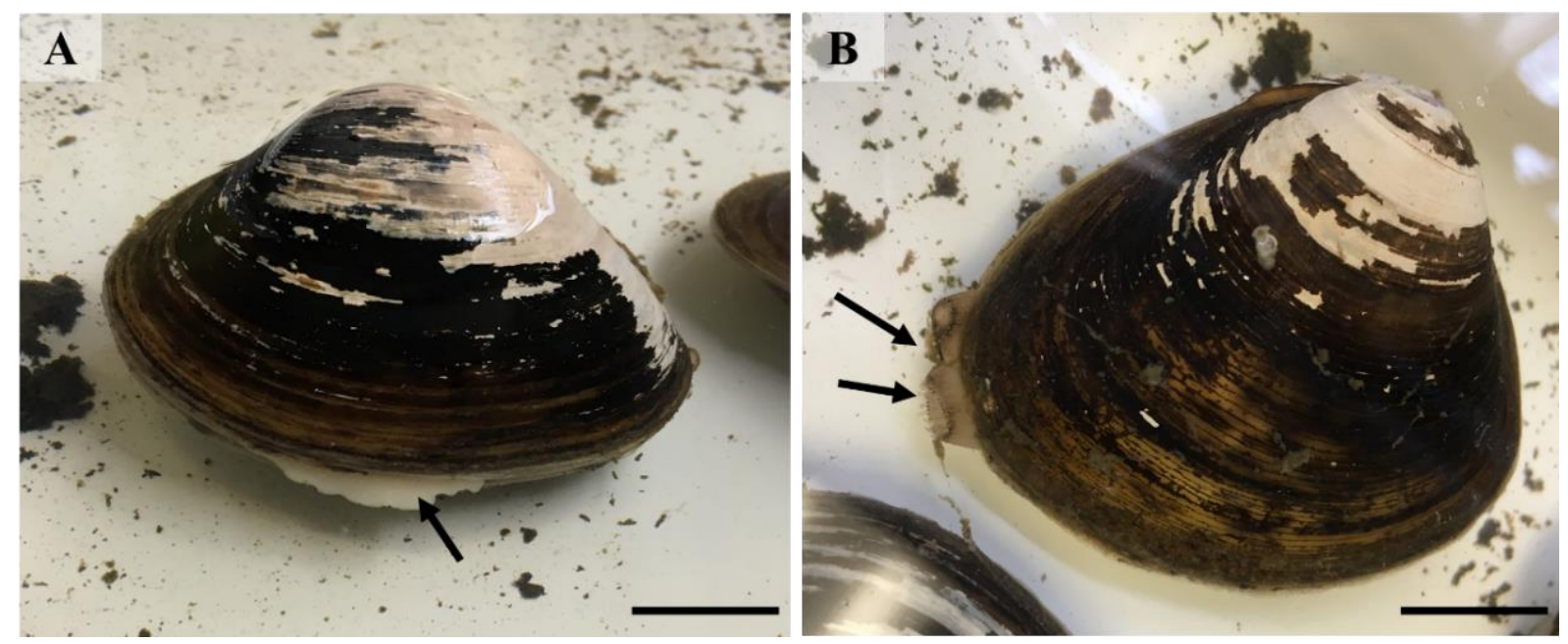

Figura 5. Aspecto externo de la almeja en cuarentena, no se observan organismos asociados ni perforaciones en conchas. A. Detalle del pie (flecha), órgano que utilizan para enterrarse en el sedimento. B. Sifones inhalante y exhalante (flechas), encargados de la introducción y expulsión de las corrientes de agua. Barra de escala $=1 \mathrm{~cm}$.

\subsection{Análisis histopatológico}

La descripción tisular de la unidad funcional de la glándula digestiva se realizó mediante el análisis de los organismos del grupo control. En la almeja de Tecolutla, los túbulos digestivos se observaron con formas de semicirculares a alveolares. El túbulo digestivo presentó de forma externa un epitelio simple con membrana basal fina y células de tipo piramidal con núcleos basales (en ninguna muestra analizada se advirtió la presencia de cilios en las células epiteliales). En el interior del túbulo fue posible observar una luz o lumen con diferentes tamaños relacionados con la fase digestiva en la que se encontraban. Rodeando los túbulos se observó tejido conectivo de tipo laxo (figura 6A).

En el $90 \%$ de las muestras analizadas del grupo control se observaron procesos de formación de vesículas secretorias derivadas de los epitelios tubulares, un proceso que permite el almacenamiento de nutrientes en el tejido conectivo de almacén (figura 6B). La identificación de estas vesículas fue posible gracias a las proyecciones evidentes en las membranas de ciertos túbulos formando evaginaciones y la ausencia de estas en otros túbulos (figuras 6C y D). Cabe destacar que en ninguna de las preparaciones analizadas del grupo control se observaron 
alteraciones de importancia patológica severa más que la presencia de células cafés en baja prevalencia, respuesta que se considera parte de la propia respuesta fisiológica del organismo.
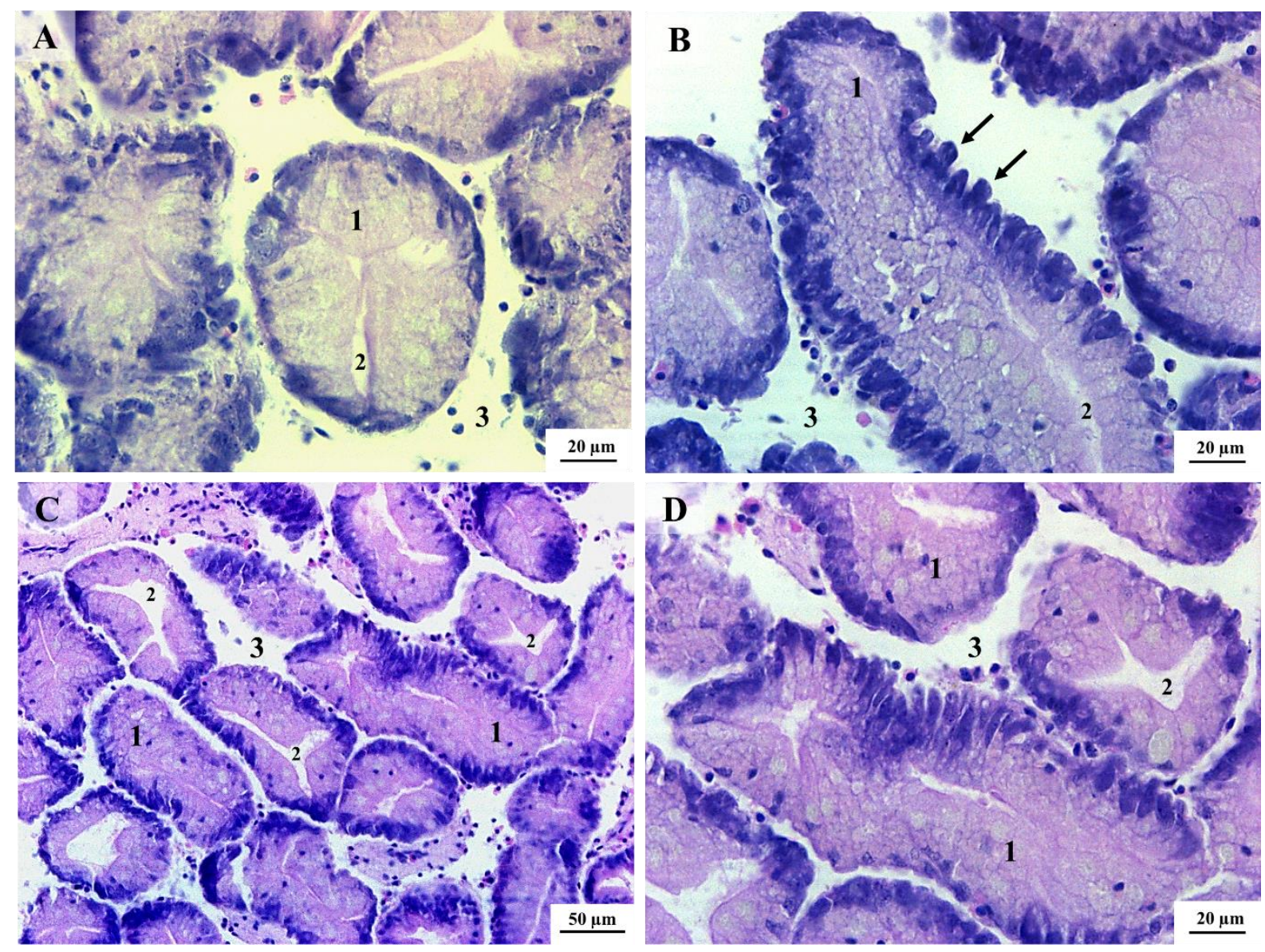

Figura 6. Descripción tisular de los túbulos de la glándula digestiva de la almeja $P$. caroliniana (organismos control). A. Aspecto normal de un túbulo digestivo con apariencia semicircular, epitelios simples (1) con células piramidales, lumen central (2) y rodeados por tejido conectivo laxo (3). B. Se observa la formación de vesículas secretorias (flechas) provenientes del epitelio de un túbulo digestivo. C. Aspecto de los túbulos digestivos con diferentes tamaños de lumen derivados de la fase digestiva en la que se encuentran. D. Detalle de la disposición de los túbulos que componen a la glándula digestiva. Tinción con H-E. 
En la unidad funcional de la glándula digestiva de los organismos experimentales se encontraron cinco alteraciones patológicas: células cafés, agregados de lipofuscina, infiltraciones hemocíticas, atrofias y parásitos. De acuerdo con la naturaleza de las alteraciones fueron agrupadas en dos reacciones patrón: alteraciones tubulares (cuando correspondían a la estructura del túbulo digestivo: epitelio y lumen) y alteraciones intertubulares (alteraciones observadas entre los túbulos, particularmente en el tejido conectivo). De acuerdo con el porcentaje de prevalencia, en el $95 \%$ de los organismos se encontró la presencia de células cafés, en el $60 \%$ agregados de lipofuscina, $40 \%$ infiltraciones hemocíticas, en $25 \%$ se observaron atrofias y solo en el $5 \%$ de ellos se presumió la presencia de un parásito (Tabla 2). Esta prevalencia fue considerada como baja respecto a otros estudios con moluscos bivalvos.

\begin{tabular}{ccc}
\hline $\begin{array}{c}\text { Tabla 2. Matriz de prevalencia de alteraciones patológicas observadas en la almeja } \boldsymbol{P} . \\
\text { caroliniana, se muestra la prevalencia (P\%). }\end{array}$ & P\% \\
\hline Alteración & No. & 95 \\
\hline Células cafés & 47 & 60 \\
Agregados de lipofuscina & 30 & 40 \\
Infiltraciones hemocíticas & 20 & 25 \\
Atrofias & 10 & 0.05 \\
Parásitos & 1 & \\
\hline
\end{tabular}

Las células cafés se observaron en todas las muestras analizadas (95\%), estas se localizaban principalmente en el tejido conectivo intertubular y asociadas a las infiltraciones hemocíticas (figura 7B-F). En las preparaciones se observaron de distintos tamaños y cercanos a hemocitos de tipo hialino (figura 7C, D y E). A las células cafés se les conoce también con el nombre de gránulos de lipofuscina los cuales al presentarse de forma agrupada en un tejido se les 
denomina agregados de lipofuscina (figura 7A, B y F). La lipofuscina es un residuo no digerible limitado por una membrana que persiste tras la degradación lisosómica, por ello a los cuerpos residuales llenos de lipofuscina se le denomina gránulos de lipofuscina. Los agregados de lipofuscina se observaron solo en algunos organismos en el tejido conectivo intertubular o invadiendo los epitelios tubulares (60\%) (figura 7F).

En el tejido conectivo intertubular se pudieron observar infiltraciones de hemocitos principalmente del tipo de los hialino (40\%). Las infiltraciones se caracterizan por la presencia en abundancia de un tejido o fluido dentro de otro que en condiciones fisiológicas normales no debería presentarse. Las infiltraciones de hemocitos se observaron en abundancia en el tejido conectivo intertubular acompañadas de células cafés o agregados de lipofuscina y en menor prevalencia, dentro de los túbulos digestivos donde también se observaron algunos hemocitos (figura $8 \mathrm{C}$ y D). El estudio citomorfológico permitió caracterizar el tipo de hemocito presente en las infiltraciones el cual se ha reportado como hialinocito por la transparencia de su citoplasma y núcleo excéntrico (figura 8E). Dentro de los túbulos digestivos no se encontraron infiltraciones hemocíticas, pero si la presencia de hialinocitos aislados, en el epitelio tubular o en el lumen.

Las atrofias son alteraciones histopatológicas que se caracterizan por una reducción en el número y volumen de las células, en las muestras analizadas, fue posible observar túbulos con extensas áreas donde predominaba el lumen en comparación con el grosor del epitelio tubular (figura 8A-D). Esta respuesta se observó en 10 organismos (25\%) y sólo dentro de los túbulos digestivos, no se evidenció la presencia de atrofias en el tejido conectivo intertubular.

Finalmente, el análisis demostró la presencia de un cuerpo extraño en el tejido conectivo intertubular, que se presume sea un parásito debido a la relación núcleo-citoplasma y la coloración que adquirió en la tinción ( $0.05 \%$ ) (figura $8 \mathrm{~F}$ ). 

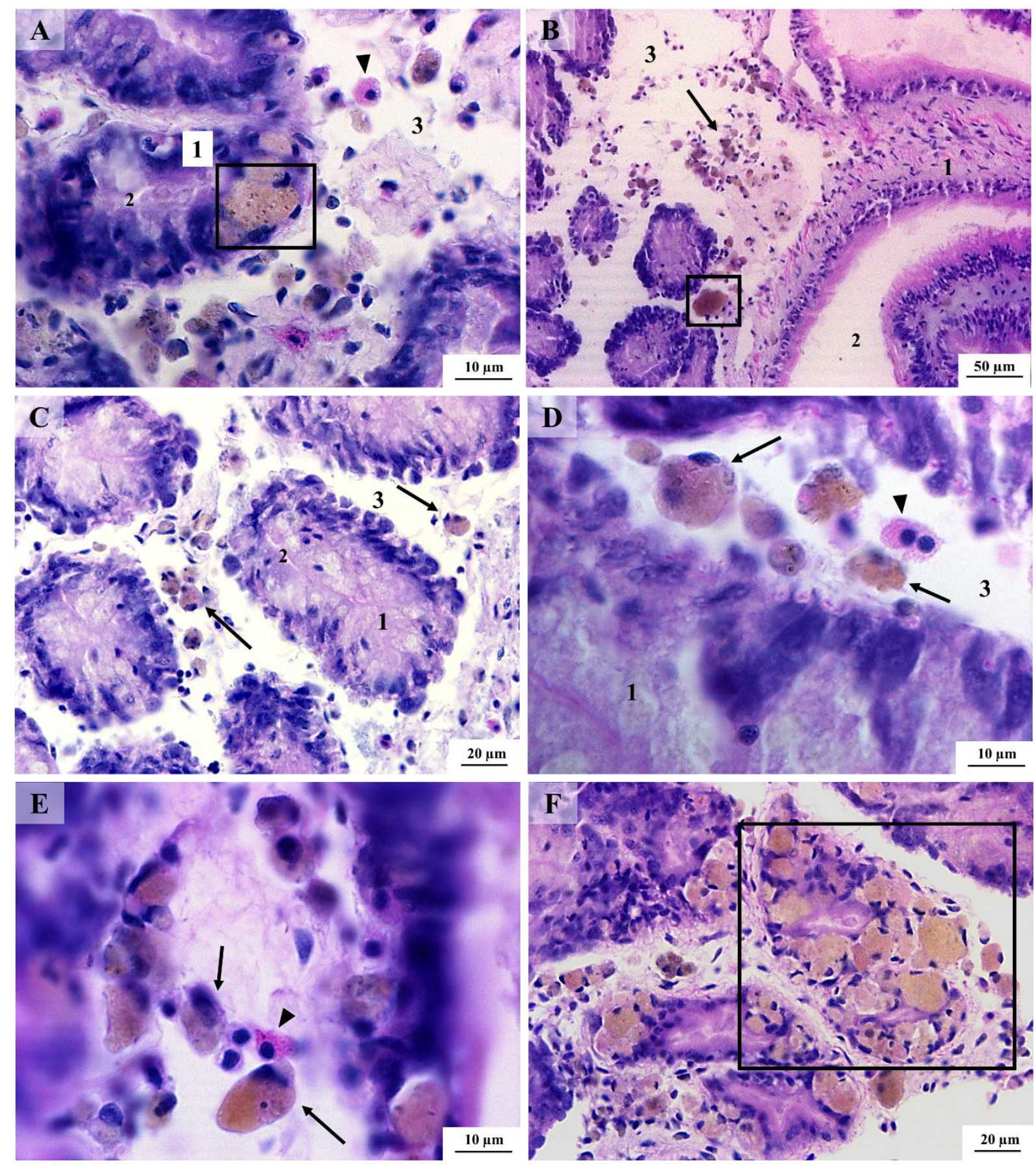

Figura 7. Descripción histopatológica de la glándula digestiva de la almeja $P$. caroliniana (organismos experimentales). A. Presencia de agregados de lipofuscina (cuadros) en los epitelios (1) de los túbulos digestivos, se observa además la presencia de un hemocito (cabeza de flecha) en el lumen (2) y tejido conectivo (3). B. Presencia de células cafés (flechas) en el tejido conectivo intertubular y agregados de lipofuscina cercanos al intestino. C. Células cafés con diferentes tamaños observadas en el tejido conectivo intertubular. D y E. Detalle de células cafés con diferente tamaño cercanas a hemocitos hialinos presentes en el tejido conectivo intertubular.

F. Alteración severa con la presencia de agregados de lipofuscina invadiendo los epitelios del túbulo digestivo. Tinción con H-E. 

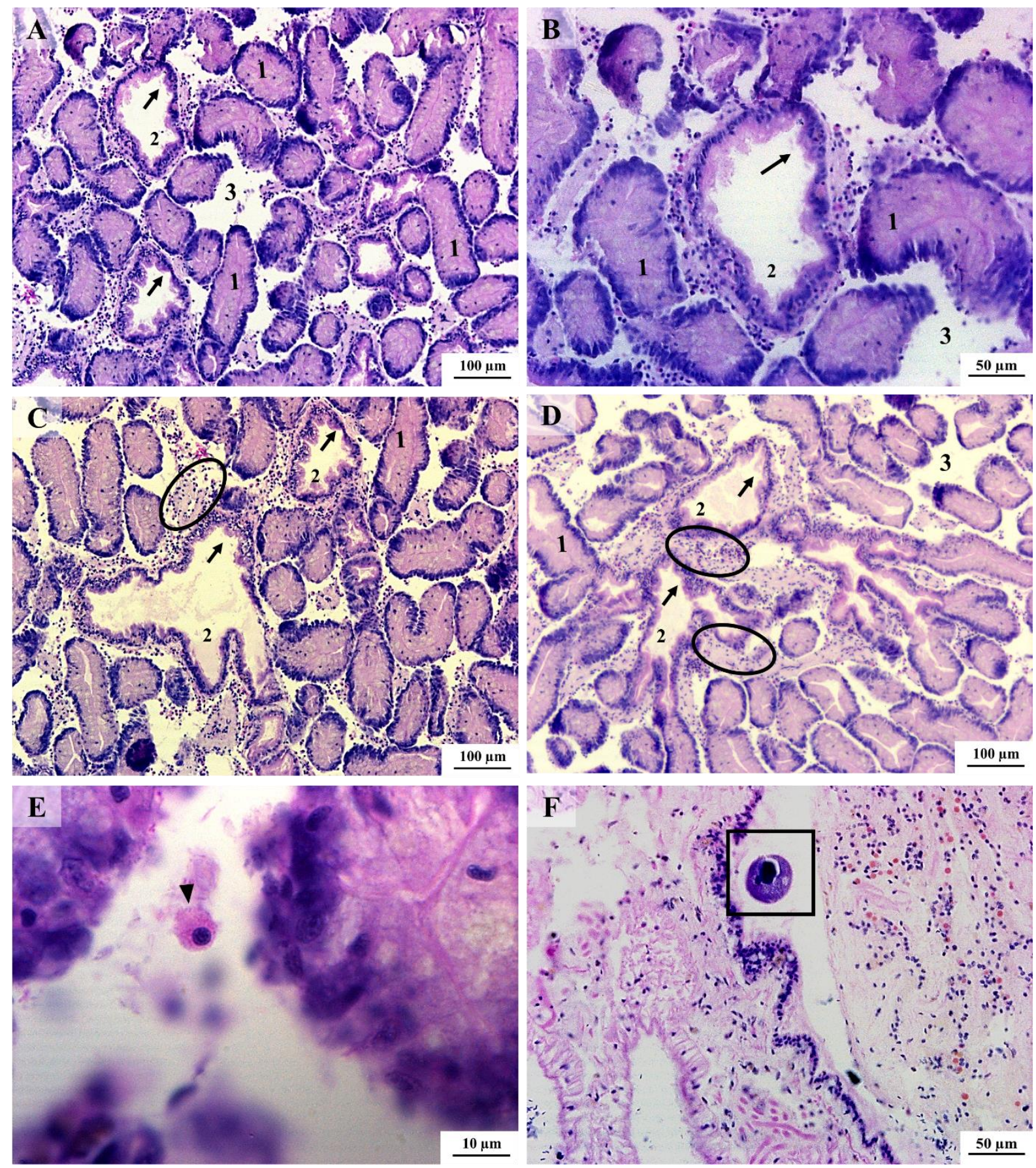

Figura 8. Descripción histopatológica de la glándula digestiva de la almeja $P$. caroliniana (organismos experimentales). A. Presencia de atrofias (flechas) en el lumen (2) de diferentes túbulos digestivos. B. Detalle de la modificación de los epitelios en un túbulo digestivo. C y D. Presencia de infiltraciones hemocíticas (óvalos) en el tejido conectivo intertubular (3), estas alteraciones se observaron con relación cercana a las atrofias de los túbulos digestivos. E y F. Perspectiva en el tamaño de un hemocito hialino en E y la presencia de una cuerpo extraño similar a un parasito (cuadro) en el tejido conectivo intertubular. Tinción con H-E. 


\subsection{1. Índice histopatológico (Ih)}

La tabla 3 muestra las alteraciones histopatológicas observadas en la almeja $P$. caroliniana agrupadas en dos reacciones patrón, así como el valor de importancia patológico asignado a cada una de ellas. Esta tabla representa un ejemplo del análisis que se hace por organismo en la obtención del índice histopatológico Las almejas del grupo experimental presentaron alteraciones mínima a moderada importancia patológica $(w)$ y en la mayoría de estas el grado de diseminación fue mínimo a moderado. El índice histopatológico $\left(\mathrm{I}_{\mathrm{h}}\right)$ obtenido para los organismos del grupo experimental fue en promedio de 0.18 mientras que para los organismos control fue de 0.01 . Estos valores son cercanos al cero, lo cual significa que el estado de salud del órgano analizado no muestra compromiso patológico.

\begin{tabular}{|c|c|c|c|}
\hline Reacción patrón & Alteración & $w$ & $a$ \\
\hline \multirow{5}{*}{ Alteraciones tubulares } & Células cafés & 1 & 2 \\
\hline & Agregados de lipofuscina & 1 & 4 \\
\hline & Infiltraciones hemocíticas & 2 & 0 \\
\hline & Atrofias & 2 & 0 \\
\hline & Parásitos & 3 & 0 \\
\hline \multirow{5}{*}{ Alteraciones intertubulares } & Células cafés & 1 & 6 \\
\hline & Agregados de lipofuscina & 1 & 2 \\
\hline & Infiltraciones hemocíticas & 2 & 6 \\
\hline & Atrofias & 2 & 6 \\
\hline & Parásitos & 3 & 2 \\
\hline \multicolumn{2}{|c|}{ Índice histopatológico $\left(I_{h}\right)$} & \multicolumn{2}{|c|}{0.18} \\
\hline
\end{tabular}




\subsubsection{Análisis inmunohistoquímico}

Se observó inmunorreacción positiva de marcadores específicos en la glándula digestiva y otros órganos blanco como en epitelios de branquias, intestino y estómago, así como en tejido muscular del pie. Se consideró reportar los resultados de estos órganos ya que son considerados como órganos blanco en estos organismos. La inmunorreacción positiva se observó como se detalla a continuación:

Proteína HSP70. El marcador de HSP70, se observó en el citoplasma y algunos núcleos de epitelios en órganos de las lamelas branquiales, gónadas masculinas y femeninas, así como en células granulares del pie. Los túbulos digestivos mostraron reacción positiva a este anticuerpo en el citoplasma de los epitelios tubulares (figura 9C y D). No se observó reacción positiva en folículos germinales de las gónadas ni en músculo del pie.

Metalotioneínas. La presencia inmunohistoquímica de MTs se observó únicamente en el citoplasma de epitelios y células granulares del pie. No se observó reacción de este anticuerpo en gónadas, branquias ni glándula digestiva (figura 9E y F).

Citocromo P450. La inmunorreacción positiva del anticuerpo CYP se observó en el citoplasma de células epiteliales de lamelas branquiales, intestino, estómago, túbulos de la glándula digestiva y pie. Además, se observó reacción positiva en el citoplasma de células granulares en el pie de la almeja (Figura 9A y B). No se observó reacción positiva de este marcador en gónadas.

La técnica fue contrastada con tejidos de almejas del grupo control como testigos negativos en donde no se observó inmunorreacción positiva para los tres marcadores (figura 9G). Además, la contratinción e intensidad de reacción se comparó con tejidos del grupo experimental de almejas tratados como testigos positivos, donde fue evidente la inmunorreacción para los tres 
marcadores. En la figura 9H se muestra solo el testigo positivo para HSP70 sin embargo los otros dos marcadores mostraron el mismo comportamiento.

En la tabla 4 se muestra un resumen de la inmunorreacción que presentaron los tres marcadores de estrés ambiental analizados. Mediante símbolos se señala la reacción inmunohistoquímica cuando fue positiva (+) o negativa (-) en los tejidos analizados. De los tres marcadores empleados los que presentaron mayor positividad entre los tejidos fueron las proteínas HSP70 seguidas del citocromo P450, los cuales fueron evidentes en epitelios de branquias, intestino, estómago y glándula digestiva. Por otro lado, el marcador para metalotioneínas MTs solo mostró reacción inmunohistoquímica en epitelios y células granulares del pie. Dentro de los órganos analizados, el único que presentó reacción positiva para los tres marcadores analizados fue el pie.

Tabla 4. Matriz de inmunorreacción positiva (+) y negativa (-) por órganos, tejidos observados y marcador aplicado.

\begin{tabular}{ccccc}
\hline Órgano & Tejido & HSP70 & MTs & CYP \\
Lamelas branquiales & Epitelio & $(+)$ & $(-)$ & $(+)$ \\
Intestino & Epitelio & $(+)$ & $(-)$ & $(+)$ \\
Estómago & Cilios & $(-)$ & $(-)$ & $(-)$ \\
Túbulos digestivos & Epitelio & $(+)$ & $(-)$ & $(+)$ \\
Gónada masculina & Eolículos germinales & $(-)$ & $(-)$ & $(+)$ \\
& Espermatogonias & $(+)$ & $(-)$ & $(-)$ \\
Gónada femenina & folículos germinales & $(-)$ & $(-)$ & $(-)$ \\
& Ovocitos & $(+)$ & $(-)$ & $(-)$ \\
Pie & Epitelios & $(+)$ & $(-)$ & $(-)$ \\
& Células granulares & $(+)$ & $(+)$ & $(+)$ \\
& Músculo & $(-)$ & $(-)$ & $(+)$ \\
\hline \hline
\end{tabular}



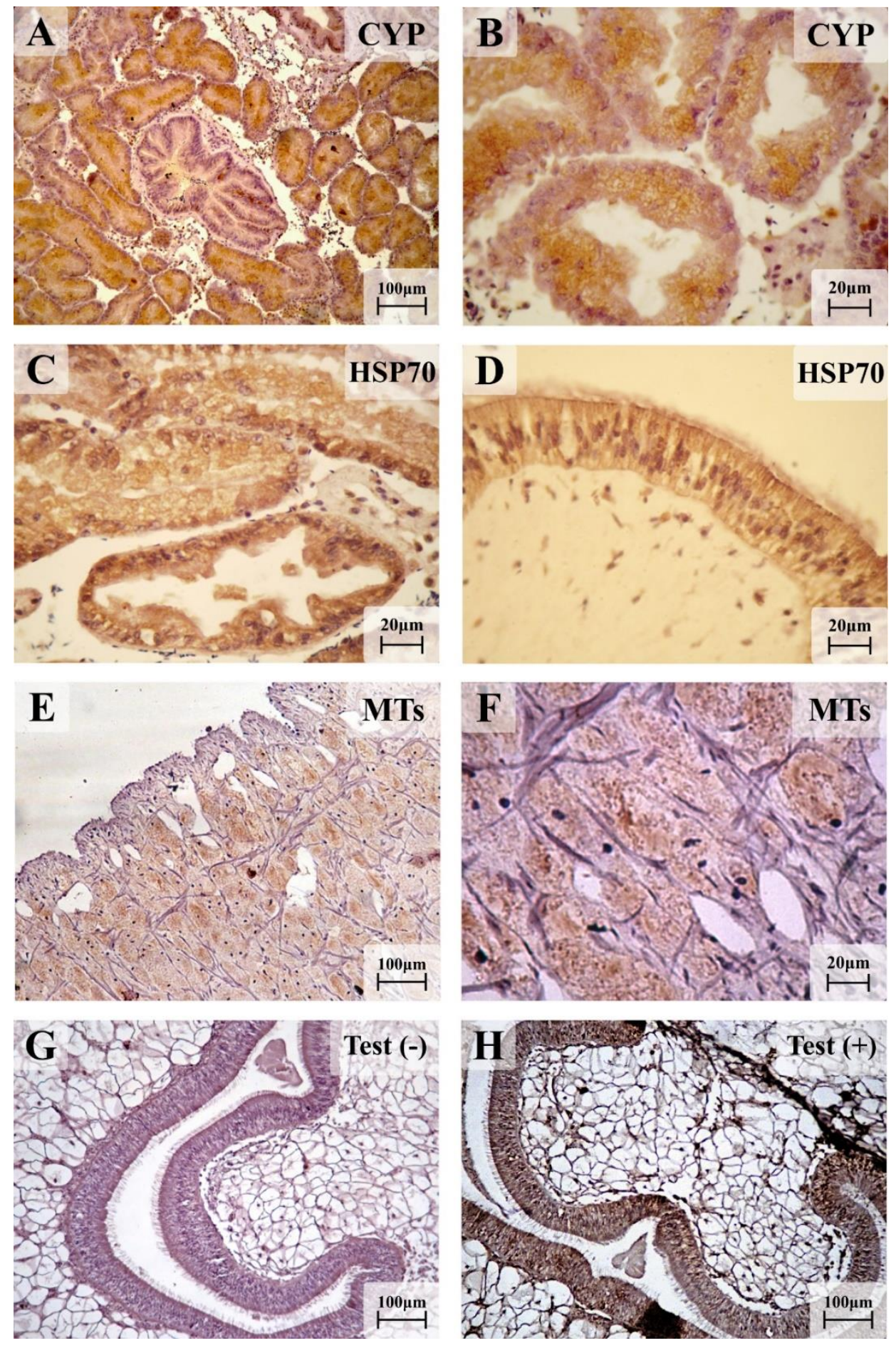

Figura 9. Inmunorreacción positiva de los marcadores CYP, proteínas HSP70 y Metalotioneínas (MTs) en diferentes tejidos de la almeja de Tecolutla. A y B. Túbulos de la glándula digestiva que muestra inmunorreacción positiva para CYP en el citoplasma de las células epiteliales $\mathbf{C}$. Túbulo digestivo que muestra la inmunorreacción en el epitelio en color marrón para el marcador de HSP70. D. Sección del intestino de la almeja con positividad para HSP70 en la región epitelial. E y F. Porción transversal del pie con inmunorreacción para el marcador de MTs. G. Sección del tracto digestivo empleado como control negativo en donde no hay inmunorreacción. H. Control positivo para el anticuerpo HSP70 con tinción marrón en el citoplasma de células epiteliales que indica la inmunorreacción. Todas las secciones fueron contrateñidas con Hematoxilina de Tacha. 


\subsection{3. Índice inmunohistoquímico (Ii)}

El hacer la sumatoria de los marcadores de estrés ambiental observados en cada órgano de la almeja se pudo determinar que, en la glándula digestiva, estómago, intestino y branquias presentaron dos de los tres marcadores analizados. En gónadas solo uno (HSP70) y en el pie se evidenciaron los tes marcadores. Con esto el índice inmunohistoquímico $\left(\mathrm{I}_{\mathrm{i}}\right)$ de las almejas experimentales fue de 2 mientras que para el grupo control fue de 0 (Tabla 5).

\begin{tabular}{ccccc}
\hline \multicolumn{6}{c}{$\begin{array}{c}\text { Tabla 5. Número de marcadores inmunohistoquímicos observados en órganos blanco de las almejas. Al } \\
\text { final se muestra el índice inmunohistoquímico. }\end{array}$} & HSP70 & MTs & CYP & Total \\
\hline Órgano & 1 & 0 & 1 & 2 \\
\hline Glándula digestiva & 1 & 0 & 1 & 1 \\
Estómago & 1 & 0 & 1 & 2 \\
Intestino & 1 & 0 & 0 & 2 \\
Branquias & 1 & 0 & 1 & 3 \\
Gónadas & 1 & 1 & 1 \\
Pie & 1 & &
\end{tabular}

\subsection{Evaluación de la vulnerabilidad: exposición, sensibilidad y capacidad de recuperación}

La evaluación de la vulnerabilidad de las almejas de Tecolutla se realizó mediante el análisis de la exposición sensibilidad y capacidad de recuperación.

Para el elemento de exposición se propusieron las siguientes categorías con base en el número promedio de marcadores observados, así tenemos: exposición nula, baja, media y alta, denominada como índice inmunohistoquímico ( $\mathrm{I}_{\mathrm{i}}$ ) (Tabla 5). Las glándulas digestivas de las almejas de Tecolutla mostraron una exposición moderada, pero muy cercana a la categoría alta 
(Tabla 6). Recomendamos el uso de al menos tres biomarcadores inmunoquímicos diferentes en tres o más órganos diana para evaluar la exposición. Posteriormente, se evaluó la sensibilidad de las almejas mediante una relación entre la clasificación del índice histopatológico $\left(I_{h}\right)$ y el nivel de exposición (Tabla 6). Determinamos que un organismo es sensible si el nivel de exposición es menor que la categoría de $\mathrm{I}_{\mathrm{h}}$. Es decir, un organismo que muestra una baja prevalencia de alteraciones histopatológicas en un ambiente con un nivel de exposición moderado tiene una baja sensibilidad (Tabla 6). En el caso de las almejas de Tecolutla al tener un nivel de exposición moderado, una baja prevalencia de alteraciones les corresponde un valor de sensibilidad de -1 que las coloca en una categoría de baja sensibilidad.

\begin{tabular}{cccccc}
\hline \hline \multicolumn{6}{c}{$\begin{array}{c}\text { Tabla 6. Relación entre la prevalencia de alteraciones histopatológicas y el nivel de exposición. El valor de } \\
\text { sensibilidad fue calculado por la resta del nivel de exposición menos la prevalencia. Se muestra, además, } \\
\text { las categorías de sensibilidad. }\end{array}$} \\
\hline $\begin{array}{c}\text { Nivel de } \\
\text { exposición }\end{array}$ & Valor & $\begin{array}{c}\text { Prevalencia de } \\
\text { alteraciones } \\
\text { histopatológicas }\end{array}$ & Valor & $\begin{array}{c}\text { Valor de } \\
\text { sensibilidad }\end{array}$ & $\begin{array}{c}\text { Categoría de } \\
\text { sensibilidad }\end{array}$ \\
\hline \hline Mínimo & 1 & Baja prevalencia & 1 & 0 & Normal \\
Moderado & 2 & 1 & -1 & Baja \\
Alto & 3 & 1 & -2 & Muy baja \\
\hline \hline $\begin{array}{c}\text { Mínimo } \\
\text { Moderado }\end{array}$ & 2 & Moderada prevalencia & 2 & 1 & Alta \\
Alto & 3 & & 2 & 0 & Normal \\
\hline Mínimo & 1 & & 3 & -1 & Baja \\
Moderado & 2 & Alta prevalencia & 3 & 1 & Muy alta \\
Alto & 3 & & 3 & 0 & Alta \\
\hline \hline
\end{tabular}

Finalmente, para evaluar la capacidad de recuperación, observamos tanto el $\mathrm{I}_{\mathrm{i}}$ como el $\mathrm{I}_{\mathrm{h}}$ del grupo control. Estas almejas depuraron moléculas tóxicas durante 40 días en un ambiente limpio, por lo que constituyeron un buen parámetro para evaluar la capacidad de recuperación. 
Las almejas del grupo de control mostraron un nivel de exposición de cero, según $\mathrm{I}_{\mathrm{i}}$. Además, estas almejas tenían un $I_{h}$ de 0.01 , lo que significa que la prevalencia de lesiones histopatológicas se invirtió casi por completo. En otras palabras, estos organismos tienen una eficiente capacidad de recuperación. Para la integración de los tres componentes de la vulnerabilidad en un modelo matemático, se necesitaba un valor de capacidad de recuperación. Sin embargo, la capacidad de recuperación se sabe regula la vulnerabilidad mediante la modulación de la exposición y la sensibilidad (Adger et al., 2007; Engle, 2011). Será necesario entonces, realizar más estudios con el fin de establecer escalas y categorías sobre la capacidad de recuperación (Tabla 7). En la tabla 7 se muestra la propuesta semicuantitativa para la evaluación de la vulnerabilidad mediante los indicadores descritos. Esta propuesta incluye la evaluación de la exposición mediante el indicador del índice inmunohistoquímico, la sensibilidad mediante la relación entre la exposición y la prevalencia de alteraciones y la capacidad de recuperación con el indicador que compara al grupo experimental y el control. Para cada indicador se propusieron categorías y escalas excepto en la capacidad de recuperación, la cual requiere de otros estudios para establecerlas de forma cuantitativa. De acuerdo con estos indicadores la exposición fue moderada, la sensibilidad fue baja y la capacidad de recuperación se consideró efectiva (Tabla 7). Estos elementos permitieron determinar que la vulnerabilidad de la almeja $P$. caroliniana en el sistema Tecolutla, es baja ya que revertían todos los efectos del estrés ambiental. 
Tabla 7. Propuesta semicuantitativa para la estimación de indicadores de vulnerabilidad

\begin{tabular}{|c|c|c|c|c|}
\hline $\begin{array}{l}\text { Elemento de la } \\
\text { vulnerabilidad }\end{array}$ & Indicador & Categoría & Escala & $\begin{array}{l}\text { Vulnerabilidad } \\
\text { de las almejas }\end{array}$ \\
\hline & & Sin exposición & 0 & \\
\hline \multirow[t]{5}{*}{ Exposición } & Índice de & Mínima & 0.1 a 1 & Exposición \\
\hline & inmunohistoquímico $\left(\mathrm{I}_{\mathrm{i}}\right)$ & Moderada & 1.1 a 2.0 & moderada \\
\hline & & Alta & 2.1 a 3 & \\
\hline & & Muy baja & -2 & \\
\hline & Exposición vs & Baja & -1 & Baja \\
\hline \multirow[t]{3}{*}{ Sensibilidad } & prevalencia de & Normal & 0 & sensibilidad \\
\hline & alteraciones $\left(\mathrm{I}_{\mathrm{i}}\right.$ vs $\left.\mathrm{I}_{\mathrm{h}}\right)$ & Alta & 1 & \\
\hline & & Muy alta & 2 & \\
\hline \multirow{3}{*}{$\begin{array}{l}\text { Capacidad de } \\
\text { recuperación }\end{array}$} & Capacidad de & Baja & ¿? & \\
\hline & recuperación en el grupo & Moderada & ¿? & Capacidad \\
\hline & control & Alta & ¿? & eficiente \\
\hline
\end{tabular}

En resumen, estos resultados indican que los efectos de los contaminantes en estos organismos aún son reversibles. Sin embargo, es importante detener la contaminación en Tecolutla para que los organismos puedan mejorar su salud.

Este trabajo representa un estudio que describe una alerta temprana sobre el estado de vulnerabilidad y salud de las almejas de Tecolutla. La cuantificación completa de índices histopatológicos para el resto de los órganos y la integración con la parte inmunohistoquímica es una perspectiva de este trabajo que contiene información valiosa sobre la vulnerabilidad de estos organismos e indirectamente del sistema. Además, es importante desarrollar un enfoque para clasificar adecuadamente la capacidad de recuperación. Adicionalmente, la perspectiva de este trabajo incluye la aplicación de esta estrategia en otros organismos indicadores para estimar en su totalidad la vulnerabilidad del sistema Tecolutla, Veracruz. 


\section{Discusión}

Este proyecto de investigación evaluó el estado de salud y vulnerabilidad de la almeja Polymesoda caroliniana de Tecolutla, Veracruz, México. A través de biomarcadores tisulares e inmunohistoquímicos se obtuvieron respuestas que fueron analizadas y categorizadas en una propuesta semicuantitativa para estimar la vulnerabilidad del organismo en el sistema.

De acuerdo con los resultados obtenidos, los parámetros fisicoquímicos del agua registrados en el río Tecolutla están dentro de los rangos recomendados para el mantenimiento y depuración de moluscos bivalvos (Lee et al., 2010). Estos parámetros se usaron, además, como medidas de referencia para los organismos control en el periodo de cuarentena, donde no se registró mortalidad. Intervalos similares de salinidad, $\mathrm{pH}$ y temperatura se reportan en trabajos donde se realizan bioensayos subletales con la misma especie de almeja (Vázquez-Castro, 2019).

Las almejas recolectadas en Tecolutla corresponden a la especie Polymesoda caroliniana, el análisis morfométrico y los caracteres morfológicas permitieron determinar su identidad. Esta almeja se caracteriza por presentar valvas robustas y negras y umbos erosionados, se ha reportado su distribución desde las costas de Carolina hasta el Golfo de México (García-Cubas y Reguero, 2007; Wakida-Kusunoki y MacKenzie, 2004). Esta almeja es recolectada por pescadores locales en Tecolutla Veracruz sin que se tengan datos oficiales sobre el volumen de captura anual o que su presencia forme parte de los listados faunísticos del municipio (LópezPortillo et al., 2009). Sin embargo, a nivel nacional, esta almeja se encuentra dentro de la categoría de protección especial por la NOM-059 (NOM-059 SEMARNAT, 2010). Cabe resaltar que para el mantenimiento de estos organismos en las instalaciones del CIDMIRA se cuenta con los permisos necesarios otorgados por la SEMARNAT como se detalla al inicio de 
esta tesis. Para realizar un muestreo con fines de monitoreo ambiental, normalmente se muestrean entre 2 y 5 sitios con 15 organismos cada uno. En este proyecto solo se evaluó un banco de almejas con una n de recolecta de 100 moluscos bivalvos adultos (entre 3 y $5 \mathrm{~cm}$ de longitud), este número es superior a lo que reportan otros estudios con bivalvos como los de Cuevas et al. (2015a) y Costa et al. (2013).

La condición macroscópica de las almejas se considera adecuada ya que no presentaron malos olores o perforaciones en conchas, respecto al porcentaje de organismos que evidenciaron organismos asociados a vermes $(25 \%)$, estos organismos se han reportado como parte de la fauna natural asociada a los bivalvos, ya que emplean las conchas como zona de resguardo, en este caso, las almejas al ser organismos sésiles favorecen el crecimiento de este tipo de organismos. Se ha reportado que, si la cantidad de organismos asociados aumenta, la apertura de valvas se puede ver limitada (Polanco Torres, 2002).

En este trabajo se utilizaron marcadores tisulares para evaluar el estado de salud de la almeja. En este sentido, la histopatología es una ciencia que a través del análisis de tejidos ofrece respuestas valiosas para evaluar los efectos de la exposición a contaminantes, las alteraciones detectadas en los tejidos representan una integración de los efectos bioquímicos y fisiológicos (Toro-Restrepo, 2011). En programas de monitoreo, se recomienda el análisis tisular empleando moluscos bivalvos (Cajaraville et al., 2000).

La descripción del tejido de la glándula digestiva de $P$. caroliniana en este trabajo muestra similitudes con otros autores que han estudiado la composición de este órgano (Cajaraville et al., 1990; Levine et al., 2006; Morse y Zardus, 1997). En este trabajo, la estructura de la glándula digestiva se observó en una sección transversal como una organización de túbulos semicirculares a ovoides con un epitelio simple, las células que conforman los epitelios de los 
túbulos son de tipo piramidal. Descripciones previas de la glándula digestiva, definen dos tipos de células presentes en los epitelios de los túbulos: células basofílicas o piramidales y células columnares o acidófilas. Se sabe que el tipo de célula epitelial está determinado por la presencia de núcleos basales, alto contenido de mitocondrias y la abundancia de retículo endoplásmico rugoso. A las células columnares también se les ha asociado la presencia de cilios, sugiriendo además que este tipo celular es el que da origen a las células piramidales (Cajaraville et al., 1990; Morse y Zardus, 1997; Robledo et al., 1997). En las almejas de Tecolutla, se observaron células de tipo piramidales o basófilas, así como un proceso de secreción de vesículas relacionado con las funciones de almacenamiento metabólico en el tejido conectivo (Morse y Zardus, 1997).

La glándula digestiva se ha recomendado para el análisis de respuestas tisulares derivadas de la contaminación ya que es un es un órgano por el cual pasan todas las sustancias que filtra el organismo, incluso los agentes contaminantes o tóxico. En este sentido, a este órgano se le atribuyen funciones no solo digestivas, sino también de desintoxicación (Levine et al., 2006; Morse y Zardus, 1997; Usheva et al., 2006). En la glándula digestiva de la almeja Polymesoda caroliniana se observaron cinco alteraciones patológicas. La alteraciones con mayor prevalencia registradas en organismos control y experimentales fueron las células cafés y agregados de lipofuscina.

A las células cafés también se les conoce con el nombre de gránulos de lipofuscina, y han sido descritos por diversos autores en moluscos bivalvos (Guzmán-García, 2007; HernándezCalderas, 2013; Vázquez-Castro, et al., 2017; Zaroogian et al., 1993). Estas células están involucradas en procesos de digestión celular y desintoxicación, siendo característico el color marrón derivado de la presencia de lipofuscina (Kühnel, 2005). La lipofuscina o pigmento 
fusco es un pigmento no digerible, conocido con el nombre común de pigmento de desgaste. Este pigmento tiene su origen en productos de desecho celular que se acumulan en los lisosomas (Chuaqui y González, 2020). Cuando las células cafés se agrupan, forman agregados denominados agregados de lipofuscina (Gómez-Mendikute et al., 2005; Zaroogian et al., 1993; Zaroogian y Yevich, 1994). La presencia y la alta frecuencia de esta alteración en organismos de vida silvestre son indicativo de que el organismo está respondiendo ante un factor estresante.

La tercera alteración más observada en las almejas de Tecolutla, fueron las infiltraciones en el tejido conectivo intertubular. Las infiltraciones hacen referencia a la acumulación de una sustancia en un tejido en el que no se encuentra en condiciones fisiológicas. En el caso de las almejas de este estudio se observaron infiltraciones hemocíticas. Los hemocitos han sido considerados como la primera línea de defensa del sistema inmunológico de la almeja, se sabe que la presencia de este tipo de células está asociada con procesos como la digestión, el transporte, la excreción y la defensa del organismo contra los patógenos (Donaghy et al., 2009; Estrada et al., 2013; Jauzein et al., 2013; Salimi et al., 2009). La presencia de los hemocitos en el tejido conectivo intertubular se puede relacionar con mecanismos de defensa ante alguna otra alteración tisular como las atrofias, ya que se evidenció una relación muy cercana entre estas dos respuestas patológicas.

Las atrofias son alteraciones que cuando se presentan, reducen el tamaño de las células y tejidos, algunos autores han considerado a estas alteraciones como una antesala de la necrosis celular. Aunque las atrofias en glándula digestiva también se pueden deber al proceso digestivo normal que presenta un molusco bivalvo, en almejas y ostiones se han considerado como un proceso patológico (Costa et al., 2013; Cuevas et al., 2015a). La alteración tisular con menos prevalencia fue la presencia de parásitos. Los parásitos son una de las causas más 
comunes de enfermedad en los moluscos bivalvos tanto en organismos cultivados como silvestres (Lee et al., 2010). En la muestra de total de organismos analizados solo observamos la presencia de un estructura extraña que por la relación núcleo-citoplasma no era una célula propia del organismo, tampoco se encontraba como parte del tracto digestivo ya que se observó en el tejido conectivo. Esta estructura recuerda a la forma que presentan los parásitos en tejidos de bivalvos (Cuevas et al., 2015a; Lassudrie et al., 2014).

Las alteraciones observadas en la almeja de estudio se categorizaron con un factor de importancia patológica $(w)$ de entre 1 y 3. De acuerdo con Cuevas et al. (2015a) las células cafés y los agregados de lipofuscina tienen un compromiso patológico del tejido "mínimo", es decir, un peso de $w=1$, por otro lado las atrofias y las infiltraciones hemocíticas en los tubos digestivos son alteraciones con un peso "moderado" $(w=2)$ y finalmente el peso de $w=3$, se le asignó solo a la presencia de un parásito. Otros autores como Bernet et al. (1999), explican que una alteración cuando es de mínima importancia patológica significa que es reversible a medida que termina la exposición a los estresores, esta situación es la que se ve implicada en los organismos que estuvieron en cuarentena ya que a pesar de que provenían de la misma recolecta, en ellos no se observaron alteraciones patológicas importantes, lo que se relaciona con lo que sugieren estos autores. Por otro lado, las alteraciones moderadas o de peso $w=2$, se consideran reversibles en su mayoría si y solo si la fuente del estresor es neutralizada. Finalmente, las alteraciones con factor de impacto patológico severo $(w=3)$ son lesiones generalmente irreversible, que llevan a la pérdida total o parcial de la función de un órgano (Bernet et al., 1999).

El índice histopatológico aplicado en este trabajo fue un enfoque originalmente propuesto para la evaluación de la contaminación acuática que utiliza el análisis de alteraciones de tejidos en peces (Bernet et al., 1999). Este protocolo ha sido recuperado y aplicado por otros autores que 
han hecho comparaciones entre áreas acuáticas utilizando peces del género Notothenia y Atherina (Donatti et al., 2012; Gusmão et al., 2012). Otros trabajos que han empleado índices histopatológicos en peces como protocolos de contaminación han evaluado el estado de salud de las especies Solea senegalensis y Platichthys flesus, cada uno con un enfoque de índice diferente (Costa et al., 2009; Lang et al., 2006). Posteriormente se realizó una correlación entre ambos índices y se observó que al aplicar estos índices diferentes entre sí, los resultados tienden a ser similares, sin embargo, se sugiere que el índice propuesto por Costa et al. (2009) muestra mayor sensibilidad en cuanto a la comprensión de los mecanismos histopatológicos ya que involucra el daño tisular (factor de importancia patológica) junto con la difusión de cada uno (grado de diseminación), mientras que el de Lang et al. (2006) solo considera la lesión más grave y su diseminación (Cuevas et al., 2015b).

Para la evaluación del índice histopatológico en $P$. caroliniana, se utilizó la propuesta de Costa et al. (2013) modificada para almejas. En los resultados obtenidos el índice histopatológico resultó ser de 0.01 para organismos en cuarentena (control) y de 0.18 para los organismos experimentales. Los coeficientes obtenidos para esta almeja son similares a los reportados por Costa et al. (2013) quienes además asignan a los índices una categoría de daño, en este sentido el índice obtenido para la almeja de Tecolutla se ubicaría en una categoría de daño "bajo" (0 a 0.25) de acuerdo con estos autores. Por otro lado, Cuevas et al. (2015a) realizaron un estudio con mejillones empleando la misma fórmula y observaron que de las cinco zonas estudiadas, las más impactadas por la contaminación presentaban los índices histopatológicos más altos de entre 0.31 y 0.39 . Otros estudios en almejas expuestas a concentraciones subletales de cadmio obtuvieron con este mismo enfoque un índice histopatológico 0.40, considerado como "moderado" (Vázquez-Castro, 2019). Por lo que se 
puede corroborar que el índice obtenido en almejas silvestres es bajo, respecto a zonas altamente contaminadas.

La aplicación de este tipo de enfoque permite la obtención de información valiosa para la clasificación de zonas de estudio, la relación de los efectos ambientales con la fuente de contaminación, la determinación del estado de salud, tener un registro basificado de los cambios a través del tiempo y facilitar el análisis de datos (Cuevas et al., 2015b, 2015a; Matadamas-Guzman et al., 2019)

Las técnicas inmunohistoquímicas se consideran métodos que proporcionan información valiosa para diagnosticar diferentes patologías (Miyamoto et al., 2018). En los moluscos bivalvos, estas técnicas también se han aplicado para analizar diferentes biomarcadores asociados con el estrés ambiental o con la presencia de agentes contaminantes en áreas específicas. Estos biomarcadores también se han aplicado a órganos diana como el manto, las branquias y las glándulas digestivas (Boscolo Papo et al., 2014b; Solé et al., 2018).

Los anticuerpos aplicados a $P$. caroliniana mostraron inmunorreacción positiva a proteínas HSP70, metalotioneínas (MTs) y citocromo P450 (CYP) en diferentes órganos. En este trabajo el marcador para proteínas HSP70 se observó en las branquias, gónadas, pie y en glándula digestiva de la almeja $P$. caroliniana. Estas proteínas se sobreexpresan cuando las células están sujetas a estímulos, como el estrés por choque calórico, la radiación, ciertas sustancias e infecciones virales; cuando se sobreexpresan, confieren protección a las células afectadas y las hacen resistentes a la apoptosis (Coronato et al., 1999). Otros estudios con enfoques inmunohistoquímicos utilizaron a la almeja Venerupis philippinarum, en ella se observó una reacción positiva a HSP70 en las células cafés del intestino de estos organismos, que habitan en lagunas contaminadas. Los autores asociaron estos cambios a la presencia de un hidrocarburo policíclico aromático (Boscolo Papo et al., 2014b, 2014a). También se ha 
observado la sobreexpresión de proteínas de HSP70 en branquias, un órgano responsable del intercambio de gases y la selección de partículas (Gómez-Mendikute et al., 2005).

Por otro lado, la inmunorreacción positiva de MTs solo se observó en epitelios y células granulares del pie de la almeja, particularmente en el citoplasma de epitelios de células granulares, pero no en otros órganos, cabe resaltar que, en esta especie de almeja, el pie tiene íntima relación con el sedimento ya que lo utilizan para excavar y enterrarse y además este fue único órgano que mostró reacción positiva a los tres marcadores inmunohistoquímicos. Se ha reportado la presencia de metalotioneínas en el pie de la almeja Corbicula fluminea, y se menciona que este órgano además de estar involucrado en los procesos fisiológicos de movimiento y fijación, está involucrado en la detección de estímulos ambientales al estar en contacto constante con el sedimento (Bonnail et al., 2018). Por otro lado, un bioensayo reciente con $P$. caroliniana se demostró que hay un aumento en las alteraciones histopatológicas cuando este organismo está en presencia de sedimentos contaminados con cadmio (Vázquez-Castro, et al., 2017). En contraste, la sobreexpresión de metalotioneínas se ha reportado en otros trabajos que emplean larvas de almejas Meretrix meretrix (Wang et al., 2010). Finalmente, otros estudios encontraron MTs en almejas que habitaban en áreas contaminadas con cobre y zinc (Fang et al., 2010; Santovito et al., 2015), concluyendo, que las metalotioneínas son un excelente biomarcador, vinculado a los procesos de desintoxicación de metales.

Finalmente, el anticuerpo para citocromo P450 se observó principalmente en las glándulas digestivas y en el pie de la almeja $P$. caroliniana. Estas proteínas se han reportado en la membrana del retículo endoplásmico hepático de peces y en el hepatopáncreas de moluscos bivalvos (Zhang et al., 2012). Se ha empleado el uso de CYP como una herramienta para la evaluación ambiental utilizando hidrocarburos policíclicos aromáticos (HAP) y metales 
pesados (Pan et al., 2011; Rodrigues-Silva et al., 2015; Zhang et al., 2012) y se ha observado la sobreexpresión de CYP en hemocitos de la almeja Venerupis philippinarum recolectada en zonas contaminadas por hidrocarburos (Boscolo Papo et al., 2014a). La almeja P. caroliniana de Tecolutla, Veracruz, mostró inmunorreacción positiva en las glándulas digestivas, órganos asociados a la digestión y desintoxicación de contaminantes (Morse y Zardus, 1997; Robledo et al., 1997).

La interpretación de las técnicas inmunohistoquímicas se puede hacer con base en el método de ubicación de la reacción antígeno-anticuerpo, ya sea en el citoplasma o núcleo celular. También se han considerado la intensidad como método para describir la inmunorreacción en un tejido (Jorge-Buys et al., 2007; Martín-Lacave y García-Caballero, 2012; Otero-González, 2010). Sin embargo, en la literatura no es posible encontrar una interpretación semicuantitativa de esta técnica que permita relacionarla con indicadores de vulnerabilidad. Aunque el enfoque inmunohistoquímico carece de cuantificación de contaminantes, promediar la reactividad inmune a diferentes biomarcadores en diferentes órganos proporciona una descripción general del nivel de exposición (Boscolo Papo et al., 2014a, 2014b). En ese sentido y empleando el concepto de un índice matemático, en este trabajo se propuso realizar un cociente que relacionará el número de marcadores observados entre el número de órganos analizados. En este trabajo, se obtuvo un $\mathrm{I}_{\mathrm{i}}$ de 2 para almejas experimentales y de 0 para organismos control, lo cual sugiere la relación que existe entre el marcador inmunohistoquímico y los estresores a los que se asocia, ya que el 0 indica una ausencia de inmunorreacción positiva a cualquiera de los tres marcadores y el 2 refleja la exposición a diversos estresores ambientales. Este índice inmunohistoquímico $\left(\mathrm{I}_{\mathrm{i}}\right)$ al igual que el índice histopatológico $\left(\mathrm{I}_{\mathrm{h}}\right)$ se relacionaron en la propuesta semicuantitativa para estimar la vulnerabilidad, como se detalla a continuación. 
La vulnerabilidad es el grado en que un sistema es susceptible a los efectos adversos provocados por el estrés ambiental (Carantoña y Hernández, 2017; Dagnino et al., 2008; Gauthier et al., 2014; Ocaña y Pech, 2018; Villa y McLeod, 2002). A lo largo de los años se han propuesto índices de vulnerabilidad ambiental con diferentes enfoques. Dichos enfoques emplean uso de indicadores e índices para estimar la vulnerabilidad desde distintos enfoques, por ejemplo, antropogénicos, biológicos, geológicos y meteorológicos (Gauthier et al., 2014; Harik et al., 2017; Karmaoui et al., 2015; Sahoo et al., 2016; Skondras et al., 2011; Villa y McLeod, 2002). Sin embargo, en estos estudios, no se considera el componente fisiológico de los organismos que habitan el sistema analizado. Algunos de estos enfoques incluyen la evaluación de la calidad del agua y la distribución de las plantas, mientras que otros estudian los rasgos fisiológicos de las plantas (Esperón-Rodríguez y Barradas, 2015; Trevisan et al., 2020). El análisis de las respuestas biológicas en los organismos se ha considerado como una herramienta para estudiar los estado de salud en el entorno en el que se desarrollan. La vulnerabilidad depende del estudio de los elementos que la componen: el nivel de exposición, la sensibilidad ante alguna presión específica y la capacidad de recuperación (capacidad de adaptarse o recuperarse) ante una presión (Carantoña y Hernández, 2017; Ocaña y Pech, 2018; Villa y McLeod, 2002). Estos componentes pueden evaluarse en diferentes niveles. En este trabajo se evaluó los tres componentes de la vulnerabilidad a través de la evaluación del estado de salud de las almejas (Tabla 7). El enfoque propuesto incluye el uso de diferentes técnicas tisulares (histopatología, índice histopatológico e inmunohistoquímica) y la integración con los componentes de la vulnerabilidad: exposición, sensibilidad y capacidad de recuperación.

Diversas actividades humanas generan productos o subproductos que provocan algún tipo de presión en los organismos. La vulnerabilidad no se puede evaluar sin exponerse a una presión. 
Por lo tanto, es necesario que el primer paso, sea la determinación de las fuentes de presión (Ocaña y Pech, 2018). La exposición ambiental está relacionada con la presencia o ausencia de biomarcadores inmunohistoquímicos (Boscolo Papo et al., 2014b; Moraga et al., 2005; Santovito et al., 2015; Wang et al., 2010). Estas respuestas reflejan el estrés ambiental que afecta a los organismos. El enfoque inmunohistoquímico determina la posible exposición a diferentes estresores ambientales. Las técnicas inmunohistoquímicas se consideran métodos que proporcionan información valiosa para diagnosticar diferentes patologías de forma rápida y sin incluir pruebas analíticas para químicos específicos (Miyamoto et al., 2018). En los moluscos bivalvos, estas técnicas también se han aplicado para analizar diferentes biomarcadores asociados con el estrés ambiental o con la presencia de agentes contaminantes en áreas específicas (Boscolo Papo et al., 2014b; Solé et al., 2018). Entre los marcadores inmunohistoquímicos empleados en este trabajo están las metalotioneínas (MTs), las proteínas HSP70 y el citocromo P450, los cuales se sobre expresan en tejidos cuando hay presencia de metales, choque térmico e hidrocarburos, respectivamente (Boscolo Papo et al., 2014b; Solé et al., 2018). Para demostrar la exposición a estresores ambientales se pueden utilizan diferentes órganos diana, como la glándula digestiva, branquias, pie y gónadas, con el fin de obtener una visión general de la exposición general de las almejas. En este trabajo, se evaluó la sobreexpresión de estos tres marcadores inmunohistoquímicos, se recopilaron las respuestas y se promediaron para crear una gama de diferentes niveles de exposición. Los órganos diana difieren en su reactividad a los biomarcadores, porque tienen diferentes funciones fisiológicas. La función fisiológica de cada órgano y su posición anatómica determinan su interacción con el medio. Por ejemplo, el pie y las branquias están en contacto directo con el sedimento y el agua, lo que los hace estar más expuestos, mientras que las gónadas están menos expuestas porque no interactúan directamente con el medio ambiente (Bonnail et al., 2018). Si bien la 
propuesta que se presenta en este trabajo pondera por igual los biomarcadores expuestos en diferentes órganos, es necesario determinar si los órganos deben ponderarse de manera diferente. Pese a ello, en este proyecto de investigación se emplea un enfoque inmunohistoquímico que incluye dos tipos de información. Por un lado, se evalúa el impacto de la posible presencia de diversos contaminantes o fuentes de estrés ambiental a los que está expuesto el organismos y por otro, se analizan diferentes órganos que pueden estar potencialmente expuestos, los cuales tienen diferentes vías metabólicas para hacer frente a los estresores (Gómez-Mendikute et al., 2005; Morse y Zardus, 1997; Robledo et al., 1997)

La sensibilidad es el grado en que un sistema o una especie se ve afectado por el estrés ambiental (Dagnino et al., 2008). Es necesaria una descripción de lo que hace que un sistema sea sensible, teniendo en cuenta que cada nivel de sensibilidad es específico para cada presión (Ocaña y Pech, 2018). Todos los organismos vivos son sensibles a su entorno para sobrevivir; sin embargo, el nivel de respuestas debe estar relacionado con un nivel de exposición para determinar si el sistema es sensible. Por tanto, para evaluar la sensibilidad del organismo, relacionamos dos aspectos. Primero, caracterizamos el tipo de alteración tisular y su prevalencia en los organismos analizados (Guzmán-García, 2007; Hernández-Calderas, 2013; Vázquez-Castro, et al., 2017; Zaroogian et al., 1993). Esta prevalencia se ha evaluado a través de los valores del índice histopatológico $\left(\mathrm{I}_{\mathrm{h}}\right)$, para la comparación entre varios organismos (Costa et al., 2013; Cuevas et al., 2015a). Cabe resaltar que esta prevalencia de alteraciones ofrece una visión del estado de salud de un organismo en un entorno especifico. En segundo lugar, se relaciona la prevalencia de alteraciones con el nivel de exposición para determinar la sensibilidad de la almeja a los contaminantes que podrían estar presentes en Tecolutla. La histopatología se utiliza ampliamente para reconocer los efectos del estrés ambiental en los organismos (Bernet et al., 1999; Boscolo Papo et al., 2014b, 2014a; Costa et al., 2013; Cuevas 
et al., 2015a, 2015b; S1kdokur et al., 2020; Usheva et al., 2006). Se ha utilizado en varios organismos para determinar el estado de salud de los cuerpos acuáticos (Boscolo Papo et al., 2014a; Chalghmi et al., 2020; Costa et al., 2013; Usheva et al., 2006). En moluscos bivalvos, particularmente se ha propuesto el análisis tisular de la glándula digestiva ya que es un órgano por el cual pasan todas las sustancias que filtra el organismo, incluso los agentes contaminantes o tóxico. En este sentido, a este órgano se le atribuyen funciones no solo digestivas, sino también de desintoxicación (Levine et al., 2006; Morse y Zardus, 1997; Usheva et al., 2006). Por tanto, en la presente propuesta, la sensibilidad es la medida de las respuestas (prevalencia de alteraciones histopatológicas) relacionadas con el nivel de exposición. Si el nivel de exposición es igual a la prevalencia de alteraciones histopatológicas, entonces la sensibilidad es normal. En caso de que el nivel de exposición sea más bajo que la prevalencia, entonces la sensibilidad es baja. Por el contrario, si el nivel de exposición es más alto que la prevalencia, la sensibilidad es alta. Hasta donde sabemos, este es el primer enfoque que proporciona un método semicuantitativo para evaluar la sensibilidad mediante la evaluación de las respuestas fisiológicas a los contaminantes.

El tercer componente de la vulnerabilidad es la capacidad de adaptación. La capacidad de adaptación se refiere a la capacidad de una especie o sistema para hacer frente al impacto ambiental con una alteración mínima (Dagnino et al., 2008). Sin embargo, la adaptación se refiere a la evolución de un sistema en ecología, y generalmente se evalúa a través de diferentes enfoques evolutivos, como la plasticidad, capacidad de dispersión y potencial evolutivo (Ocaña y Pech, 2018). Tecolutla carece de programas de monitoreo que evalúen el estado de salud a través del tiempo, por lo que se requiere otra estrategia para evaluar este componente de vulnerabilidad. Se determinó que en su lugar se podría utilizar el atributo de 
capacidad de recuperación. La capacidad de recuperación generalmente se evalúa mediante factores extrínsecos y rasgos intrínsecos (Ocaña y Pech, 2018). En este trabajo, se evaluó mediante el análisis de un grupo de control de almejas que vivió en un ambiente limpio durante 40 días. De acuerdo con los parámetros fisicoquímicos del agua y mantenimiento empleados en este trabajo para la cuarentena de las almejas, estos parámetros son los recomendados para el mantenimiento y depuración de moluscos bivalvos (Lee et al., 2010). Luego, las almejas en cuarentena fueron sometidas al análisis histopatológico e inmunohistoquímico para observar diferencias con el grupo experimental. Se observó una recuperación completa del grupo de control. El grupo de control no mostró inmunorreacción positiva a ningún biomarcador de exposición (análisis inmunoquímico). Además, tuvo un índice histopatológico menor $\left(\mathrm{I}_{\mathrm{h}}=0.01\right)$ en comparación con el grupo experimental $\left(\mathrm{I}_{\mathrm{h}}=\right.$ 0.18). Pese a esto, se carece de un análisis más completo que permita la obtención de categorías que permita evaluar la capacidad de recuperación ante diferentes niveles de exposición. No obstante, se concluyó que, teniendo el nivel actual de exposición, las almejas de Tecolutla tienen la capacidad de recuperación suficiente para revertir las consecuencias del estrés ambiental. Se emplearon diferentes indicadores para medir los tres componentes de la vulnerabilidad. Sin embargo, para integrarlos en un modelo matemático, es necesaria la estandarización, la escala de respuesta, la ponderación y la agregación. Aunque se tenían valores semicuantitativos para los niveles de exposición y sensibilidad, se carecía de valores para el componente de capacidad de recuperación. No obstante, sabiendo que las almejas pudieron recuperarse con un nivel de exposición moderado y una sensibilidad baja, se pudo estimar la vulnerabilidad. En este trabajo, la capacidad de recuperación se consideró como una medida de la capacidad adaptativa, ya que se ha reportado que este elemento regula la vulnerabilidad mediante la modulación de la exposición y la sensibilidad (Adger et al., 2007; 
Engle, 2011). Existen estudios donde se emplea el mismo enfoque para la capacidad de recuperación comparando los resultados obtenidos de los niveles de exposición y sensibilidad entre los grupos control y experimental (Adger et al., 2007; Engle, 2011). Como se observó que las almejas revirtieron casi todos los efectos del estrés ambiental, se determinó que la capacidad de recuperación excedía la exposición y la sensibilidad. Por tanto, estos resultados indicaron que las almejas de Tecolutla presentaban una vulnerabilidad baja. Una mayor capacidad de recuperación o adaptación ayuda a reducir los efectos de la exposición y la sensibilidad y, en consecuencia, reduce la vulnerabilidad del sistema (Dagnino et al., 2008; Thomas et al., 2018). El rol básico de la recuperación o capacidad adaptativa se acepta como un atributo positivo para reducir la vulnerabilidad (Engle, 2011; Thomas et al., 2018). Como se mencionó anteriormente, aún es necesario desarrollar un ensayo para identificar los límites de la capacidad de recuperación de las almejas a diferentes niveles de exposición.

Este trabajo buscó en términos generales establecer una alternativa metodológica para la evaluación de la vulnerabilidad y la salud de los recursos acuáticos. Se logró establecer respuestas que permitieron relacionarlas con indicadores de vulnerabilidad y salud sugiriendo el estado que guardan las almejas de Tecolutla, Veracruz y proponiendo así una nueva perspectiva en la evaluación integral de los recursos naturales frente a los estresores ambientales. 


\section{Conclusiones}

- Los indicadores macroscópicos no revelan lesiones aparentes en las almejas experimentales y del grupo control.

- Tisularmente, la prevalencia de alteraciones histopatológicas, la importancia patológica y diseminación de las alteraciones indican que el estado fisiológico actual no compromete la salud o el estatus fisiológico de la almeja P. caroliniana.

- La importancia patológica y diseminación de las alteraciones tisulares observadas en la glándula digestiva de la almeja $P$. caroliniana no comprometen la funcionalidad del órgano.

- De conformidad con el índice histopatológico $\left(\mathrm{I}_{\mathrm{h}}\right)$ obtenido, el estado de salud de las almejas de Tecolutla, Veracruz no se encuentra comprometido lo que confirma lo observado en la prevalencia de alteraciones.

- La sobreexpresión inmunohistoquímica de proteínas HSP70, metalotioneínas y citocromo P450 en la glándula digestiva reveló la exposición a diversos estresores ambientales. De acuerdo con estos marcadores se asume la presencia de diferentes estresores ambientales presentes en el sistema Tecolutla, tales como metales e hidrocarburos.

- De acuerdo con las categorías establecidas para este trabajo, las almejas de Tecolutla mostraron un nivel de exposición moderado, baja sensibilidad y una efectiva capacidad de recuperación.

- La evaluación de los elementos de la vulnerabilidad (exposición, sensibilidad y capacidad de recuperación) permitió determinar que las almejas presentan una vulnerabilidad baja en el sistema Tecolutla, Veracruz. 
- Se logró el establecimiento de una propuesta semicuantitativa para estimar la vulnerabilidad de la almeja a través de la definición de tres indicadores relacionados con las respuestas histopatológicas e inmunohistoquímicas.

- El análisis de la vulnerabilidad de organismos acuáticos a través de respuestas histopatológicas e inmunohistoquímicas representa una herramienta potencial en la evaluación del estado de organismos de vida silvestre frente a estresores ambientales y la primera contribución de este tipo en México. 


\section{Perspectivas y recomendaciones}

1. Se recomienda realizar otros estudios para establecer categorías que estimen la capacidad de recuperación de esta almeja en el sistema Tecolutla, con lo que se completaría la propuesta semicuantitativa para la evaluación de la vulnerabilidad.

2. Se pueden incorporar nuevos indicadores y análisis estadísticos en esta propuesta para la evaluación de la vulnerabilidad.

3. Con esta base de información, se propone estimar la vulnerabilidad en diversos organismos acuáticos del sistema con el fin de conocer el grado de vulnerabilidad del sistema Tecolutla.

4. Se recomienda el análisis del índice histopatológico e inmunohistoquímico en estudios de monitoreo ambiental con moluscos bivalvos para facilitar la toma de decisiones.

5. El análisis del índice histopatológico puede ser empleado para la comparación entre diferentes zonas del estado de Veracruz para conocer la afectación por estresores ambientales en moluscos bivalvos. Con lo que se genere información necesaria para el establecimiento de políticas de mitigación y control. 


\section{Referencias bibliográficas}

Adger, W.N., Agrawala, S., Mirza, M.N.Q., Conde, C., O’Brien, K., Pulhin, J., Pulwarty, R., Smit, B., Takahashi, K., 2007. Assessment of adaptation practices, options, constraints and capacity, in: Palutikof, J.P., Hanson, C.E., van der Linden, P.J. (Eds.), Climate Change 2007: Impacts, Adaptation and Vulnerability. Contribution of Working Group II to the Fourth Assessment Report of the Intergovernmental Panel on Climate Change. Cambridge University Press, pp. 717-743.

Araujo González, R., 2015. Vulnerabilidad y riesgo en salud: ¿dos conceptos concomitantes? Rev. Noved. En Poblac. 11, 89-96.

Araya-Ulloa, A., Calvo-Brenes, G., 2017. Diagnóstico sobre la vulnerabilidad ecológica y calidad del agua en la quebrada La Central, Pacayas de Alvarado, Costa Rica. Rev. Tecnol. En Marcha 30, 47-58.

Arriaga-Gaona, M.L., Hernández-Limón, L., Sandoval-Reyes, F., Vera-Lara, J., VargasMoreno, E., García-Rojas, L., 2013. Monitoreo de la calidad del agua del río Tecolutla desde Coyutla hasta Gutierrez Zamora, Veracruz. Artículo Científico. Facultad de Ciencias Químicas de la Universidad.

Baum, A., Singer, J., Baum, C., 1984. Stress and the environment, in: Evans, G.W. (Ed.), Environmental Stress. CUP Archive, New York, pp. 89-127.

Bayne, B.L., Widdows, J., Thompson, T.J., 1976. Physiological integrations, in: Bayne, B.L. (Ed.), Marine Mussels: Their Ecology and Physiology. Cambridge University Press, Cambridge, pp. 261-291.

Bernet, D., Schmidt, H., Meier, W., Burkhardt-Holm, P., Wahli, T., 1999. Histopathology in fish: proposal for a protocol to assess aquatic pollution. J. Fish Dis. 22, 25-34. https://doi.org/10.1046/j.1365-2761.1999.00134.x

Bonnail, E., Cunha Lima, R., Bautista-Chamizo, E., Salamanca, M.J., Cruz-Hernández, P., 2018. Biomarker responses of the freshwater clam Corbicula fluminea in acid mine drainage polluted systems. Environ. Pollut. 242, 1659-1668. https://doi.org/10.1016/j.envpol.2018.07.111

Boscolo Papo, M., Bertotto, D., Pascoli, F., Locatello, L., Vascellari, M., Poltronieri, C., Quaglio, F., Radaelli, G., 2014a. Induction of brown cells in Venerupis philippinarum exposed to benzo(a)pyrene. Fish Shellfish Immunol. 40, 233-238. https://doi.org/10.1016/j.fsi.2014.07.006

Boscolo Papo, M., Bertotto, D., Quaglio, F., Vascellari, M., Pascoli, F., Negrato, E., Binato, G., Radaelli, G., 2014b. Histopathology and stress biomarkers in the clam Venerupis philippinarum from the Venice Lagoon (Italy). Fish Shellfish Immunol. 39, 42-50. https://doi.org/10.1016/j.fsi.2014.04.016

Botello, A.V., 2010. Introducción, in: Botello, Alfonso Vázquez, Villanueva-Fragoso, S., Gutiérrez, J., Galaviz, J.L.R. (Eds.), Vulnerabilidad de las zonas costeras mexicanas ante el cambio climático. SEMARNAT-INE. UNAM-ICMyL. Universidad Autónoma de Campeche, México, pp. 1-14.

Cadena Monroy, L.A., 2009. Biología y vulnerabilidad humana. Rev. Colomb. Bioét. 4, 131145.

Cajaraville, M.P., Bebianno, M.J., Blasco, J., Porte, C., Sarasquete, C., Viarengo, A., 2000. The use of biomarkers to assess the impact of pollution in coastal environments of the Iberian Peninsula: a practical approach. 247 2000, 295-311. 
Cajaraville, M.P., Guzmán, D., Marigómez, I.A., Angulo, E., 1990. Responses of basophilic cells of the digestive gland of mussels to petroleum hydrocarbon exposure. Dis. aquat. Org. 9, 221-228.

Camarena-Novelo, I.S., 2012. Evaluación del biomarcador histológico en Crassostrea virginica (Gmelin, 1791) de Tampamachoco, Veracruz, México (Tesis de Maestría en Biología Experimental). Universidad Autónoma Metropolitana Unidad Iztapalapa, Ciudad de México.

Carantoña, T., Hernández, D., 2017. Indicador de vulnerabilidad de especie ante el cambio climático en áreas naturales de Venezuela. Terra Nueva Etapa XXXIII, 75-103.

Carneiro, M., Reis, B., Azevedo, J., Campos, A., Osório, H., Vasconcelos, V., Martins, J., 2015. Glutathione Transferases Responses Induced by Microcystin-LR in the Gills and Hepatopancreas of the Clam Venerupis philippinarum. Toxins 7, 2096-2120. https://doi.org/10.3390/toxins7062096

Chalghmi, H., Bourdineaud, J.P., Chbani, I., Haouas, Z., Bouzid, S., Er-Raioui, H., SaidaneMosbahi, D., 2020. Occurrence, sources and effects of polycyclic aromatic hydrocarbons in the Tunis lagoon, Tunisia: an integrated approach using multi-level biological responses in Ruditapes decussatus. Environ. Sci. Pollut. Res. 27, 36613674. https://doi.org/10.1007/s11356-019-04220-3

Chuaqui, B.J., González, S.B. (Eds.), 2020. Capítulo 2. Patológia celular, in: Manual de Patología General. Publicaciones Universidad Cartólica de Chile, Chile.

Colombres, B., Miguel, E., Lozano, Z.P, 1999. Metalotioneínas, bioquímica y funciones propuestas. BEB Bol. Educ. Bioquímica 18, 21-22.

CONAGUA, 2016. Estadísticas del Agua en México. Edición 2016, Sistema Nacional de Información sobre Cantidad, Calidad, Usos y Conservación del Agua (SINA). Comisión Nacional del Agua. Secretaría de Medio Ambiente y Recursos Naturales, México.

Coronato, S., Girolamo, Di.W., Salas, M., Spinelli, O., Languens, Z., 1999. Biología de las proteínas de shock térmico. Med. B. Aires 59, 477-486.

Costa, P.M., Carreira, S., Costa, M.H., Caeiro, S., 2013. Development of histopathological indices in a commercial marine bivalve (Ruditapes decussatus) to determine environmental quality. Aquat. Toxicol. Amst. Neth. 126, 442-454. https://doi.org/10.1016/j.aquatox.2012.08.013

Costa, P.M., Diniz, M.S., Caeiro, S., Lobo, J., Martins, M., Ferreira, A.M., Caetano, M., Vale, C., DelValls, T.A., Costa, M.H., 2009. Histological biomarkers in liver and gills of juvenile Solea senegalensis exposed to contaminated estuarine sediments: a weighted indices approach. Aquat. Toxicol. Amst. Neth. 92, 202-212. https://doi.org/10.1016/j.aquatox.2008.12.009

Cuevas, N., Zorita, I., Costa, P.M., Franco, J., Larreta, J., 2015a. Development of histopathological indices in the digestive gland and gonad of mussels: integration with contamination levels and effects of confounding factors. Aquat. Toxicol. Amst. Neth. 162, 152-164. https://doi.org/10.1016/j.aquatox.2015.03.011

Cuevas, N., Zorita, I., Costa, P.M., Quincoces, I., Larreta, J., Franco, J., 2015 b. Histopathological indices in sole (Solea solea) and hake (Merluccius merluccius) for implementation of the European Marine Strategy Framework Directive along the Basque continental shelf (SE Bay of Biscay). Mar. Pollut. Bull. 94, 185-198. https://doi.org/10.1016/j.marpolbul.2015.02.030 
Dagnino, A., Sforzini, S., Dondero, F., Fenoglio, S., Bona, E., Jensen, J., Viarengo, A., 2008. A "Weight-of-Evidence" Approach for the Integration of Environmental "Triad" Data to Assess Ecological Risk and Biological Vulnerability. Integr. Environ. Assess. Manag. 4, 314. https://doi.org/10.1897/IEAM_2007-067.1

Delgado-Alvarez, C., Ruelas-Inzunza, J., Escobar-Sánchez, O., Covantes-Rosales, R., PinedaPérez, I.B., Osuna-Martínez, C.C., Aguilar-Júarez, M., Osuna-López, J.I., Voltolina, D., Frías-Espericueta, M.G., 2019. Metal Concentrations in Age-Groups of the Clam, Megapitaria squalida, from a Coastal Lagoon in Mexico: A Human Health Risk Assessment. Bull. Environ. Contam. Toxicol. 103, 822-827. https://doi.org/10.1007/s00128-019-02723-w

Donaghy, L., Lambert, C., Choi, K.-S., Soudant, P., 2009. Hemocytes of the carpet shell clam (Ruditapes decussatus) and the Manila clam (Ruditapes philippinarum): Current knowledge and future prospects. Aquaculture 297, 10-24. https://doi.org/10.1016/j.aquaculture.2009.09.003

Donatti, L., Rios, S., Machato, C., Pedreiro, D., Krebsbach, J., Piechnik, C.A., Zaleski, T., Forgati, M., Badelik, C., Vaz da Silva, Subchnuk, N., Dos Santos Carvalho, C., Rodrigues, E., Rodrigues Junior, E., Feijó de Oliveira, M., 2012. Histopathological Alterations on Antarctic Fish Notothenia coriiceps and Notothenia rossii as Biomarkers of aquatic contamination [WWW Document]. URL http://www.academia.edu/28882285/Histopathological_Alterations_on_Antarctic_Fish _Notothenia_Coriiceps_and_Notothenia_Rossii_as_Biomarkers_of_Aquatic_Contami nation (accessed 5.7.17).

Engle, N., 2011. Adaptive Capacity and Its Assessment. Glob. Environ. Change 21, 647-656. https://doi.org/10.1016/j.gloenvcha.2011.01.019

Esperón-Rodríguez, M., Barradas, V.L., 2015. Comparing environmental vulnerability in the montane cloud forest of eastern Mexico: A vulnerability index. Ecol. Indic. 52, 300310. https://doi.org/10.1016/j.ecolind.2014.12.019

Espina, S., Vanegas, C., 2005. Ecofisiología y Contaminación, in: Vázquez-Botello, A., Rendón von Ostén, J., Gold-Bouchot, G., Agraz-Hernández, C. (Eds.), Golfo de México: contaminación e impacto ambiental : diagnóstico y tendencias. Univ. Autón. de Campeche, Univ. Nal. Autón de México, Instituto Nacional de Ecología, México, pp. 53-78.

Estrada, N., Velázquez, E., Rodríguez-Jaramillo, C., Ascencio, F., 2013. Morphofunctional study of hemocytes from lions-paw scallop Nodipecten subnodosus. Immunobiology 218, 1093-1103. https://doi.org/10.1016/j.imbio.2013.03.004

Fang, Y., Yang, H., Wang, T., Liu, B., Zhao, H., Chen, M., 2010. Metallothionein and superoxide dismutase responses to sublethal cadmium exposure in the clam Mactra veneriformis. Comp. Biochem. Physiol. Toxicol. Pharmacol. CBP 151, 325-333. https://doi.org/10.1016/j.cbpc.2009.12.005

Figueira, E., Branco, D., Antunes, S.C., Gonçalves, F., Freitas, R., 2012. Are metallothioneins equally good biomarkers of metal and oxidative stress? Ecotoxicol. Environ. Saf. 84, 185-190. https://doi.org/10.1016/j.ecoenv.2012.07.012

Flores-López Lena, T., 2014. Análisis histopatológico en el ostión Crassostrea virginica expuesto a hidrocarburos aromáticos policíclicos (HAP'S) (Tesis de Licenciatura en Biología). Universidad Nacional Autónoma de México, México.

García-Cubas, A., Reguero, M., 2007. Catalogo ilustrado de moluscos del Golfo de México y Mar Caribe. UNAM. 
Gauthier, S., Bernier, P., Burton, P.J., Edwards, J., Isaac, K., Isabel, N., Jayen, K., Le Goff, H., Nelson, E., 2014. Climate change vulnerability and adaptation in the managed Canadian boreal forest. Environ. Rev. 22, 256-285. https://doi.org/10.1139/er-20130064

Gómez-Mendikute, A., Elizondo, M., Venier, P., Cajaraville, M.P., 2005. Characterization of mussel gill cells in vivo and in vitro. Cell Tissue Res. 321, 131-140. https://doi.org/10.1007/s00441-005-1093-9

Gusmão, E.P., Rodrigues, R.V., Moreira, C.B., Romano, L.A., Sampaio, L.A., Miranda-Filho, K.C., 2012. Growth and Histopathological Effects of Chronic Exposition of Marine Pejerrey Odontesthes argentinensis Larvae to Petroleum Water-Soluble Fraction (WSF). Ambio 41, 456-466. https://doi.org/10.1007/s13280-012-0259-4

Guzmán-García, X., 2007. Empleo de biomarcadores para evaluar el proceso de daño en ostión Crasssotrea virginica y su respuesta ambiental (Tesis de Doctorado en Biología Experimental). Universidad Autónoma Metropolitana. Unidad Iztapalapa, México.

Häder, D.-P., Banaszak, A.T., Villafañe, V.E., Narvarte, M.A., González, R.A., Helbling, E.W., 2020. Anthropogenic pollution of aquatic ecosystems: Emerging problems with global implications. Sci. Total Environ. 136586. https://doi.org/10.1016/j.scitotenv.2020.136586

Harik, G., Alameddine, I., Maroun, R., Rachid, G., Bruschi, D., Astiaso Garcia, D., El-Fadel, M., 2017. Implications of adopting a biodiversity-based vulnerability index versus a shoreline environmental sensitivity index on management and policy planning along coastal areas. J. Environ. Manage. 187, 187-200. https://doi.org/10.1016/j.jenvman.2016.11.038

Hernández-Calderas, I., 2013. Aplicación de técnicas especiales de tinción en organismos acuáticos como biomarcadores de exposición ambiental (Tesis de Licenciatura en Biología). Universidad Nacional Autónoma de México, México.

Hickman, C.P., 2009. Principios integrales de zoología. McGraw-Hill Interamericana de España S.L.

Jauzein, C., Donaghy, L., Volety, A.K., 2013. Flow cytometric characterization of hemocytes of the sunray venus clam Macrocallista nimbosa and influence of salinity variation. Fish Shellfish Immunol. 35, 716-724. https://doi.org/10.1016/j.fsi.2013.06.003

Jerónimo-Juárez, J.R., 2013. Biomarcadores de salud y calidad aplicados a la almeja Polymesoda caroliniana (Bosc, 1801) (Bivalva: Corbiculidae) de Tecolutla, Veracruz (Tesis de Maestría en Biología). Universidad Autónoma Metropolitana Unidad Iztapalapa, México.

Jorge-Buys, D.L., Lara Torres, C.O., Ortíz Hidalgo, C., 2007. Interpretación básica de inmunohistoquímica. Características generales de diversos anticuerpos y su localización celular y subcelular. Patología 45, 126-140.

Karmaoui, A., Alameddine, I., Maroun, R., Rachid, G., Bruschi, D., Astiaso Garcia, D., 2015. A Multidisciplinary Approach to Assess the Environmental Vulnerability at Local Scale in Context of Climate Change (Pilot Study in Upper Draa Valley, South Morocco). Glob. J. Technol. Optim. 06. https://doi.org/10.4172/2229-8711.1000167

Kühnel, W., 2005. Atlas color de citología e histología. Ed. Médica Panamericana.

Lang, T., Wosniok, W., Baršienė, J., Broeg, K., Kopecka, J., Parkkonen, J., 2006. Liver histopathology in Baltic flounder (Platichthys flesus) as indicator of biological effects of contaminants. Mar. Pollut. Bull. 53, 488-496. https://doi.org/10.1016/j.marpolbul.2005.11.008 
Lassudrie, M., Soudant, P., Richard, G., Henry, N., Medhioub, W., Da Silva, P.M., Donval, A., Bunel, M., Le Goïc, N., Lambert, C., 2014. Physiological responses of Manila clams Venerupis (= Ruditapes) philippinarum with varying parasite Perkinsus olseni burden to toxic algal Alexandrium ostenfeldii exposure. Aquat. Toxicol. 154, 27-38.

Lee, R., Lovatelli, A., Ababouch, L., Food and Agriculture Organization of the United Nations, 2010. Depuración de bivalvos: aspectos fundamentales y prácticos.

Levine, J.F., Law, M., Corsin, F., 2006. Capítulo 7 Bivalvos, in: Medicina de los invertebrados. Acribia S.A., Zaragoza, España, pp. 111-140.

Limón-Hernández, R.A., 2019. Electrocogulación como tratamiento de aguas de descarga al Río Tecolutla en la zona de Gutiérrez Zamora, Veracruz (Tesis de Especialización). Universidad Veracruzana, Veracruz.

López-Portillo, J., Lara-Domínguez, L., Áviles-Ángeles, A., Vázquez-Lule, A.D., 2009. Caracterización del sitio de manglar Tecolutla, en Comisión Nacional para el Conocimiento y Uso de la Biodiversidad (CONABIO), Sitios de manglar con relevancia biológica y con necesidades de rehabilitación ecológica. Comisión Nacional para el Conocimiento y Uso de la Biodiversidad CONABIO, Ciudad de México.

Magaña, V., 2012. Guía metodológica para la evaluación de la vulnerabilidad ante cambio climático. México PNUD-INECC-SEMARNAT.

Mares-Guzmán, F.A., Muñoz-Najera, M.A., Barrera-Escorcia, G., Ramírez-Romero, P., 2020. Effects induced by the presence of metals in species of economic and ecological importance in mexican aquatic environments, in: Gómez-Oliván, L.M. (Ed.), Pollution of Water Bodies in Latin America. Impact of Contaminants on Species of Ecological Interest. Springer Nature Switzerland, pp. 201-228.

Martín-Lacave, I., García-Caballero, T., 2012. Atlas de Inmunohistoquímica. Caracterización de células, tejidos y órganos normales, Primera. ed. Ediciones Díaz de Santos, España.

Matadamas-Guzman, M., Hernández-Calderas, I., Segoviano-Ramirez, J., Guzmán-García, X., 2019. Histopathological Assessment of Organisms in Ecotoxicological Studies from Mexico, in: Gómez-Oliván, L.M. (Ed.), Pollution of Water Bodies in Latin America. Impacts of Contaminants on Species of Ecological Insterest. Springer, pp. 311-317. https://doi.org/10.1007/978-3-030-27296-8_17

Mikkelsen, P.M., Bieler, R., 2008. Seashells of Southern Florida: Living Marine Mollusks of the Florida Keys and Adjacent Regions: Bivalves (v. 1): Princeton University Press, United Kingdom.

Mille-Pagaza, S.M., Parra, A., Pérez-Chi, M. de J., 1993. Guía para la identificación de invertebrados. Trillas.

Miyamoto, D., Maruta, C., Santi, C., Zoroquiain, P., Dias, A.B., Fukumori, L., Perigo, A., Aoki, V., Burnier, M., 2018. How can immunohistochemistry improve the diagnosis of pemphigus foliaceus? Hum. Pathol. Case Rep. 12, 1-8. https://doi.org/10.1016/j.ehpc.2017.12.001

Moraga, D., Meistertzheim, A.L., Tanguy-Royer, S., Boutet, I., Tanguy, A., Donval, A., 2005. Stress response in $\mathrm{Cu} 2+$ and $\mathrm{Cd} 2+$ exposed oysters (Crassostrea gigas): An immunohistochemical approach. Comp. Biochem. Physiol. Toxicol. Pharmacol. CBP 141, 151-6. https://doi.org/10.1016/j.cca.2005.05.014

Morse, P.M., Zardus, J.D., 1997. Chapter 2 Bivalvia, in: Microscopic Anatomy of Invertebrates. Wiley-Liss, New York, pp. 7-118. 
Newton, T.J., Cope, G., 2007. Biomarker responses of Unionid mussels to environmental contaminants, in: Farris, J.L., Hassel, J.H.V. (Eds.), Freshwater Bivalve Ecotoxicology. CRC Press, pp. 270-281.

NOM-059 SEMARNAT, 2010. NOM-059-SEMARNAT 2010. Protección ambiental de especies nativas de México de flora y fauna silvestres. Categorías de riesgo y especificaciones para su inclusión, exclusión o cambio. Lista de especies en riesgo [WWW Document].

URL http://dof.gob.mx/nota_detalle.php?codigo=5173091\&fecha=30/12/2010 （accessed 5.7.17).

Ocaña, F., Pech, D., 2018. Marco metodológico para evaluar la vulnerabilidad del bentos ante múltiples presiones en la región del Caribe, in: Adaptación basada en Ecosistemas: alternativa para la gestión sostenible de los recursos marinos y costeros del Caribe. Instituto de Oceanología, La Habana, pp. 122-124.

Otero-González, A.J., 2010. Los anticuerpos y su papel como herramientas analíticas en los ensayos inmunoenzimáticos. Rev. Cubana Med. Trop. 62, 85-92.

Pan, L., Liu, N., Xu, C., Miao, J., 2011. Identification of a novel P450 gene belonging to the CYP4 family in the clam Ruditapes philippinarum, and analysis of basal- and benzo(a)pyrene-induced mRNA expression levels in selected tissues. Environ. Toxicol. Pharmacol. 32, 390-398. https://doi.org/10.1016/j.etap.2011.08.005

Pérez Figueredo, A., 2012. La integración de la gestión de riesgos en la gestión del desarrollo local desde la perspectiva de la vulnerabilidad ambiental en los territorios. DELOS Desarro. Local Sosten. 5, 1-7.

Polanco Torres, E. (Ed.), 2002. Impulso, desarrollo y potenciación de la ostricultura en España. Ediciones Mundi-Prensa, España.

Ramírez, L.H., Torres, B., 2010. Metodología para evaluar vulnerabilidad costera por los efectos del cambio climático, in: Botello, A.V., Villanueva, S., Gutiérrez, J., RojasGalaviz, J.L. (Eds.), Vulnerabilidad de Las Zonas Costeras Mexicanas Ante El Cambio Climático. Gobierno del estado de Tabasco. SEMARNAT-INE. UNAM-ICMyL. Universidad Autónoma de Campeche, pp. 403-426.

Robledo, Y., Madrid, J.F., Leis, O., Cajaraville, M.P., 1997. Analysis of the distribution of glycoconjugates in the digestive gland of the bivalve mollusc Mytilus galloprovincialis by conventional and lectin histochemestry. Cell. Tissue Res. 288, 591-601.

Rodrigues-Silva, C., Flores-Nunes, F., Vernal, J.I., Cargnin-Ferreira, E., Bainy, A.C.D., 2015. Expression and immunohistochemical localization of the cytochrome P450 isoform 356A1 (CYP356A1) in oyster Crassostrea gigas. Aquat. Toxicol. 159, 267-275. https://doi.org/10.1016/j.aquatox.2014.12.021

Roesijadi, G., 1992. Metallothioneins in metal regulation and toxicity in aquatic animals. Aquat. Toxicol. 22, 81-113. https://doi.org/10.1016/0166-445X(92)90026-J

Ryan, J.A., Hightwer, L.E., 1996. Stress protein as molecular biomarkers for environmental toxicology, in: Feige, U., Morimoto, R.I., Polla, B. (Eds.), Stress-Inducible Cellular Responses. Birkhäuser, p. 42.

SAGARPA-CONAPESCA, 2013. Anuario estadístico de acuacultura y pesca 2013. Secretaria de Agricultura, Ganadería y Desarrollo Rural, Pesca y Alimentación [WWW Document].

URL http://www.conapesca.sagarpa.gob.mx/wb/cona/cona_anuario_estadistico_de_pesca 
Sahoo, S., Dhar, A., Kar, A., 2016. Environmental vulnerability assessment using Grey Analytic Hierarchy Process based model. Environ. Impact Assess. Rev. 56, 145-154. https://doi.org/10.1016/j.eiar.2015.10.002

Salimi, L., Jamili, S., Motalebi, A., Eghtesadi-Araghi, P., Rabbani, M., Rostami-Beshman, M., 2009. Morphological characterization and size of hemocytes in Anodonta cygnea. J. Invertebr. Pathol. 101, 81-85. https://doi.org/10.1016/j.jip.2009.03.003

Santovito, G., Boldrin, F., Irato, P., 2015. Metal and metallothionein distribution in different tissues of the Mediterranean clam Venerupis philippinarum during copper treatment and detoxification. Comp. Biochem. Physiol. Part C Toxicol. Pharmacol. 174-175, 4653. https://doi.org/10.1016/j.cbpc.2015.06.008

Singh, M.R., Gupta, A., 2017. Water pollution-sources, effects and control.

Sıkdokur, E., Belivermiş, M., Sezer, N., Pekmez, M., Bulan, Ö., Kılıç, Ö., 2020. Effects of microplastics and mercury on manila clam Ruditapes philippinarum: Feeding rate, immunomodulation, histopathology and oxidative stress. Environ. Pollut. 262, 114247. https://doi.org/10.1016/j.envpol.2020.114247

Skondras, N.A., Karavitis, C.A., Gkotsis, I., Scott, P.J.B., Kaly, U.L., Alexandris, S.G., 2011. Application and assessment of the Environmental Vulnerability Index in Greece. Ecol. Indic. 11, 1699-1706. https://doi.org/10.1016/j.ecolind.2011.04.010

Solé, M., Bonsignore, M., Rivera-Ingraham, G., Freitas, R., 2018. Exploring alternative biomarkers of pesticide pollution in clams. Mar. Pollut. Bull. 136, 61-67. https://doi.org/10.1016/j.marpolbul.2018.08.062

Thomas, K., Hardy, R.D., Lazrus, H., Mendez, M., Orlove, B., Rivera-Collazo, I., Timmons, R., Marcy, R., Wharner, B.P., Winthrop, R., 2018. Explaining differential vulnerability to climate change: A social science review. WIREs Clim. Change 1-18.

Toro-Restrepo, B., 2011. Uso de los biomarcadores en la evaluación de la contaminación. Rev. Luna Azul 32, 121-127.

Trevisan, D.P., da Conceicao Bispo, P., Almeida, D., Imani, M., Balzter, H., Moschini, L.E., 2020. Environmental vulnerability index: An evaluation of the water and the vegetation quality in a Brazilian Savanna and Seasonal Forest biome. Ecol. Indic. 112, 106-163. https://doi.org/10.1016/j.ecolind.2020.106163

UNDRR, 2004. Vulnerabilidad [WWW Document]. Oficina Las N. U. Para Reducc. Riesgo Desastres. URL https://www.undrr.org/ (accessed 10.4.20).

Usheva, L.N., Vaschenko, M.A., Durkina, V.B., 2006. Histopathology of the digestive gland of the bivalve mollusk Crenomytilus grayanus (Dunker, 1853) from southwestern Peter the Great Bay, Sea of Japan. Russ. J. Mar. Biol. 32, 166-172. https://doi.org/10.1134/S1063074006030047

Vargas Burgoa, O.A., Villalba Herrera, E.W., 2014. Anticuerpos. Rev. Actual. Clínica Investiga 42, 2342-2346.

Vázquez-Castro, J.A., 2019. Evaluación de la condición fisiológica de la almeja Polymesoda caroliniana (Bivalva: Corbiculidae) expuesta a cadmio (Maestría). Universidad Autónoma Metropolitana Unidad Iztapalapa, Ciudad de México.

Vázquez-Castro, J.A., Barrera-Escorcia, G., Ramírez-Romero, P., Jerónimo-Juárez, J.R., Muñoz-González, F., Guzmán-García, X., 2017. Assessment of the importance factor in tissue responses of clam Polymesoda caroliniana exposed to cadmium. Presented at the Sociedad Española de Histología e Ingeniería tisular, Santiago de Compostela, España. 
Villa, F., McLeod, H., 2002. Environmental Vulnerability Indicators for Environmental Planning and Decision-Making: Guidelines and Applications. Environ. Manage. 29, 335-348. https://doi.org/10.1007/s00267-001-0030-2

Villamar, Z., 2011. ¿Cuál fue la visión oficial estadunidense del daño ambiental producido por el derrame de crudo del pozo Macondo? Norteamérica 6, 205-218.

Vodopivez, C., Curtosi, A., Villaamil, E., Smichowski, P., Pelletier, E., Mac Cormack, W.P., 2015. Heavy metals in sediments and soft tissues of the Antarctic clam Laternula elliptica: More evidence as a ? possible biomonitor of coastal marine pollution at high $\begin{array}{lllll}\text { latitudes? } & \text { Sci. } & \text { Total } & \text { Environ. } & \text { 375-384, }\end{array}$ https://doi.org/10.1016/j.scitotenv.2014.09.031

Wakida-Kusunoki, A.T., MacKenzie, Jr.C., 2004. Rangia and Marsh Clams, Rangia cuneata, R. flexuosa, and Polymesoda caroliniana, in Eastern México: Distribution, Biology and Ecology, and Historical Fisheries. Mar. Fish. Rev. 66, 13-20.

Wang, Q., Wang, Xiaomei, Wang, Xiaoyu, Yang, H., Liu, B., 2010. Analysis of metallotionein expression and antioxidant enzyme activities in Meretrix meretrix larvae under sublethal cadmium exposure. Aquat. Toxicol. Amst. Neth. 100, 321-328. https://doi.org/10.1016/j.aquatox.2010.08.012

Yue, X., Liu, B., Sun, L., Tang, B., 2011. Cloning and characterization of a hsp70 gene from Asiatic hard clam Meretrix meretrix which is involved in the immune response against bacterial infection. Fish Shellfish Immunol. 30, 791-799. https://doi.org/10.1016/j.fsi.2010.12.027

Zaroogian, G., Yevich, P., 1994. The nature and function of the brown cell in Crassostrea virginica. Mar. Environ. Res. 37, 355-373.

Zaroogian, G., Yevich, P., Anderson, S., 1993. Effect of selected inhibitors on cadmium, nickel, and benzo (a) pyrene uptake into brown cells of Mercenaria mercenaria. Mar. Environ. Res. 35, 41-45.

Zhang, L., Gan, J., Ke, C., Liu, X., Zhao, J., You, L., Yu, J., Wu, H., 2012. Identification and expression profile of a new cytochrome P450 isoform (CYP414A1) in the hepatopancreas of Venerupis (Ruditapes) philippinarum exposed to benzo[a]pyrene, cadmium and copper. Environ. Toxicol. Pharmacol. 33, 85-91. https://doi.org/10.1016/j.etap.2011.08.015

\section{Fotografías}

Luis Hernández D.I. (2012). Acervo Fotográfico del Laboratorio de EcotoxicologíaHistología. UAM-I.

Jerónimo Juárez J.R. y Márquez Ramos J.A (2016 y 2018). Acervo Fotográfico del Laboratorio de Ecotoxicología-Histología. UAM-I. 


\section{Artículo doctoral}

Cita:

Jerónimo-Juárez J.R., Matadamas-Guzmán M.L., Guerrero-Legarreta I., Segoviano-Ramírez

J.C., Zarate-Hernández M.D.R., Arteaga-Silva M., y Guzmán-García X. 2020. Tissue biomarkers as vulnerability indicators in the clam Polymesoda caroliniana. Invertebrate Survival Journal, 17(2020): 186-197.

DOI: https://doi.org/10.25431/1824-307X/isj.v0i0.186-197

Revista: Invertebrate Survival Journal (http://www.isj.unimo.it/index.php/ISJ).

ISSN: 1824-307X

País: Italia.

Factor de impacto (2020): 0.78 


\title{
Tissue biomarkers as vulnerability indicators in the clam Polymesoda caroliniana
}

\author{
JR Jerónimo-Juárez ${ }^{1}$, ML Matadamas-Guzman ${ }^{2}$, I Guerrero Legarreta $^{3}, \mathrm{JC}$ Segoviano-Ramírez ${ }^{4}, \mathrm{M}$ \\ del Rocío Zarate-Hernández ${ }^{5}, M$ Arteaga-Silva ${ }^{6}, X$ Guzmán-García $^{7^{*}}$ \\ ${ }^{1}$ Posgrado en Energía y Medio Ambiente, Universidad Autónoma Metropolitana, 09340, Ciudad de México, México \\ ${ }^{2}$ Doctorado en Ciencias Biomédicas, UNAM, Ciudad de México, México \\ ${ }^{3}$ Departamento de Biotecnología, Universidad Autónoma Metropolitana, Unidad Iztapalapa, 09340, Ciudad de México, \\ México \\ ${ }^{4}$ Unidad de Bioimagen, Centro de Investigación y Desarrollo en Ciencias de la Salud, Universidad Autónoma de Nuevo \\ León, Monterrey, Nuevo León, México \\ ${ }^{5}$ Laboratorio de Peces, Departamento de Biología, Universidad Autónoma Metropolitana, 09340, Ciudad de México, \\ México \\ ${ }^{6}$ Laboratorio de Neuroendocrinología Reproductiva, Departamento de Biología de la Reproducción, Universidad \\ Autónoma Metropolitana, 09340, Ciudad de México, México \\ ${ }^{7}$ Departamento de Hidrobiología, Laboratorio de Ecotoxicología, Universidad Autónoma Metropolitana, Unidad \\ Iztapalapa, 09340, Ciudad de México, México
}

\begin{abstract}
Vulnerability depends on the exposure and sensitivity levels of a system to a specific pressure, together with the capacity to cope, recover, or adapt to this pressure. We propose the use of well- known tissular techniques to measure the components of vulnerability. Immunohistochemistry and histopathology indicate the health status of living organisms and the environment. Therefore, these techniques should provide the necessary information to determine the vulnerability of an organism. Immunohistochemical analysis uses biomarkers to determine the presence of toxic compounds, reflecting the exposure level of an organism. Histopathological analysis reveals the environmental impact of a given toxin, reflecting the sensitivity level of the organism to said toxin. Here, we propose a strategy to use these techniques to assess the vulnerability of clams from Tecolutla, Veracruz. We developed categories for each vulnerability component using semi-quantitative scales. Briefly, we calculated the exposure level based on the average number of positive immunohistochemical biomarkers among several organs of clams. Then, we compared the prevalence of histological alterations with the exposure level to determine the sensitivity level. Finally, to estimate the recovery capacity, we placed the control group in a clean environment for 40 days. These led us to observe the capacity of the clams to reverse the effects of environmental stress. Clams showed a moderate level of exposure, a low sensitivity level, and an effective recovery capacity. In conclusion, these results indicate that clams have a low level of vulnerability. This proposal has the potential to guide future works assessing the vulnerability of organisms and later include them in the estimation of vulnerability from aquatic bodies.
\end{abstract}

Key Words: Polymesoda caroliniana; histopathological index; vulnerability; immunohistochemistry; environmental stress

\section{Introduction}

Coastal areas are considered one of the most vulnerable environments affected by pollutants. Some studies have already proposed some vulnerability

Corresponding author:

Xochitl Guzmán-García

Universidad Autónoma Metropolitana, Unidad Iztapalapa San Rafael Atlixco 186, Vicentina, C.P. 09340, Iztapalapa, Ciudad de México, México

E-mail: xgg@xanum.uam.mx parameters for coastal areas (Ramírez and Torres, 2011). However, none of these assessments included animal physiological traits that describe the health status of living organisms. Environmental stress can cause measurable effects over the physiological state of different animals, compromising their health (Bayne et al., 1976; Baum et al., 1984; Häder et al., 2020). Diverse methodological approaches measure these effects at different biological levels. Histopathological and 
immunohistochemical analyses evaluate the effects of environmental stress at the tissue level (Costa et al., 2013; Cuevas et al., 2015). On one hand, histopathological analysis determines the physiological consequences of pollutants over organisms, through a characterization of tissue injuries (Usheva et al., 2006; Boscolo Papo et al., 2014b). These toxic responses are semi-quantified through the histopathological index (Ih), detailing the health status of an organism (Costa et al., 2013; Cuevas et al., 2015). On the other hand, immunohistochemical analysis determines cytological responses related to the presence of some pollutants. Many biomarkers are used to this end, indicating several types of toxic compounds that affect living organisms (Moraga et al., 2005; Wang et al., 2010; Zhang et al., 2012; Boscolo Papo et al., 2014a). Consequently, the integration of histopathological and immunohistochemical approaches constitutes a valuable strategy to investigate the vulnerability of an organism to a specific environment (Boscolo Papo et al., 2014a).

Tecolutla is located in Veracruz state, along the eastern coast of Mexico (Fig 1). The town of Tecolutla surrounds a river that has associated estuaries, canals, and mangroves, giving this locale huge biodiversity. The most important and growing economic activity in the zone is tourism, hence the river receives many discharges of wastewater, agrochemicals, and hydrocarbons, which impact on the natural environment (López-Portillo et al., 2009;
Arriaga-Gaona, 2009; Temino-Boes et al., 2020). Water samples taken from the Tecolutla river exceed the limits of total and fecal coliform bacteria allowed according to Mexican standards (Arriaga- Gaona, 2009). Moreover, Veracruz state shows a high vulnerability, according to impact studies conducted on fishery production and damage to the mangrove (Ramírez and Torres, 2011). Nevertheless, none of these studies included physiological indicators of the health of living organisms. Clams are bioindicators of the health status of an environment (Markert et al., 2003; Park et al., 2007; Wu et al., 2013; Boscolo Papo et al., 2014a; Zhang et al., 2014; Carneiro et al., 2015; Cuevas et al., 2015; Santovito et al., 2015; Vodopivez et al., 2015; Delgado-Alvarez et al., 2019). Among the diversity of Tecolutla, we found the clam Polymesoda caroliniana, commonly named black clam. Therefore, these organisms are potential sources of vulnerability data.

Vulnerability depends on the exposure and sensitivity levels of a system to a specific pressure, together with the capacity to cope, recover, or adapt to this pressure (Villa and McLeod, 2002; Stein et al., 2014; Carantoña and Hernández, 2017; Ocaña and Pech, 2018). These components are measured through indicators at different biological levels. Here, we created an approach to measuring the three vulnerability components by assessing the health status of the clams. The proposed approach includes the use of different tissular techniques to

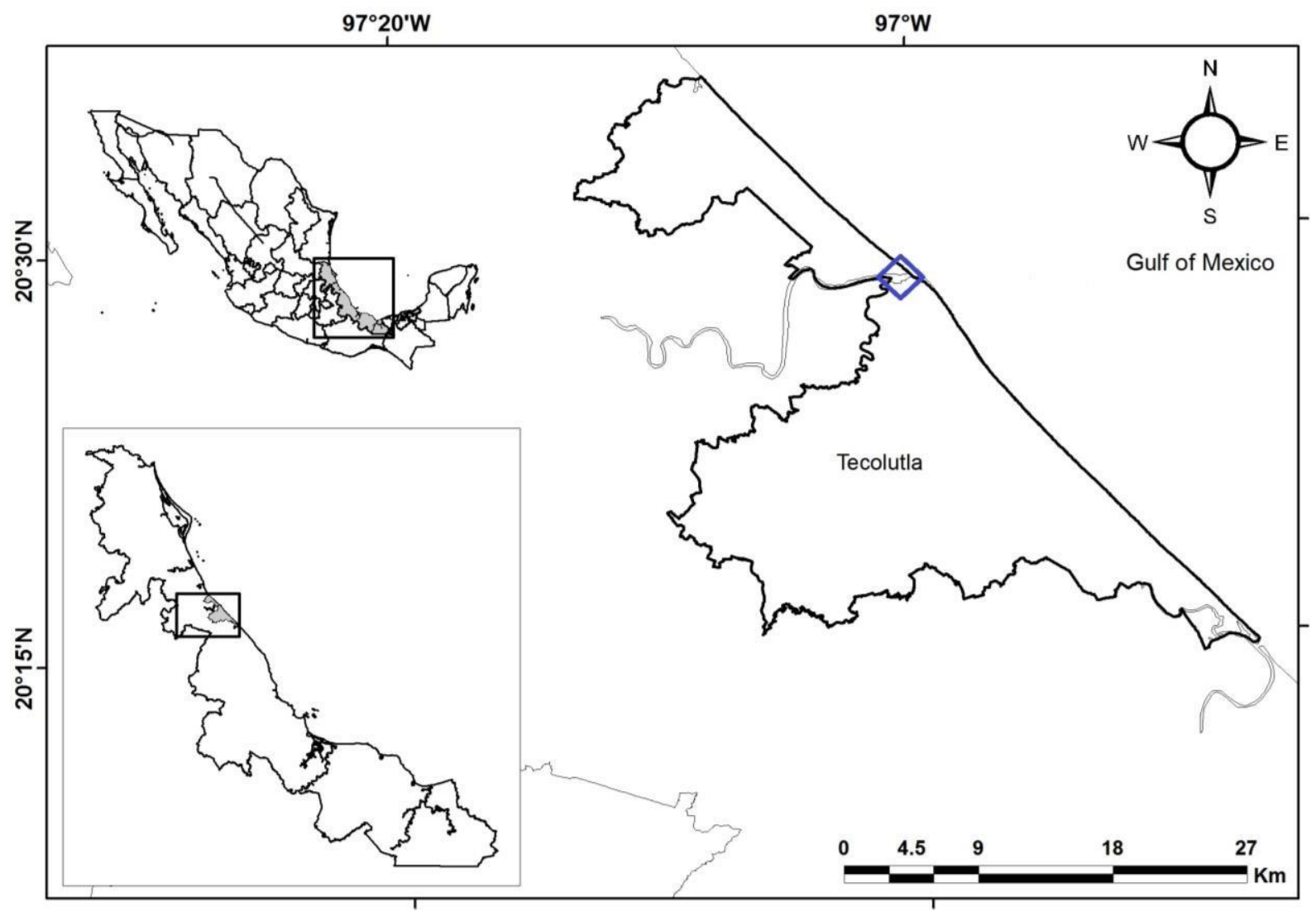

Fig. 1 Map indicating the location of Tecolutla in Veracruz State, Mexico 
this end. To measure the exposure level, we used immunohistochemical analysis. Immunohistochemical analysis reflects the level of exposure, indicating cytological responses to the presence of different pollutants. Then, to measure the sensitivity level, we correlated the prevalence of histopathological injuries with the level of exposure. Finally, we estimated the recovery capacity through a group of clams that depurated pollutants for 40 days in a clean environment. These organisms were shown to be sensitive enough to reflect that Tecolutla is polluted but also resilient enough to resist and survive environmental stress. Moreover, they showed an effective recovery capacity when introduced to a clean environment. Here we

proposed the integration of histopathological and immunohistochemical analyses through semiquantitative scales to assess the vulnerability of clams from Tecolutla. We created categories for each component, proposing approaches to their measurement. In conclusion, we determined that the clam $P$. caroliniana has a low vulnerability, based on the fact that clams could recover fully in a clean environment. This first proposal is a guide for future investigations to determine the vulnerability of specific organisms. The vulnerability of several organisms based on physiological traits should be included in the determination of the health status and vulnerability of an environment.

\section{Material and methods}

\section{Sampling area and sample collection}

The Tecolutla River is located in the state of Veracruz between parallels $96^{\circ} 59^{\prime} 849^{\prime \prime} \mathrm{W}$ and $20^{\circ} 27^{\prime} 628^{\prime \prime} \mathrm{N}$, on the eastern coast, facing the Gulf of Mexico (Fig 1). Prior to collection, we obtained physicochemical water parameters (temperature, salinity, dissolved oxygen, and $\mathrm{pH}$ ) with a Hach ${ }^{\circledR}$ model DR / 2000 direct reading spectrophotometer. The physicochemical parameters of Tecolutla, Veracruz characterize a typical estuarine environment: $22{ }^{\circ} \mathrm{C}, 2 \%$ salinity, $6.6 \mathrm{mg} / \mathrm{l}$ dissolved oxygen, and $\mathrm{pH}$ 7.7. These were later used to maintain the same conditions in the control group.

Local fishermen collected 100 adult Polymesoda caroliniana clams (4 to $5.5 \mathrm{~cm}$ in length). The clams were divided into a control and an experimental group, each containing 50 individuals. Transportation to the laboratory was in thermal boxes at $4{ }^{\circ} \mathrm{C}$. Once they arrived, all the clams were cleaned with $70 \%$ alcohol. Then, all the clams were subjected to a macroscopic evaluation, and the following parameters were recorded: shell perforations and the presence of vermes or ectoparasites. Macroscopic analysis of Polymesoda caroliniana clams showed healthy organisms without shell distortion or perforations, but some of them had parasitic worms.

Immediately, the visceral mass of the experimental group was dissected and processed for histopathological and immunohistochemical analysis. The clams in the control group were maintained in seawater under the original physicochemical parameters $\left(22{ }^{\circ} \mathrm{C}, 2 \%\right.$ salinity, $6.6 \mathrm{mg} / \mathrm{L}$ dissolved oxygen, and $\mathrm{pH} 7.7$ ) for 40 days. During the 40 days, the seawater was continuously
Table 1 Percentage of dissemination degree assigned to each a value

\begin{tabular}{cc}
\hline Dissemination degree & a value \\
\hline $0-9 \%$ & 0 \\
$10-40 \%$ & 2 \\
$50-70 \%$ & 4 \\
$70-100 \%$ & 6 \\
\hline
\end{tabular}

aerated with partial water replacement every $72 \mathrm{~h}$. The clams were fed with a suspension of 909,935 cells $/ \mathrm{ml}$ microalgae culture of Chlorella $s p$ every day. After 40 days of maintenance, these clams were subjected to histopathological and immunohistochemical analysis.

\section{Tissue preparation}

The visceral mass of all clams was fixed in $10 \%$ neutral buffered formalin for $48 \mathrm{~h}$, dehydrated through a graded series of ethanol in a tissue processor (Leica, model TP1020), and embedded in paraffin using a paraffin embedding station (Leica, model EG1140-H). Serial 5 - $\mu$-thick sections were cut in a microtome (Microm, model HM3156).

\section{Histopathological analysis}

Histopathological slides were prepared by a standard technique, stained with hematoxylin-eosin (Cuevas et al., 2015), and examined under light microscopy (Zeiss, PrimoStar) to observe the general morphology, presence of parasites, and histological alterations. For each clam, three slides were analyzed. For each slide, we observed six different optical fields, each one at three magnifications, $10 \mathrm{X}, 40 \mathrm{X}$, and 100X. Three different people analyzed the slides separately following the same criteria. Each person observed and quantified the alterations to report the number of clams presenting each alteration in a prevalence matrix.

The histopathological analysis included: $i$. observation and description of tissue alterations, ii. construction of an alteration prevalence matrix, and

iii. pathological importance factor $(w)$ assignment and the degree of dissemination value $(a)$. These values created a prevalence matrix, used to calculate the histopathological index.

\section{Histopathological index}

The histopathological index $\left(I_{h}\right)$ is part of a protocol for the evaluation of aquatic pollution, and it was calculated according to previous studies (Bernet et al., 1999; Costa et al., 2013; Cuevas et al., 2015). First, each type of alteration was categorized with respect to reaction patterns. A reaction pattern is the set of alterations in the functional unit of the targeted organ. The reaction patterns were tubular alterations and intertubular alterations. Then, we calculated the pathological importance factor $(w)$ and the degree of dissemination (a). The pathological importance factor $(w)$ is defined as the degree of damage or 
compromise of an organ after an alteration on a scale of 0 to $3(0=$ absence, $1=$ negligible, $2=$ moderate, and 3 = severe pathological importance), according to the original work (Cuevas et al., 2015; Costa et al., 2013). Parasites were weighted as $w=3$, hemocytic infiltrations and atrophies as $w=2$, and brown cells and lipofuscin aggregates were assigned $w=1$, according to the original proposal for clams (Costa et al., 2013; Cuevas et al., 2015). The degree of dissemination (a) was the level of spread of a particular alteration in a functional unit or organ, in the range of zero to six. Therefore, to assign a value, we used a prevalence matrix (Table 1).

Each a value correspond to (0) unchanged, (2) mild occurrence, (4) moderate occurrence, and (6) severe occurrence, according to previous reports (Bernet et al., 1999; Cuevas et al., 2015). Later, we calculated the $I_{h}$ using the following equation (Costa et al., 2013)

$$
I_{h}=\frac{\sum_{1}^{j} w_{j} \cdot a_{j h}}{\sum_{1}^{j} M_{j}}
$$

Where $w_{j}$ is the pathological importance factor of each alteration, $a_{j h}$ is the degree of dissemination of an individual alteration, and $M_{j}$ is the maximum attributable value for the alteration, estimated from the maximum value of $w$ times the maximum value of $a$. This denominator normalizes $I_{h}$ to a value between 0 and 1 , thus permitting comparisons between distinct organs.

\section{Immunohistochemistry}

For immunohistochemical staining, tissue slides were deparaffinized in xylene before hydration via a graded series of ethanol. To retrieve the heat- induced antigen, we used a recuperator (Diva Decloaker 20x DV2005, Biocare Medical) diluted 1:20 with distilled water in a digital electric pressure cooker (Decloaking Chamber, model DC2002, Biocare Medical) at 25 PSI and $125{ }^{\circ} \mathrm{C}$ for $5 \mathrm{~min}$. Slides were washed with TBS (Auto Wash Buffer, 40X, Biocare Medical) and then cooled down progressively at room temperature for $20 \mathrm{~min}$. Endogenous peroxidases were neutralized by incubating the slides with the blocker (endogenous peroxidase blocker PX968G, Biocare Medical) for 5 min at room temperature in an incubator chamber (model RMIQ105, Biocare Medical), to avoid natural temperature fluctuations. Excess blocking solution was removed by washing in TBS. Thereafter, all incubations were performed at room temperature. Serial sections were incubated for 45 min with $100 \mu \mathrm{L}$ of the primary antibodies inside the incubator chamber. For metallothioneins, we used mouse monoclonal metallothionein antibody [UC1MT] (Genentex Catalog Number: GTX12228), dilution 1:30. For cytochrome P450, we used mouse monoclonal antibody CYP1A2 [15E2] (Genentex Catalog Number: GTX84638), dilution 1:50. Finally, for HSP70, we used a mouse monoclonal Hsp70 antibody [3A3] (Genentex® Catalog Number: GTX25439), dilution 1:50. TBS solution without primary antibody served as the control. After washing in TBS, sections were incubated with a polymer (EnVision+ System-HRP, Labelled Polymer (Mouse) K4000, Agilent Dako) that contained secondary antibody and streptavidin for $45 \mathrm{~min}$. Then, we stained the slides with diaminobenzidine (DAB), using $1 \mathrm{ml}$ of substrate buffer and $50 \mu \mathrm{L}$ of chromogen (Dako Liquid DAB+ Substrate Chromogen System K3465, Agilent Dako) for $10 \mathrm{~min}$. The slides were counterstained with hematoxylin (Tacha's Automated Hematoxylin, Biocare Medical) for $10 \mathrm{~min}$ and later dehydrated. Samples were mounted with a 50\% synthetic xylene resin solution. Staining was performed in triplicate for each tissue of three clams. All slides were observed under a light microscope (Zeiss $\AA$, PrimoStar 176045) coupled to a digital camera (CANON, Powershot G10). Immunolabeling was considered positive when the staining intensity was greater than the background observed in the negative control. The specificity of the immunostaining was verified by incubating the sections with PBS instead of the specific primary antibody. This validation was performed for all antibodies in each the tissues. All preparations were kept in a buffer solution to avoid drying.

Table 2 Relations between the prevalence of histopathological alterations and level of exposure. The sensitivity value was calculated by subtracting the prevalence minus exposure level. These relations resulted in a categorization of sensitivity (Very low $=-2$, Low $=-1$, Normal $=0$, High $=1$, Very high $=2$ )

\begin{tabular}{|c|c|c|c|c|c|}
\hline $\begin{array}{l}\text { Exposure } \\
\text { level }\end{array}$ & Value & $\begin{array}{c}\text { Prevalence of } \\
\text { histopathological } \\
\text { alterations }\end{array}$ & Value & $\begin{array}{l}\text { Sensitivity } \\
\text { value }\end{array}$ & $\begin{array}{l}\text { Sensitivity } \\
\text { category }\end{array}$ \\
\hline Minimal & 1 & Low prevalence & 1 & 0 & Normal \\
\hline Moderate & 2 & & 1 & 1 & High \\
\hline High & 3 & & 1 & 2 & Very high \\
\hline Minimal & 1 & Moderate prevalence & 2 & -1 & Low \\
\hline Moderate & 2 & & 2 & 0 & Normal \\
\hline High & 3 & & 2 & 1 & High \\
\hline Minimal & 1 & High prevalence & 3 & -2 & Very low \\
\hline Moderate & 2 & & 3 & -1 & Very low \\
\hline High & 3 & & 3 & 0 & Low \\
\hline
\end{tabular}



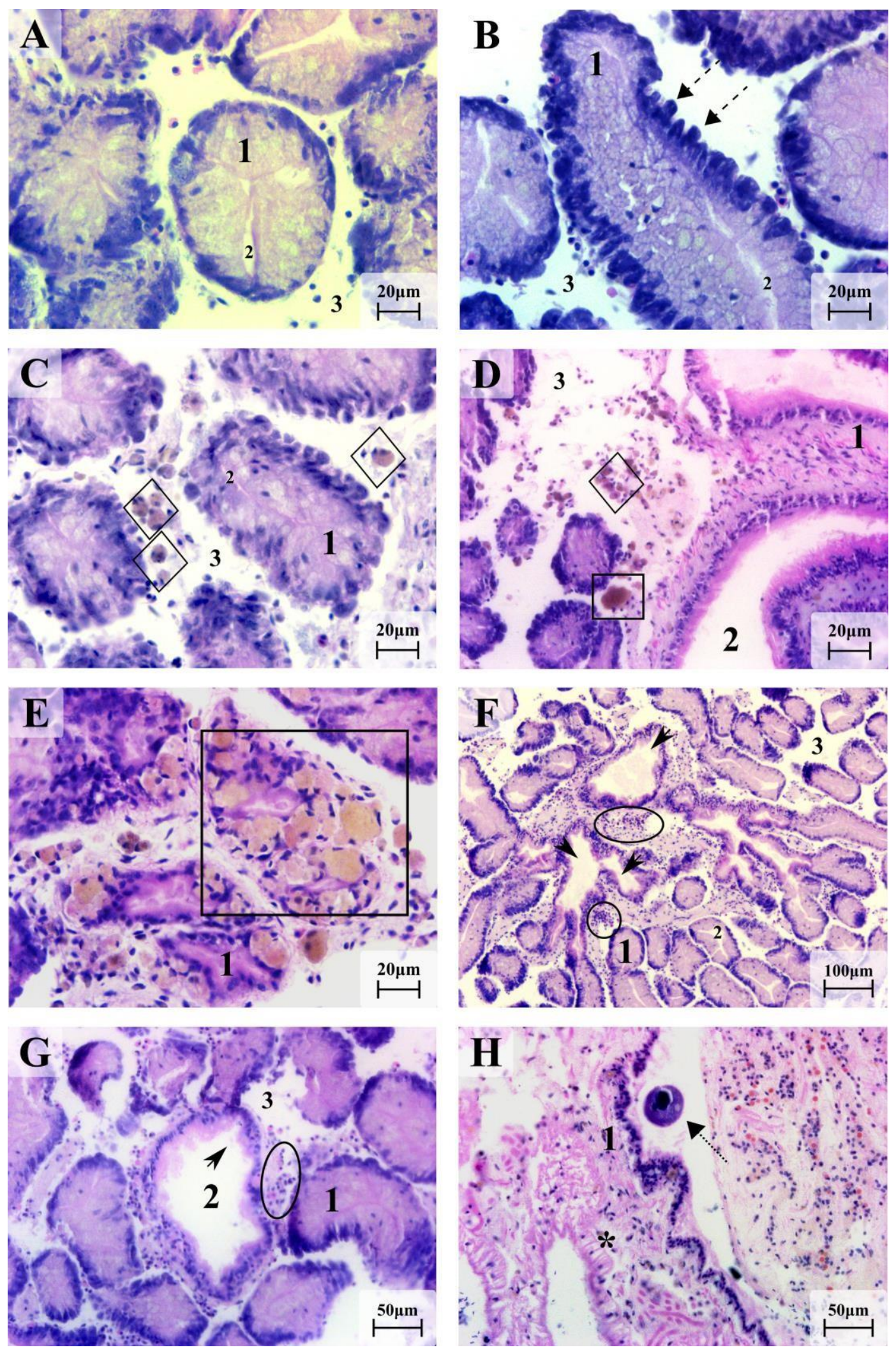

Fig. 2 Digestive gland histological description of several organisms showing different dissemination degrees (a). A. Digestive tubules showing semi-circular normal aspects. Basophilic cells lining the lumen of digestive tubules. B. Secretory vesicles (dashed arrows) derived from epithelium. C. Digestive gland tubules showing few brown cells $(a=2$, diamonds). D. Digestive gland tissue showing an increase of brown cells $(a=4)$, and some lipofuscin aggregates ( $a=2$, square). E. Tubules showing lipofuscin aggregates (square) with the highest dissemination degree $(a=6)$. F-G. Digestive gland showing atrophy (solid arrows) of the tubule epithelium $(a=2)$, and hemocyte infiltration $(a=6$, circles). H. Digestive gland tissue showing inclusions of possible parasites $(a=2) .1$. Epithelium 2. Lumen 3. Connective tissue. Hematoxylin-eosin staining 


\section{Vulnerability parameters}

Vulnerability is composed of the levels of exposure, sensitivity, and recovery capacity (Ocaña and Pech, 2018). Exposure was measured through the number of immunohistochemical biomarkers identified. The immunohistochemical index $\left(l_{1}\right)$ is the average of biomarkers found in different organs of the organisms. This average was categorized into four groups: no exposure $\left(l_{1}=0\right)$, minimal exposure $\left(l_{1}\right.$ between 0.1 and $1)$, moderate exposure ( $I$, between 1.1 and 2 ), and high exposure ( $l_{1}$ between

2.1 and 3). Moreover, the sensitivity is the level of response according to the level of exposure to certain stresses (Ocaña and Pech, 2018). Therefore, the sensitivity relates the prevalence of histopathological alterations to the level of exposure, hence we assigned values to each category. The prevalence of histopathological alterations is a classification derived from the histopathological index, where $0-0.25$ is low, 0.25

-0.50 moderate, $0.50-0.75$ high, and $0.75-1$, very high (Costa et al., 2013). We considered high and very high prevalence as the same category. All the organisms are sensitive to their environment to survive, thus we made four categories of sensitivity from very low to very high. These categories were assigned according to the following criteria. If an organism was exposed to a low level of exposure and had a low level of prevalence of alterations, then it had a normal sensitivity. However, if the organism was exposed to a low level of exposure but had a moderate or high prevalence of alterations, then the organism was highly sensitive (Table 2).

\section{Results}

Clams from Tecolutla had a low prevalence of histopathological alterations

The digestive glands have been used to assess pollution effects on many organisms, as epithelial cells lining the digestive glands are very sensitive to environmental stress (Usheva et al., 2006). On one hand, the digestive gland of $P$. caroliniana clams in the control group showed tubular structures with an epithelial lining and a central lumen (Fig 2A, 2B). Moreover, on this epithelium we observed secretory vesicles (Fig 2B), which aid in the detoxifying processes of the clam (Usheva and Frolova, 2006).
Around the tubules we observed connective tissue, which provides support to the digestive gland and a medium for oxygen and nutrients to diffuse to cells. Moreover, we found few hemocytes, brown cells and lipofuscin aggregates in the connective tissue, as expected. Most of this histological morphology agrees with the description of digestive glands in other clam species (Usheva and Frolova, 2006; Usheva et al., 2006; Sıkdokur et al., 2020; Bejaoui et al., 2020; Costa et al., 2013). On the other hand, as compared with the control groups, digestive gland sections from the experimental group underwent a change in their structure. Brown cells and lipofuscin aggregates in the slides from the experimental group increased (Fig 2C, 2D, 2E), as did hemocytic infiltrations, atrophy, and parasites (Fig 2F, 2G, 2H, and Table 3). These responses were classified into tubular and intertubular alterations. We used this classification to associate a pathological importance factor $(w)$ and degree of dissemination (a) (Costa et al., 2013), to further determine the general health status of clams from Tecolutla, Veracruz. The clams from the experimental group presented alterations with diverse pathological importance factors $(w)$; however, the most disseminated pathologies had a low $w$ (Table 4). These results suggest that the most prevalent pathologies are the least harmful for the organisms.

To integrate both $w$ and $a$, we calculated the histopathological indices for these clams. The average histopathological index $\left(I_{h}\right)$ for the control group was 0.01 , while the average $I_{h}$ for the experimental group was 0.18 . Based on these results, we concluded that the clams from Tecolutla, Veracruz had a low prevalence of histopathological alterations, according to previous reports classifying the $\mathrm{I}_{\mathrm{h}}$ (Costa et al., 2013; Cuevas et al., 2015).

Clams from Tecolutla are exposed to several pollutants

Besides histopathological analysis, other biomarkers are used to corroborate the impact of environmental stress. Some of these biomarkers include P450 cytochromes (CYPs), metallothionein proteins (MTs), and heat-shock proteins (HSP) (Moraga et al., 2005; Boscolo Papo et al., 2014a; b). We used these biomarkers to assess environmental

Table 3 Pathological alterations and dissemination degree observed in clams from the experimental group. A total of 50 clams belonged to this group. Clams from the control group lacked any of these alterations. Dissemination degree $(a)$ is the percentage of clams presenting each alteration

\begin{tabular}{ccc}
\hline Alteration & Number of clams with the alteration & Dissemination degree $(\boldsymbol{a})$ \\
\hline Brown cells & 47 & 95 \\
Lipofuscin aggregates & 30 & 60 \\
Hemocytic infiltrations & 20 & 40 \\
Atrophy & 10 & 25 \\
Parasites & 1 & 0.05 \\
\hline
\end{tabular}


Table 4 Values of pathological importance factor $(w)$ and degree of dissemination $(a)$ of clams from the experimental group. At the end is the $I_{h}$ for this group

\begin{tabular}{lccc}
\hline Reaction pattern & Alteration & $\boldsymbol{w}$ & $\boldsymbol{a}$ \\
\hline \multirow{3}{*}{ Tubular alterations } & Brown cells & 1 & 2 \\
& Lipofuscin aggregates & 1 & 4 \\
& Hemocytic Infiltrations & 2 & 0 \\
& Atrophy & 2 & 0 \\
\hline \multirow{3}{*}{ Intertubular alterations } & Parasites & 3 & 0 \\
& Browns cells & 1 & 6 \\
& Lipofuscin aggregates & 1 & 2 \\
& Hemocytic Infiltrations & 2 & 6 \\
\hline Histopathological index $(\mathbf{l n})$ & Atrophy & 2 & 6 \\
\hline
\end{tabular}

stress effects on the clam of Tecolutla (Table 5). Digestive gland slides of the control group lacked any immunoreactivity. However, digestive gland slides of the experimental group showed positive immunoreactivity to P450 cytochrome (CYP) and heatshock protein 70 (HSP70), but not to MTs. Both CYP and HSP70 were observed on the cytoplasm of the epithelial tissue lining of the digestive tubules (Fig 3A, $3 \mathrm{~B}, 3 \mathrm{C})$. These results suggest that injuries caused to the digestive gland by environmental stress are reversible, as the control group did not show immunoreactivity to these markers. Nevertheless, the digestive system of clams is composed of other organs, such as a short esophagus, a stomach, and a gut. Hence, we tested the same biomarkers on the rest of them. Stomach and gut tissues showed immunoreactivity to HSP70 and CYP but not to MTs (Fig 3D). The immunohistochemical responses indicated that the Tecolutla environment has many pollutants, but apparently the concentration of heavy metals is low, as the digestive system did not show any immunoreactivity.

Nevertheless, to obtain an overview about the overall health of the clams, we tested the same antibodies in other target organs (Table 5). The gills, the gonads and the foot are widely used to assess the health of many mollusks through histopathological and immunohistochemical approaches (Moraga et al., 2005; Usheva et al., 2006; Costa et al., 2013; Boscolo Papo et al., 2014a; Cuevas et al., 2015; Sıkdokur et al., 2020). In our clams, the gills showed immunoreactivity to HSP70 and CYP, but not to MTs. Meanwhile, the gonads showed immunoreactivity only to HSP70. Finally, the foot showed immunoreactivity to all the biomarkers, HSP70, CYP, and MTs (Fig 3E, 3F). To observe the accuracy of the immunohistochemical test, we showed that in the absence of the antibody, the color of the slides changes dramatically (Fig 3G, $3 \mathrm{H})$. These organs have different levels of exposure to the environment, due to their diverse physiological functions. Accordingly, the gills are highly related to water quality, while the foot is more related to sediment quality. However, the general response to immunohistochemical biomarkers indicated that the environment is affecting all the organs. Furthermore, as the control group lacked immunoreactivity to any biomarker, we concluded that the health of our clams from Tecolutla could be restored if the quality of the environment is improved.

Proposed approach to assess vulnerability using tissular analysis

Vulnerability is the degree to which a system is susceptible to adverse effects caused by environmental stress (Villa and McLeod, 2002; Stein et al., 2014; Gauthier et al., 2014; Carantoña and Hernández, 2017; Ocaña and Pech, 2018). The strategies to estimate environmental vulnerability

Table 5 Immunoreactivity responses in different organs of clams from the experimental group

\begin{tabular}{ccccc}
\hline Organ & CYP & HSP70 & MTs & Total \\
\cline { 1 - 1 } Digestive gland & 1 & 1 & 0 & 2 \\
Stomach & 1 & 1 & 0 & 2 \\
Gut & 1 & 1 & 0 & 2 \\
Gills & 1 & 1 & 0 & 2 \\
Gonad & 0 & 1 & 0 & 1 \\
Foot & 1 & 1 & 1 & 3 \\
\hline Immunohistochemical index $\left(\mathrm{I}_{\mathrm{I}}\right)=2$ & & \\
\hline
\end{tabular}



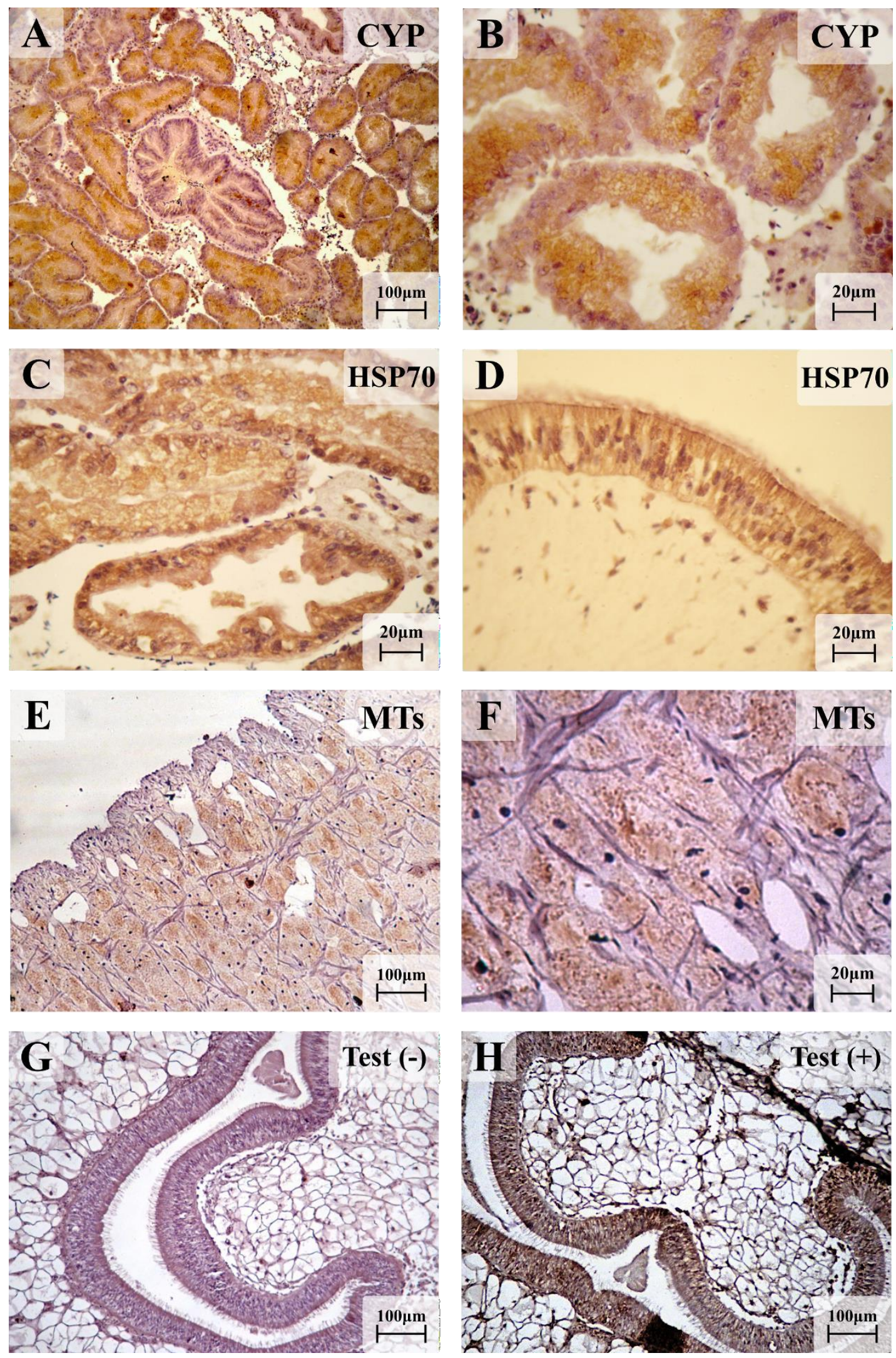

Fig. 3 Immunoreactivity of CYP, HSP70, and MTs in different tissues of clam from Tecolutla. All sections are counterstained with Tacha Hematoxylin. A-B. Digestive gland showing an immunoreactivity to CYP. C. Digestive gland showing an immunoreactivity to HSP70. D. Intestine showing immunoreactivity to HSP70. E-F. Foot showing immunoreactivity to MTs. G-H Immunoreactivity controls showing difference in the brown staining, both from foot tissue. Negative control $(\mathrm{G})$ processed with PBS instead of the HSP70 antibody and positive control (H) processed with the HSP70 antibody 
include indicators categorized in anthropogenic, biological, geological, and meteorological components (Villa and McLeod, 2002; Skondras et al., 2011; Karmaoui, 2015; Sahoo et al., 2016; Harik et al., 2017). However, these indicators do not include any physiological trait of the living organisms of each system. Therefore, we propose the integration of the histopathological index and immunohistochemical approaches as valuable tools to assess the vulnerability of clams from Tecolutla. The assessment of vulnerability includes the measure of exposure, sensitivity, and recovery capacity (Villa and McLeod, 2002; Ocaña and Pech, 2018). To begin with, exposure was measured through the immunoreactivity of different biomarkers. We created a range based on the immunohistochemical data previously presented. The average number of biomarkers found in the organs was classified into no, low, medium, and high exposure, called the Immunohistochemical Index $\left(I_{1}\right)$ (Table 5). The digestive glands of clams from Tecolutla showed medium exposure, but very close to the high category (Table 6). We recommend the use of at least three different immunochemistry biomarkers in three or more target organs to assess exposure. The gills, digestive gland, and foot constitute the preferred organs to evaluate this (Moraga et al., 2005; Usheva et al., 2006; Boscolo Papo et al., 2014a; Cuevas et al., 2015). Afterwards, the sensitivity of clams was assessed through a comparison between the histopathological index $\left(I_{h}\right)$ classification and the exposure level (Table 2). We determined that an organism is sensitive if the level of exposure is lower than the category of the $I_{h}$. In other words, an organism that shows a low prevalence of histopathological alterations in an environment with moderate exposure level has low sensitivity (Table 2). Therefore, clams from Tecolutla had low sensitivity to the environment. Finally, to assess recovery capacity, we observed both the $I_{l}$ and the $I_{h}$ of the control group. These clams depurated toxic molecules during 40 days in a clean environment, hence they constituted a good parameter to assess recovery capacity. Clams from the control group showed an exposure level of zero, according to $I_{\mid}$. Furthermore, these clams had an $I_{h}$ of 0.01 , meaning that the prevalence of histopathological injuries was reversed almost completely. In other words, these organisms have a good recovery capacity (Table 6). However, another study is necessary to propose an approach that classifies the levels of recovery capacity in these organisms.

For the integration of the three vulnerability components in a mathematical model, we needed a value of recovery capacity. However, recovery capacity regulates vulnerability through the modulation of exposure and sensitivity (Adger et al., 2007; Engle, 2011). Therefore, we concluded that clams from Tecolutla had a low vulnerability, as they reversed all the effects of environmental stress.

In summary, these physiological traits and their semiquantification should be included in the vulnerability measurements of aquatic bodies. These traits represented directly the health status of Tecolutla, Veracruz. Briefly, these results indicate that the effects of pollutants in these organisms are still reversible. However, it is important to stop

Table 6 Proposed semiquantification of parameters considered as indicators of vulnerability

\begin{tabular}{|c|c|c|c|c|}
\hline $\begin{array}{l}\text { Vulnerability } \\
\text { factor }\end{array}$ & Indicator & Scale & & $\begin{array}{l}\text { Clams } \\
\text { vulnerability }\end{array}$ \\
\hline Exposure & Immunoreactıvity Index (II) & $\begin{array}{l}\text { No exposure } \\
\text { Minimal } \\
\text { Moderate } \\
\text { High }\end{array}$ & $\begin{array}{c}0 \\
0.1-1 \\
1.1-2 \\
2.1-3\end{array}$ & Moderate \\
\hline Sensitivity & $\begin{array}{l}\text { Exposure vs prevalence of } \\
\text { histopathological alterations }\left(I_{I} v s I_{h}\right)\end{array}$ & $\begin{array}{c}\text { Very low } \\
\text { Low } \\
\text { Normal } \\
\text { High } \\
\text { Very high }\end{array}$ & $\begin{array}{r}-2 \\
-1 \\
0 \\
1 \\
2\end{array}$ & Low sensitivity \\
\hline $\begin{array}{l}\text { Recovery } \\
\text { capacity }\end{array}$ & Control group assessment & $\begin{array}{c}\text { Low } \\
\text { Moderate } \\
\text { High }\end{array}$ & $\begin{array}{l}? \\
? \\
?\end{array}$ & $\begin{array}{l}\text { Efficient recovery } \\
\text { capacity }\end{array}$ \\
\hline
\end{tabular}


pollution on Tecolutla so that organisms can improve their health. This work sets a health record for future monitoring references. The full quantification of histopathological indexes for the rest of the organs and the integration with the immunohistochemical part is a perspective of this work that contains valuable information about the vulnerability of these organisms. Furthermore, it is important to develop an approach to classify the recovery capacity properly. Additionally, the perspective of this work includes the application of this strategy in other indicator organisms to fully estimate the vulnerability of Tecolutla.

\section{Discussion}

Vulnerability is the degree to which a system is susceptible to adverse effects caused by environmental stress (Villa and McLeod, 2002; Gauthier et al., 2014; Stein et al., 2014; Carantoña and Hernández, 2017; Ocaña and Pech, 2018). Environmental vulnerability indexes created along the last years, through many approaches, take into account indicators categorized into anthropogenic, biological, geological, and meteorological components (Villa and McLeod, 2002; Skondras et al., 2011; Gauthier et al., 2014; Karmaoui, 2015; Sahoo et al., 2016; Harik et al., 2017). However, these indicators do not include any physiological traits of the living organisms of each system. Some approaches include water quality and plant distribution, while others include plant physiological traits (Esperón-Rodríguez and Barradas, 2015; Trevisan et al., 2020). The biological responses of organisms reflect the health status of a particular environment. Recently, some vulnerability indexes analyzed responses based on specific biomarkers (Gauthier et al., 2014; Chalghmi et al., 2020). Vulnerability depends on the levels of exposure and sensitivity of a system to a specific pressure, altogether with the capacity to cope, recover, or adapt to this pressure (Villa and McLeod, 2002; Stein et al., 2014; Carantoña and Hernández, 2017; Ocaña and Pech, 2018). These components can be assessed at different levels. Here, we created an approach to measure the three vulnerability components through the assessment of the health status of the clams (Table 6). The proposed approach includes the use of different tissular techniques to this end.

\section{Exposure}

Several human activities generate pressure on aquatic bodies. Vulnerability cannot be assessed without exposure to a pressure. Therefore, the first step is to determine the sources of pressure (Ocaña and Pech, 2018). Environmental exposure is related to the presence and absence of immunohistochemical biomarkers (Moraga et al., 2005; Wang et al., 2010; Boscolo Papo et al., 2014a; Santovito et al., 2015). These responses reflect the environmental stress that affects the organisms. The immunohistochemical approach determines the exposure to pollutants quickly, without the need for specific chemical procedures. The biomarkers used cover a broad range of pollutants. Among them, we used P450 cytochromes (CYPs), metallothionein proteins (MTs), and heatshock proteins (HSP) that are expressed after exposure to pesticides, hydrocarbons, metals, heat shock, and other toxic compounds (Moraga et al., 2005; Boscolo Papo et al., 2014a; b). These biomarkers are widely used in different organisms to show exposure to environmental stress (Moraga et al., 2005; Wang et al., 2010; Boscolo Papo et al., 2014a; Santovito et al., 2015). Different target organs are used to this aim, such as the digestive gland, gills, foot, and gonads. To obtain an overview of the general exposure of the clams, we evaluated several target organs. These responses were compiled and averaged to create a range of different levels of exposure. Although the immunochemical approach lacks quantification of pollutants, averaging the immune reactivity to different biomarkers in different organs provides an overview of the level of exposure. The target organs differed in their reactivity to the biomarkers, because they have different physiological functions. The physiological function of each organ and its anatomical position determine its interaction with the environment. For instance, the foot and the gills are in direct contact with sediment and water, making them more exposed, while the gonads are less exposed because they do not interact directly with the environment. Our proposal weights equally the biomarkers exposed in different organs; however, it is necessary to determine if the organs should be weighted differently. Nevertheless, our proposal, using an immunochemical approach, includes two types of exposure information. On one side, it evaluates a broad range of pollutants to which organisms are exposed. On the other side, it includes different target organs with distinct metabolic pathways that cope with the toxic compounds.

\section{Sensitivity}

Sensitivity is the degree to which a system or species is affected by environmental stress (Stein et al., 2014). A description of what makes a system sensitive is necessary, keeping in mind that each sensitivity level is specific to each pressure (Ocaña and Pech, 2018). All living organisms are sensitive to their environment to survive; however, the level of responses should be related to an exposure level to determine if the system is sensitive. Hence, to evaluate the organism's sensitivity, we related two aspects. On one hand, we measured the types and dissemination of the responses to a stress, called the prevalence of histopathological alterations. This prevalence categorizes the values of the histopathological index $\left(I_{h}\right)$, for comparison among several organisms (Costa et al., 2013; Cuevas et al., 2015). Besides, the prevalence correlates with the health status of a specific environment. On the other hand, we correlated the prevalences with the exposure level to determine the clam's sensitivity to the pollutants present in Tecolutla. Histopathology is widely used to recognize the effects of environmental stress on the organisms (Bernet et al., 1999; Usheva et al., 2006; Costa et al., 2013; 
Boscolo Papo et al., 2014a; b; Cuevas et al., 2015; Sıkdokur et al., 2020). It has been used in several organisms to determine the health status of aquatic bodies (Usheva et al., 2006; Chalghmi et al., 2020; Costa et al., 2013; Boscolo Papo et al., 2014a). Therefore, in our proposal, sensitivity is the measure of responses (prevalence of histopathological alterations) related to the exposure level. If the exposure level is equal to the prevalence of histopathological alterations, then the sensitivity is normal. In case the exposure level is lower than the prevalence, then the sensitivity is low. In contrast, if the exposure level is higher than the prevalence then the sensitivity is high. As far as we know, this is the first approach giving a semiquantitative method to assess sensitivity through the evaluation of physiological responses to pollutants.

\section{Recovery capacity}

The third component of vulnerability is adaptive capacity. Adaptive capacity refers to the ability of a species or system to cope with environmental impact with minimal disruption (Stein et al., 2014). However, adaptive refers to the evolution of a system in ecology, and it is usually assessed through evolutionary potentials, such as plasticity, dispersal ability and evolutionary potential (Ocaña and Pech, 2018). Tecolutla lacks monitoring programs that assess health status through time, hence we required another strategy to evaluate this vulnerability component. We determined that the recovery capacity attribute could be used instead. Recovery capacity is usually assessed through both extrinsic factors and intrinsic traits. To evaluate this capacity, we develop an approach to evaluate the ability of the organism to cope with the consequences of environmental stress. A control group of clams lived in a clean environment for 40 days. Then, they were subjected to histopathological and immunohistochemical analysis to observe differences with the experimental group. We observed a full recovery of the control group. The control group did not show immunoreactivity to any exposure biomarker (immunochemical analysis). Moreover, it had a lower histopathological index $\left(\mathrm{I}_{\mathrm{h}}=\right.$ $0.01)$ compared with the experimental group $\left(I_{h}=0.18\right)$. Nonetheless, we lacked a categorization for this component. Another essay is necessary to evaluate different levels of recovery capacity related to different levels of exposure. Nevertheless, we concluded that, having the current level of exposure, the clams from Tecolutla have sufficient recovery capacity to reverse the consequences of environmental stress.

Briefly, we employed different indicators to measure the three components of vulnerability. However, to integrate them in a mathematical model, standardization, response scaling, weighting, and aggregation are necessary. Although we had semiquantitative values for exposure and sensitivity levels, we lacked values for the recovery capacity component. Nonetheless, knowing that the clams were able to recover with a moderate exposure level and a low sensitivity, we can estimate the vulnerability. Recovery capacity was taken as a measure of adaptive capacity, hence both regulate vulnerability through modulation of exposure and sensitivity (Adger et al., 2007; Engle, 2011). This agreed with the method we used to assess recovery capacity, evaluating exposure and sensitivity levels through the same methods and then compare the results of the control versus the experimental group. As we observed that the clams reverted almost all the effects of environmental stress, we determined that the recovery capacity exceeded the exposure and sensitivity. Therefore, these results indicated that clams from Tecolutla showed a low vulnerability. Higher recovery or adaptive capacity aids in reducing the effects of exposure and sensitivity and, in consequence, reduces the vulnerability of the system (ART Vulnerability \& Risk Assessment Report, 2012; Stein et al., 2014; Thomas et al., 2019). The basic role of recovery or adaptive capacity is accepted as a positive attribute to reduce vulnerability (Engle, 2011; Thomas et al., 2019). As previously mentioned, it is still necessary to develop an assay to identify the limits of the recovery capacity of clams at different exposures levels.

In conclusion, adding the vulnerability components, exposure, sensitivity, and recovery capacity, we determined that the clams of Tecolutla have a low vulnerability. These clams had a moderate exposure level, low sensitivity, and a high recovery capacity. Assets with a higher adaptive capacity, or recovery capacity, and low sensitivity better tolerate impacts, and therefore have a lower vulnerability (Engle, 2011; ART Vulnerability \& Risk Assessment Report, 2012). As far as we know, this is the first approach to semiquantifying the vulnerability of an organism. Besides, this proposal constitutes an appealing approach for organisms in aquatic bodies that lack monitoring programs. The perspective of this work is to create categories to divide the recovery capacities of several organisms and compare them. Also, we propose to determine the vulnerability from several organisms, in order to estimate the general vulnerability of an environment. Finally, along with other approaches we aim to determine in the future the vulnerability of Tecolutla, Veracruz.

\section{Declaration of conflict of interest}

The authors declare no conflict of interests.

\section{Acknowledgments}

This study is part of the graduate program on Energy and Environmental Sciences (Doctorado en Energía y Medio Ambiente), Universidad Autónoma Metropolitana Iztapalapa (UAM-I), México. R Jerónimo Juárez is a doctoral student in this program and has received CONACyT fellowship 470845 . This study was supported by UAM-I through the project Ecological Integrity and Environmental Health Indices (Indicadores de Integridad Ecológica y Salud Ambiental), and by PRODEP-SEP through the project Enviromental Diagnostic of the Town of Tecolutla, Veracruz (Diagnóstico ambiental del Municipio de Tecolutla Veracruz). We thank Miguel Ángel León Tapia (Institute of Biology, National University of Mexico) for drawing the map. Also, to Dr. Katya Frank Hoeflich the Manuscript Writing Training Team 
(CEMAI-CONACYT) for the structure, reviews and constructive criticism of this research paper. We greatly acknowledge the technical support of M. Sc. José Ángel Vázquez Castro and B.S. in biology Irma Hernández Calderas. We thank Dr. Patricia Ramirez Romero for the review and comments on the manuscript.

\section{References}

Adger WN, Agrawal S, Mirza MMW, Conde C, O'Brien $\mathrm{KL}$, Pulhin J, et al. Assessment of adaptation practices, options, constraints and capacity. In: Climate Change 2007: Impacts, Adaptation and Vulnerability. Contribution of Working Group II to the Fourth Assessment Report of the Intergovernmental Panel on Climate Change, Parry ML, Canziani OF, Palutikof JP, Hanson CE, van der Linden PJ. (eds.), Cambridge University Press, pp 719- 743, 2007.

Arriaga-Gaona ML. Monitoreo de la calidad del agua del río Tecolutla desde Coyutla hasta Gutierrez Zamora, Veracruz. Rev. Lat. De Rec. Nat. 5: 141-147, 2009.

ART Vulnerability \& Risk Assessment Report.

http://www.adaptingtorisingtides.org/wp-

content/uploads/2015/04/ART_Project_VR_Rep

ort_all_sm.pdf (2012).

Baum A, Singer J, Baum C. Stress and environment. In: Evans GW. (ed.) Environmental Stress, CUP Archive, pp 89-127, 1984.

Bayne BL, Widdows J, Thompson TJ. Physiological integrations. In: Bayne BL. (ed.) Marine Mussels: Their Ecology and Physiology,

Cambridge University Press, pp 261-291, 1976.

Bejaoui S, Telahigue K, Chetoui I, Trabelsi W, Rabeh

I, Nechi S, et al. Effects of lead exposure on redox status, DNA and histological structures in Venus verrucosa gills and digestive gland. Chem. Ecol.

2020.

36: 434-457,

Bernet D, Schmidt H, Meier W, Burkhardt-Holm P, Wahli T. Histopathology in fish: proposal for a protocol to assess aquatic pollution. J. Fish Dis. 22: 25-34, 1999.

Boscolo Papo M, Bertotto D, Quaglio F, Vascellari M, Pascoli F, Negrato E, et al. Histopathology and stress biomarkers in the clam Venerupis philippinarum from the Venice Lagoon (Italy). Fish Shellfish Immunol. 39: 42-50, 2014.

Boscolo Papo M, Bertotto D, Pascoli F, Locatello L, Vascellari M, Poltronieri C, et al. Induction of brown cells in Venerupis philippinarum exposed to benzo(a)pyrene. Fish Shellfish Immunol. 40: 233-238, 2014.

Carantoña T, Hernández D. Indicador de vulnerabilidad de especie ante el cambio climático en áreas naturales protegidas, Venezuela. Terra. Nueva Etapa 13: 75-103,

2017.

Carneiro M, Reis B, Azevedo J, Campos A, Osório H, Vasconcelos V, et al. Glutathione transferases responses induced by microcystin- LR in the gills and hepatopancreas of the clam Venerupis philippinarum. Toxins 7: 2096-2120,

2015.
Chalghmi H, Bourdineaud J-P, Chbani I, Haouas Z, Bouzid S, Er-Raioui $\mathrm{H}$, et al. Occurrence, sources and effects of polycyclic aromatic hydrocarbons in the Tunis lagoon, Tunisia: an integrated approach using multi-level biological responses in Ruditapes decussatus. Environ. Sci. Pollut. Res. Int. 27: 36613674, 2020.

Climate-Smart Conservation: Putting Adaptation Principles into Practice, National Wildlife Federation, 2014.

Costa PM, Carreira S, Costa MH, Caeiro, S. Development of histopathological indices in a commercial marine bivalve (Ruditapes decussatus) to determine environmental quality. Aquat. Toxicol. 126: 442-454, 2013.

Cuevas N, Zorita I, Costa PM, Franco J, Larreta J. Development of histopathological indices in the digestive gland and gonad of mussels: integration with contamination levels and effects of confounding factors. Aquat. Toxicol. 162: 152-164, 2015.

Delgado-Alvarez C, Ruelas-Inzunza J, EscobarSánchez O, Covantes-Rosales R, Pineda- Pérez IB, Osuna-Martínez CC, et al. Metal concentrations in age-groups of the clam, Megapitaria squalida, from a coastal lagoon in Mexico: A human health risk assessment. Bull. Environ. Contam. Toxicol. 103: 822827, 2019.

Engle NL. Adaptive capacity and its assessment. Global Environmental Change 21: 647-656,

2011.

Esperón-Rodríguez M, Barradas VL. Comparing environmental vulnerability in the montane cloud forest of eastern Mexico: A vulnerability index. Ecol. Indicators 52: 300-310, 2015.

Gauthier S, Bernier P, Burton PJ, Edwards J, Isaac K, Isabel $\mathrm{N}$, et al. Climate change vulnerability and adaptation in the managed Canadian boreal forest. Env. Rev. 22: 256-285, 2014.

Häder D-P, Banaszak AT, Villafañe VE, Narvarte MA, González RA, Helbling EW. Anthropogenic pollution of aquatic ecosystems: Emerging problems with global implications. Sci. Total Environ. 713: 136586, 2020.

Harik G, Alameddine I, Maroun R, Rachid G, Bruschi $D$, Astiaso Garcia D, et al. Implications of adopting a biodiversity-based vulnerability index versus a shoreline environmental sensitivity index on management and policy planning along coastal areas. J. Environ. Manage. 187: 187-200, 2017.

Karmaoui AA. Multidisciplinary Approach to Assess the Environmental Vulnerability at Local Scale in Context of Climate Change (Pilot Study in Upper Draa Valley, South Morocco). Glob. J. Tech. Optim. 06, 2015.

López-Portillo J, Lara-Domínguez AL, A ÁvilaÁngeles, AD Vázquez-Lule. Caracterización del sitio de manglar Tecolutla, en Comisión Nacional para el Conocimiento y Uso de la Biodiversidad (CONABIO). In: CONABIO (ed.) Sitios de manglar con relevancia biológica y con necesidades de rehabilitación ecológica, CONABIO, 2009.

Markert BA, Breure AM, Zechmeister HG. Bioindicators and Biomonitors, Elsevier, 2003. 
Moraga D, Meistertzheim A-L, Tanguy-Royer S, Boutet I, Tanguy A, Donval A, et al. Stress response in Cu2+ and $\mathrm{Cd} 2+$ exposed oysters (Crassostrea gigas): an immunohistochemical approach. Comp. Biochem. Physiol. C. Toxicol. Pharmacol. 141: 151-156, 2005.

Ocaña FA, Pech D. Marco metodológico para evaluar la vulnerabilidad del bentos ante múltiples presiones en la región del gran caribe. In Adaptación basada en

Ecosistemas:alternativa para la gestión sostenible de los recursos marinos y costeros del Caribe (ed. Hernández-Zanuy, A. C.) 122- 135 (Red CYTED 410RT0396. Editorial Instituto de Oceanología, 2018). Park H, Ahn I-Y, Lee HE. Expression of heat shock protein 70 in the thermally stressed antarctic clam Laternula elliptica. Cell Stress Chaperones 12: 275282, 2007.

Ramírez LH, Torres B. Metodología para evaluar vulnerabilidad costera por los efectos del cambio climático. In: Botello AV, Villanueva- Fragoso S, Gutiérrez J, Galaviz JLR. (eds.) Vulnerabilidad de las zonas costeras mexicanas ante el cambio climático SEMARNAT-INE. UNAM-ICMyL, Universidad Autónoma de Campeche, pp 403-423, 2011.

Sahoo S, Dhar A, Kar A. Environmental vulnerability assessment using Grey Analytic Hierarchy Process based model. Env. Impact Asses Rev. 56: 145-154 (2016).

Santovito G, Boldrin F, Irato, P. Metal and metallothionein distribution in different tissues of the Mediterranean clam Venerupis philippinarum during copper treatment and detoxification. Comp. Biochem. Physiol. C. Toxicol. Pharmacol. 174-175: 46-53, 2015. Sıkdokur E, Belivermiş M, Sezer N, Pekmez M, Bulan ÖK, Kılıç Ö. Effects of microplastics and mercury on manila clam Ruditapes philippinarum: Feeding rate, immunomodulation, histopathology and oxidative stress. Environ. Pollut. 262: 114247,

2020.

Skondras NA, Karavitis CA, Gkotsis II, Scott PJB, Kaly UL, Alexandris SG. Application and assessment of the Environmental Vulnerability Index in Greece. Ecol. Indicators 11: 1699- 1706, 2011.

Temino-Boes R, Romero-Lopez R, Ibarra-Zavaleta SP, Romero I. Using grey clustering to evaluate nitrogen pollution in estuaries with limited data. Sci. Total Environ. 722: 137964, 2020.

Thomas K, Hardy RD, Lazrus H, Mendez M, Orlove
B, Rivera-Collazo I, et al. Explaining differential vulnerability to climate change: A social science review. Wiley Interdiscip. Rev. Clim. Change 10: e565, 2019.

Trevisan DP, da Conceição Bispo P, Almeida D, Imani $\mathrm{M}$, Balzter H, Moschini LE. Environmental vulnerability index: An evaluation of the water and the vegetation quality in a Brazilian Savanna and Seasonal Forest biome. Ecol. Indicators 112: 106163, 2020.

Usheva LN, Frolova LT. Morphofunctional changes of the digestive gland in the bivalve mollusk Crenomytilus grayanus (Dunker, 1853) in normal conditions and after parasitic invasion by trematodes. Rus. J. Mar. Biol. 32: 96-105, 2006.

Usheva LN, Vaschenko MA, Durkina VB. Histopathology of the digestive gland of the bivalve mollusk Crenomytilus grayanus (Dunker, 1853) from southwestern Peter the Great Bay, Sea of Japan. Rus. J. Mar. Biol. 32: 166-172, 2006.

Villa $F$, McLeod $H$. Environmental vulnerability indicators for environmental planning and decisionmaking: guidelines and applications. Environ. Manage. 29, 335-348 (2002).

Vodopivez C, Curtosi A, Villaamil E, Smichowski P, Pelletier E, Mac Cormack WP. Heavy metals in sediments and soft tissues of the Antarctic clam Laternula elliptica: More evidence as a possible biomonitor of coastal marine pollution at high latitudes? Sci. Tot. Env. 502: 375-384, 2015.

Wang Q, Wang X, Wang X, Yang H, Liu B. Analysis of metallotionein expression and antioxidant enzyme activities in Meretrix meretrix larvae under sublethal cadmium exposure. Aquat. Toxicol. 100: 321-328, 2010.

Wu H, Ji C, Wang Q, Liu X, Zhao J, Feng J. Manila clam Venerupis philippinarum as a biomonitor to metal pollution. Chin. J. Oceanol. Limnol. 31: 65-74, 2013.

Zhang $\mathrm{H}$, Pan L, Tao $\mathrm{Y}$. Toxicity assessment of environmental pollutant phenanthrene in clam Venerupis philippinarum using oxidative stress biomarkers. Environ. Toxicol. Pharmacol. 37: 697-704, 2014.

Zhang L, Gan J, Ke C, Liu X, Zhao J, You L, et al. Identification and expression profile of a new cytochrome P450 isoform (CYP414A1) in the hepatopancreas of Venerupis (Ruditapes) philippinarum exposed to benzo[a]pyrene, cadmium and copper. Environ. Toxicol. Pharmacol. 33: 85-91, 2012. 


\section{Erratum to: Tissue biomarkers as vulnerability indicators in the clam Polymesoda caroliniana [17: 186-197, 2020]}

\section{JR Jerónimo-Juárez ${ }^{1}$, ML Matadamas-Guzman², I Guerrero Legarreta ${ }^{3}$, JC Segoviano-Ramírez ${ }^{4}$, M del Rocío Zarate-Hernández ${ }^{5}$, M Arteaga-Silva ${ }^{6}, X_{\text {Guzmán-García }}^{7^{*}}$}

${ }^{1}$ Posgrado en Energía y Medio Ambiente, Universidad Autónoma Metropolitana, 09340, Ciudad de México, México ${ }^{2}$ Doctorado en Ciencias Biomédicas, UNAM, Ciudad de México, México

${ }^{3}$ Departamento de Biotecnología, Universidad Autónoma Metropolitana, Unidad Iztapalapa, 09340, Ciudad de México, México

${ }^{4}$ Unidad de Bioimagen, Centro de Investigación y Desarrollo en Ciencias de la Salud, Universidad Autónoma de Nuevo León, Monterrey, Nuevo León, México

${ }^{5}$ Laboratorio de Peces, Departamento de Biología, Universidad Autónoma Metropolitana, 09340, Ciudad de México, México

${ }^{6}$ Laboratorio de Neuroendocrinología Reproductiva, Departamento de Biología de la Reproducción, Universidad Autónoma Metropolitana, 09340, Ciudad de México, México

${ }^{7}$ Departamento de Hidrobiología, Laboratorio de Ecotoxicología, Universidad Autónoma Metropolitana, Unidad Iztapalapa, 09340, Ciudad de México, México

In the above article Table 2 was reproduced incorrectly, the table and caption should have appeared as below:

Table 2 Relations between the prevalence of histopathological alterations and level of exposure. The sensitivity value was calculated by subtracting the prevalence minus exposure level. These relations resulted in a categorization of sensitivity (Very low $=-2$, Low $=-1$, Normal $=0$, High $=1$, Very high $=2$ )

\begin{tabular}{|c|c|c|c|c|c|}
\hline $\begin{array}{c}\text { Exposition } \\
\text { level }\end{array}$ & Value & $\begin{array}{c}\text { Prevalence of } \\
\text { histopathological } \\
\text { alterations }\end{array}$ & Value & Sensitivity value & Sensitivity category \\
\hline Minimal & 1 & Low prevalence & 1 & 0 & Normal \\
\hline Moderate & 2 & & 1 & -1 & Low \\
\hline High & 3 & & 1 & -2 & Very low \\
\hline Minimal & 1 & Moderate prevalence & 2 & 1 & High \\
\hline Moderate & 2 & & 2 & 0 & Normal \\
\hline High & 3 & & 2 & -1 & Very high \\
\hline Minimal & 1 & High prevalence & 3 & 2 & High \\
\hline Moderate & 2 & & 3 & 1 & Normal \\
\hline High & 3 & & 3 & 0 & \\
\hline
\end{tabular}

Corresponding author:

Xochitl Guzmán-García

Universidad Autónoma Metropolitana, Unidad Iztapalapa

San Rafael Atlixco 186, Vicentina, C.P. 09340, Iztapalapa, Ciudad de México, México

E-mail: xgg@xanum.uam.mx 


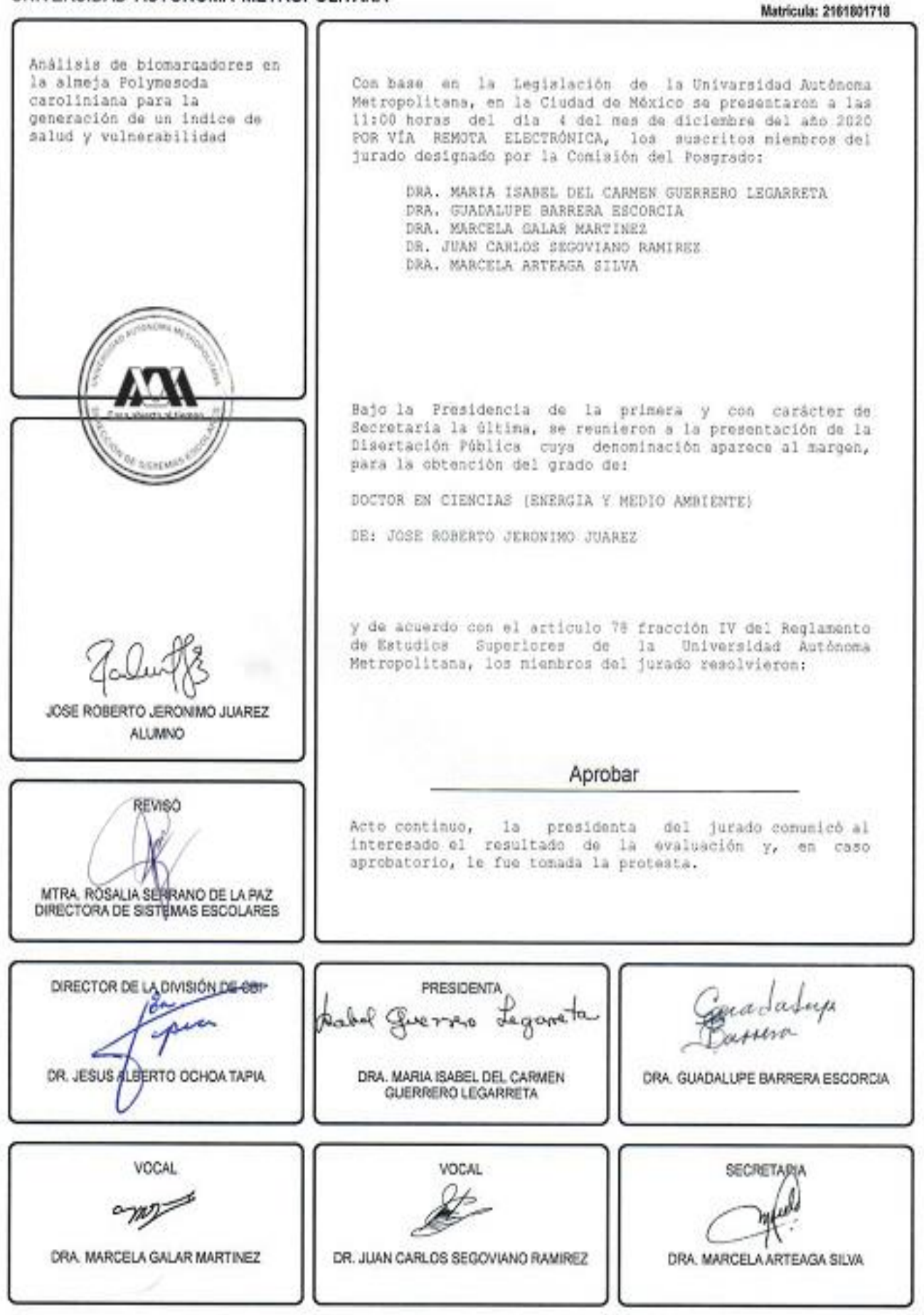

E presente documento cueata con la firma -Lutógrafa, escaneuda o digital, según correspoeda- del funcioeario universitario competente, que certifica que las firmas que aparecen en esta acta - Temporil, digital o dictamen- son auténticas y las mismas que usan los c.c. profesores mescioeados en ella 